SIRRVIÇO DIE POSS-GRAJUAÇÃO IOO ICMC-IISP

Data de Depósito: $23 /(14 / 20 \times() 2$

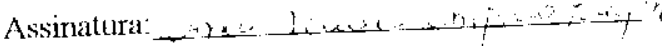

\title{
Uma extensão do sistema de telemetria e telecomandos do Projeto ARARA para transmissão digital de vídeo e dados
}

Kleber Manrique Trevizani

Orientador: Prof. Dr. Onofre Trindade Junior

Dissertação apresentada ao Instituto de Ciências Matemáticas e de Computação - ICMC-USP, como parte dos requisitos para obtenção do título de Mestre em Ciências de Computação e Matenática Computacional.

USP - São Carlos

Abril/2002 


\section{A Comissão Julgadora:}

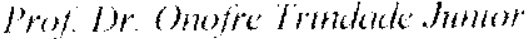

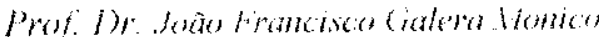

Prot. Dr. Valentin Obac Roda

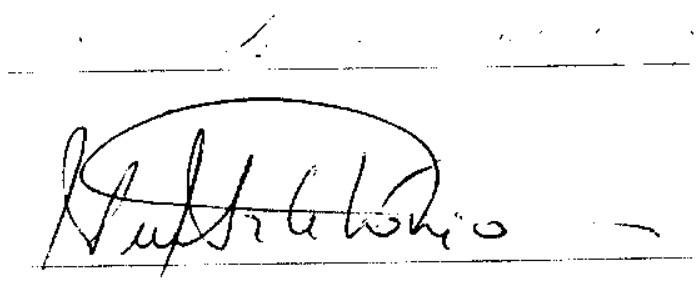

$\tau$$$
\text { . }
$$ 
Ao meus pais, Angelo e Elizete. 


\section{Agradecimentos}

À Deus, por todas as pessoas especiais que tem colocado em meu caminho e por todas as oportunidades a mim concedidas.

Seria impossível expressar com palavras o quanto sou grato aos meus pais, Angelo e Elizete, e aos meus irmãos Fernando e Telma, que em todos os momentos de minha vida tem me apoiado e incentivado a prosseguir com ânimo e coragem. Amo vocês!

Gostaria de agradecer especialmente, ao amigo e orientador Onofre, pelo apoio, companheirismo, orientação, críticas e pela confiança depositada em mim durante a execução deste trabalho. Obrigado amigo!

Aos amigos de república: André (Maluquinho), Gustavo (Amebão), Reginaldo (Ré), Ricardo (Mininim) e Rodrigo (Cabeção), pela amizade, companheirismo e pelos momentos que nunca mais serão apagados da minha memória. Vai com Deus, sejas feliz...

Aos companheiros do "velho" LCAD: André (Charlie), Alexandre (AlexK), Alexandre (Cereal), Cesar, Daniela, Emílio, Fernando (Tranqüilo), Gustavo, Luciana (Uái), Lisandro (Wow), Luciano (Draga), Lúcio, Mário (Peste), Maxweel (Fã do Marciano), Rodrigo (Marmita), Rômulo, Sidnei, Valério (O cara virtual) e Viviane. Obrigado pelos momentos inesquecíveis, pelas contribuições e principalmente pela grande amizade. Valeu pessoal!

A todos os meus familiares. Muito obrigado pelo incentivo. Vocês sempre estiveram em meu coração durante todo esse período em que estive distante!

À Renata, pelo grande incentivo, compreensão e principalmente pelo amor e carinho dedicados a mim durante todo o tempo que estivemos juntos.

Ao seu Walter, dona Cleusa, Saulo e Laurinha pelo apoio e carinho. 
Ao pessoal do LABES, pela amizade, pclas contribuições e pelos momentos de alegria.

Aos amigos que adquiri neste período de permanência em São Carlos: Ana Cláudia, Eroldi (o amigo Holandês), Marcelão (Senhor), Cássio, Simone e Silvão, pelos momentos de descontração e alegria.

Aos mestres e amigos da UNOESTE: André (Charlie), Cláudio, Eduardo e Rogério pela amizade, companheirismo e pelo apoio para o ingresso neste programa de mestrado.

Aos colegas de mestrado do ICMC pelo momentos de estudo e alegria compartilhados.

Aos professores do ICMC, pelos ensinamentos e pela dedicação.

Aos funcionários do ICMC, que direta ou indiretamente, contribuíram com este trabalho.

Ao $\mathrm{CNPq}$, pelo suporte financeiro sem o qual este trabalho não teria sido realizado.

A todas as pessoas que de alguma forma, me incentivaram ou contribuíram para a realização deste trabalho. 
1 Introdução $\quad 1$

1.1 Estrutura do Texto . . . . . . . . . . . . . . . . . 2

2 Revisão Bibliográfica $\quad 4$

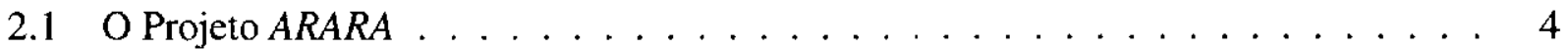

2.2 Transmissão de Dados via-Rádio . . . . . . . . . . . . . . . . . . 6

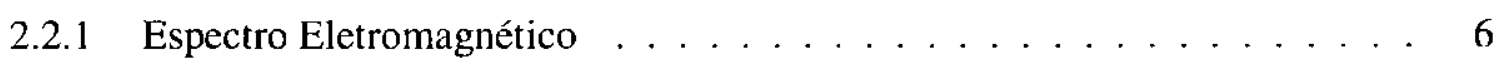

2.2 .2 Transmissão de Rádio . . . . . . . . . . . . . . . . . . . 8

2.2 .3 Transmissão de Microondas . . . . . . . . . . . . . . . . . . . . . 9

2.2 .4 Técnica Spread Spectrum . . . . . . . . . . . . . . . . . . . 10

2.2.5 Tópicos de Redes de Computadores . . . . . . . . . . . . . . . . . . . . 14

2.2 .6 Equipamentos para Transmissão de Dados . . . . . . . . . . . . . . . 17

2.3 Vídeo Digital . . . . . . . . . . . . . . . . . . . . . . . . . . . . . . . . . 19

2.3.1 Câmeras de Vídeo . . . . . . . . . . . . . . . . . . . . . . . . 19

2.3 .2 Vídeo Analógico . . . . . . . . . . . . . . . . . 21

2.3 .3 Vídeo Digital . . . . . . . . . . . . . . . . . . . . 24

2.3.4 Compressão de Vídeo Digital . . . . . . . . . . . . . . . . . . 27

2.3.5 Algoritmos e Padrões de Compressão de Vídeo . . . . . . . . . . . . . . . . 30

2.4 Sumário . . . . . . . . . . . . . . . . . . . . . . . 34

3 Análise de Requisitos $\quad 35$

3.1 Hardware do Sistema . . . . . . . . . . . . . . . . . . . . 37

3.1 .1 Requisitos de Hardware . . . . . . . . . . . . . . . . 37

3.2 Software do Sistema . . . . . . . . . . . . . . . . . . . . . . . . . . . . . . . . . . .

3.2 .1 Requisitos Funcionais de Software . . . . . . . . . . . . . . . 39

3.2 .2 Requisitos Não Funcionais de Software . . . . . . . . . . . . . . . . 43

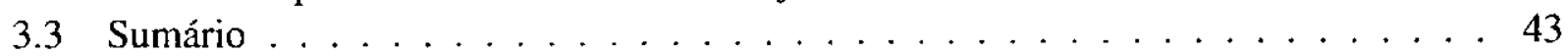

4 Modelagem do Sistema $\quad 44$

4.1 Notação Estendida de Ward e Mellor . . . . . . . . . . . . . . . . . . 47 
4.2 Diagrama de Contexto . . . . . . . . . . . . . . . . 48

4.3 Diagrama de Contexto MA e MB . . . . . . . . . . . . . . . . . . . . 49

4.4 Diagramas de Fluxo de Dados do MA . . . . . . . . . . . . . . . . . . . . 49

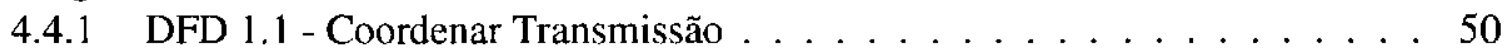

4.4.2 DFD 1.2 - Executar Telecomandos . . . . . . . . . . . . . 52

4.4.3 DFD 1.3 - Formatar Dados dos Sensores . . . . . . . . . . . . . 52

4.4.4 DFD 1.4 - Comprimir Fluxo de Vídeo . . . . . . . . . . . . 53

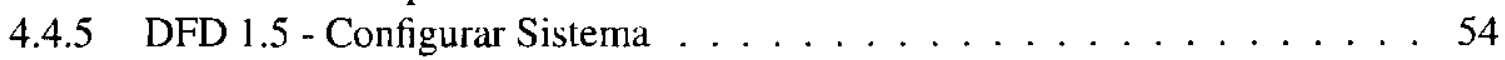

4.5 Diagramas de Fluxo de Dados do MB . . . . . . . . . . . . . . . 54

4.5.1 DFD 1.6 - Coordenar Transmissão . . . . . . . . . . . . . 55

4.5.2 DFD 1.7 - Apresentar Telemetria . . . . . . . . . . . . . 57

4.5.3 DFD 1.8 - Descomprimir Vídeo . . . . . . . . . . . . . . . 59

4.5.4 DFD 1.9 - Mostrar Arquivo de $\log \ldots \ldots \ldots \ldots \ldots$

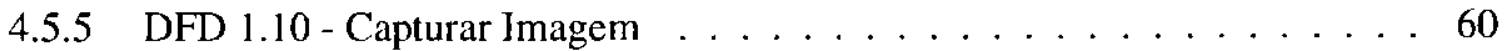

4.5.6 DFD 1.11 - Visualizar Imagem . . . . . . . . . . . . . . . 60

4.5.7 DFD 1.12 - Mostrar Estatística . . . . . . . . . . . . . . 61

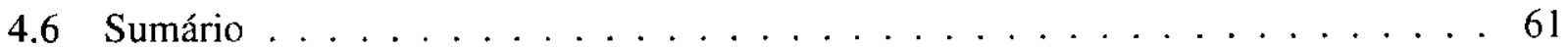

5 Projeto e Implementação $\quad 62$

5.1 Projeto de Hardware . . . . . . . . . . . . . . . . . . 63

5.1.1 Componentes de Hardware da Aeronave . . . . . . . . . . . . 63

5.1.2 Componentes de Hardware da Estação de Solo . . . . . . . . . . . 65

5.2 Programas para Transmissão de Vídeo . . . . . . . . . . . . . . . 66

$5.2 .1 \quad$ FFMPEG . . . . . . . . . . . . . . . . 66

$5.2 .2 \quad$ MPEG4IP . . . . . . . . . . . . . . . . 68

5.2 .3 Testes de Transmissão de Vídeo . . . . . . . . . . . . . . . . . . . 69

5.3 o Protocolo de Comunicação . . . . . . . . . . . . . . . . . 70

5.3.1 Dados de Telecomando . . . . . . . . . . . . . . . . . 70

5.3 .2 Dados de Telemetria . . . . . . . . . . . . . . . . . . 72

5.4 Detalhes de Implementação . . . . . . . . . . . . . . . . . . . . . 74

5.4 .1 Módulo Aéreo . . . . . . . . . . . . . . . . . . . 74

5.4 .2 Módulo Base . . . . . . . . . . . . . . . 76

5.5 Interface Gráfica do STT . . . . . . . . . . . . . . 80

5.5 .1 Tela Principal . . . . . . . . . . . . . . . . . 81

5.5 .2 Painel de Instrumentação . . . . . . . . . . . . . . . . . . . . 82

5.5 .3 Painel de Apresentação de Falhas . . . . . . . . . . . . . 83

5.5 .4 Configurações Gerais . . . . . . . . . . . . . . . . 83

5.5 .5 Visualização de $\log \ldots \ldots \ldots \ldots \ldots \ldots$

5.5 .6 Visualização de Estatísticas . . . . . . . . . . . . . . 85

5.5 .7 Configuração dos Parâmetros de Alerta . . . . . . . . . . . 85

5.5 .8 Visualização de Imagens . . . . . . . . . . . . . . . . . 86

5.6 Testes e Validação do STT . . . . . . . . . . . . . . . . . . 86

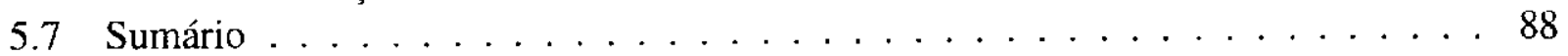


6 Conclusões $\quad 89$

6.1 Contribuições do Trabalho . . . . . . . . . . . . . . . . . . . . . 90

6.2 Sugestões para Trabalhos Futuros . . . . . . . . . . . . . . . . . 91

$\begin{array}{ll}\text { Referências Bibliográficas } & 92\end{array}$

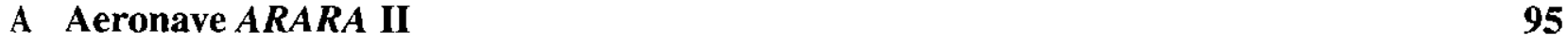

B Dicionário de Dados $\quad 97$

B.1 MA (Módulo Aéreo) . . . . . . . . . . . . . . . . . . . . 97

B.1.1 Depósitos de Dados . . . . . . . . . . . . . . . . . . . . . 97

B.1.2 Fluxos de Dados . . . . . . . . . . . . . . . . . . . 98

B.2 MB (Módulo Base) . . . . . . . . . . . . . . . . . . . . . . . . . . . . 104

B.2.1 Depósitos de Dados . . . . . . . . . . . . . . . . . . . 104

B.2.2 Fluxos de Dados . . . . . . . . . . . . . . . . . 105

B.3 Dados Auxiliares . . . . . . . . . . . . . . . . . 118 
2.1 O espectro eletromagnético e o seu uso na comunicação (Tanenbaum, 1996).

2.2 (a) Comportamento das bandas VLF, VF e MF. (b) Comportamento da ondas HF e VHF (Tanenbaum, 1996). . . . . . . . . . . . . . . . . . 9

2.3 Direct sequence spread spectrum. . . . . . . . . . . . . . . . . . . 12

2.4 Frequency hopping spread spectrum. . . . . . . . . . . . . . . . . . . 13

2.5 Câmera de vídeo monocromática e seu sinal de saída (Luther, 1995) . . . . . . . . . 19

2.6 Câmera de vídeo colorida com três sensores (Luther, 1995) . . . . . . . . . . . . 20

2.7 CCD de uma câmera fotográfica digital. . . . . . . . . . . . . 20

2.8 Rastreamento progressivo (Luther, 1995) . . . . . . . . . . . . . . . . 22

2.9 Codificação de RGB para NTSC $($ Cisco, 2001) . . . . . . . . . . . . . . 23

2.10 Conversão de vídeo analógico para digital $($ Cisco, 2001) . . . . . . . . . . . . 24

3.1 Componentes de hardware da primeira versão do STT (Ribeiro, 2000). . . . . . . . 36

3.2 Hardware do projeto ARARA. . . . . . . . . . . . . . 38

4.1 Diagrama de fluxo de dados do MA (nível 1) (Ribeiro, 2000). . . . . . . . . 45

4.2 Diagrama de fluxo de dados do MB (nível 1) (Ribeiro, 2000). . . . . . . . . . . 46

4.3 Notação estendida de Ward e Mellor. . . . . . . . . . . . . . . . . . . . . 47

4.4 Diagrama de contexto. . . . . . . . . . . . . . . . . 48

4.5 Diagrama de contexto MA e MB. . . . . . . . . . . . . . . . . 49

4.6 Diagrama de fluxo de dados do MA (nível 1) . . . . . . . . . . . . 50

4.7 DFD 1.1 - Coordenar transmissão. . . . . . . . . . . . . . . . 51

4.8 DFD 1.2 - Executar telecomandos. . . . . . . . . . . . . . . 52

4.9 DFD 1.3 - Formatar dados dos sensores. . . . . . . . . . . . . 52

4.10 DFD 1.4 - Comprimir fluxo de vídeo. . . . . . . . . . . . . 53

4.11 DFD 1.5 - Configurar sistema. . . . . . . . . . . . . . . 54

4.12 Diagrama de fluxo de dados do MB (nível 1) . . . . . . . . . . . 55

4.13 DFD 1.6 - Coordenar transmissão. . . . . . . . . . . . . . . 56

4.14 DFD 1.7 - Apresentar telemetria. . . . . . . . . . . . . . . 57

4.15 DFD 1.8 - Descomprimir vídeo. . . . . . . . . . . . . 59 
4.16 DFD 1.9 - Mostrar arquivo de $l o g . \ldots \ldots \ldots$. . . . . . . . . . . 59

4.17 DFD 1.10 - Capturar imagem. . . . . . . . . . . . . . . . . 60

4.18 DFD 1.11 - Visualizar imagem. . . . . . . . . . . . . . . 60

4.19 DFD 1.12 - Mostrar estatística. . . . . . . . . . . . . . . . 61

5.1 Componentes de hardware do STT. . . . . . . . . . . . . . . 64

5.2 Interface gráfica do gmp4player. . . . . . . . . . . . . . . . . 68

5.3 Interface gráfica do mp4live. . . . . . . . . . . . . . . . . . 69

5.4 Arquitetura de software do STT. . . . . . . . . . . . . . . . . . 74

5.5 Estado da implementaçāo do MA. . . . . . . . . . . . . . . . 75

5.6 Diagrama de classes simplificado do MB . . . . . . . . . . . . . . 76

5.7 Estado da implementação do MB. . . . . . . . . . . . . . . . . . . . . . 79

5.8 Fluxo de navegação das telas do MB . . . . . . . . . . . . . . . . . . 80

5.9 Tela de principal do MB. . . . . . . . . . . . . . . . . . 81

5.10 Painel de instrumentação do MB. . . . . . . . . . . . . . . . . . 82

5.11 Painel de apresentação de falhas. . . . . . . . . . . . . . . 83

5.12 Tela de configurações gerais. . . . . . . . . . . . . . . . . . . 84

5.13 Tela de visualização de $\log \ldots \ldots \ldots \ldots \ldots$

5.14 Tela de visualizaçāo de estatísticas. . . . . . . . . . . . . . . 85

5.15 Tela de configuração dos parâmetros de alerta. . . . . . . . . . . . . . . 85

5.16 Tela de visualização de imagens. . . . . . . . . . . . . . . . . 86

A.1 Aeronave ARARA II . . . . . . . . . . . . . . . . . . . . . . 95

A.2 Dimensões da aeronave ARARA II. . . . . . . . . . . . . . 96 
2.1 Comparação entre modems de RF disponíveis no mercado. . . . . . . . . . . 18

5.1 Formatos de arquivo utilizados pelo FFMPEG. . . . . . . . . . . . . . 67

5.2 CODECs utilizados pelo FFMPEG. . . . . . . . . . . . . . . 67

5.3 Formato dos pacotes de superfície de comando. . . . . . . . . . . . 71

5.4 Descriçāo dos canais ON/OFF. . . . . . . . . . . . . . . 72

5.5 Formato dos pacotes de parâmetros de configuração. . . . . . . . . . . 72

5.6 Formato dos pacotes de telemetria. . . . . . . . . . . . . . . 73 
O monitoramento aéreo é uma ferramenta excelente para descobrir problemas que, analisados ao nível do solo, podem consumir muito mais tempo e até mesmo passarem despercebidos. Entre esses problemas estão a detecção de defeitos em linhas de transmissão de energia elétrica e a realização do mapeamento geográfico de uma certa área.

Para realizar o monitoramento aéreo utilizam-se aviōes dotados de equipamentos de fotografia ou filmagem que possam voar em baixa velocidade. O custo do avião convencional, sua manutenção e operação apresentam valores elevados, restringindo seu uso em diversas aplicações. A utilização de aeronaves não tripuladas (UAVs) de escala reduzida inverte esse quadro, possibilitando que qualquer pessoa possa ser treinada para a realização desse tipo tarefa a baixo custo.

O projeto ARARA (Aeronaves de Reconhecimento Assistidas por Rádio e Autônomas), em que este trabalho está incluído, tem por objetivo o desenvolvimento de UAVs de baixo custo para a realização de missões autônomas, pré-estabelecidas pelos usuários. O STT (Sistema de Telemetria e Telecomandos) do projeto ARARA foi desenvolvido para possibilitar o envio de sinais de telemetria e telecomando entre uma aeronave e uma estação no solo. A primeira versão do STT utiliza o canal de áudio de um transmissor de vídeo analógico para enviar esses dados.

Neste trabalho, o STT é estendido para possibilitar a utilização de um canal digital de comunicação entre a aeronave e a estação no solo. Esse canal substitui a transmissão analógica da versão anterior, possibilitando novas opções como a transmissão de vídeo digital com parâmetros ajustáveis e a geração dos sinais de radio controle a partir do computador da estação. O protocolo de comunicação da primeira versão foi revisto e ampliado.

O software do sistema foi desenvolvido e documentado utilizando-se técnicas de análise estruturada. Os testes realizados em bancada mostraram a perfeita adequação do novo sistema aos objetivos do projeto ARARA e uma considerável evolução em relação à primeira versão desenvolvida para o STT. 
Aerial surveillance is an outstanding tool to find out problems that are difficult or take too much time to perceive at ground level. Power line fault detection and geographical mapping are among these problems. Acquisition, maintenance and operational costs associated with conventional aircraft limit the use of aerial surveillance in several applications. Unmanned Aerial Vehicles (UAVs) have much lower costs and can be operated by anyone after some training sessions.

This work is part of the ARARA project (Autonomous and Radio-Assisted Reconnaissance Aircraft). The main goal of the $A R A R A$ project is the development of low cost UAVs for the accomplishment of autonomous missions, pre-established by the users. The STT (Telemetry and Telecommand System) is part of the ARARA project and make possible the communication of telemetry data and telecommand control signals between the aircraft and the ground station. The first version of STT uses the analog audio channel of a video transmitter to send telemetry data from the aircraft to the ground station.

In this work, the STT is extended to make possible the use of a digital communication channel between the aircraft and the ground station. This channel replace the analog transmission channel of the previous version, making possible new features such as the transmission of digital video with adjustable parameters and the generation of telecommand control signals. The communication protocols used in the first version of STT were reviewed and extended.

The software of the STT was developed and documented using structured analysis techniques. Bench tests have shown that the new STT is working properly and has all the wanted features for the use in ARARA aircraft. The new STT represents a major improvement over its first version. 


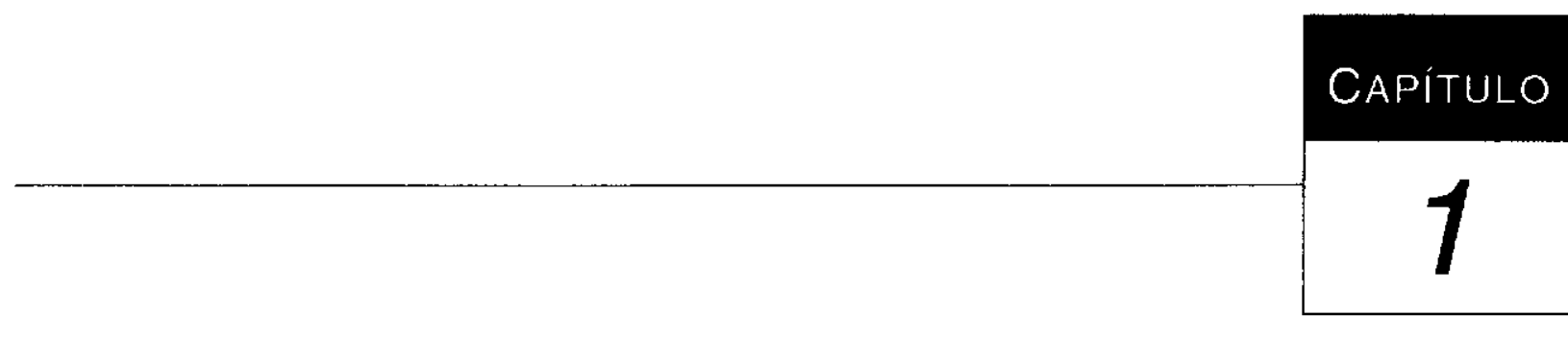

Introdução

O conceito de aeronave não tripulada tem acompanhado quase toda a história da aviação. Os primeiros projetos na área militar consistiam em bombas ou alvos não tripulados. Existe uma variedade de termos para designar aeronaves não tripuladas, entretanto o termo UAV (Unmanned Aerial Vehicle) é o mais utilizado.

Nos últimos anos, os UAVs têm desempenhado um papel importante em diversas aplicações. Com a miniaturização dos componentes eletrônicos e o incremento do poder de processamento dos computadores, tornou-se possível o desenvolvimento e utilização de UAVs em diversas áreas.

UAVs de baixo custo podem realizar tarefas, até então somente possíveis com a utilização de aeronaves tripuladas. Os UAVs atuais podem chegar a lugares de difícil acesso, como encostas de montanhas e vales, desenvolver velocidades muito altas e ficar suspensos no ar (no caso de helicópteros) para o monitoramento de um incêndio, sem colocar a vida de pilotos em risco.

No desenvolvimento da tecnologia de aviões, os UAVs têm sido utilizados como ferramentas para proporcionar baixo custo nos testes de novos conceitos aerodinâmicos. Na área militar, os UAVs são utilizados em missões de reconhecimento e prática de tiro ao alvo, sendo comumente projetados para reutilização, diferentemente dos mísseis que são utilizados uma única vez. Embora os UAVs apresentem um custo relativamente pequeno, em aplicações militares, um projeto de UAV pode, facilmente, chegar à casa de dezenas ou até mesmo centenas de milhares de dólares. 
A fotografia aérea e a coleta de dados para monitoramento ambiental têm feito uso intensivo de UAVs e se beneficiado do sistema de posicionamento GPS (Global Positioning System), da miniaturização das câmeras de vídeo, da câmera fotográfica digital, dos equipamentos de rádio e dos sensores para captação de dados atmosféricos.

$\mathrm{Na}$ agricultura, a fotografia aérea tem sido usada como uma ferramenta suplementar na identificação de problemas, como pragas causadas por insetos, fungos e elementos atmosféricos. Segundo Ribeiro (2000), o custo de obtenção de fotos aéreas utilizando um UAV é muito menor, se comparado a um sistema de vôo tripulado, podendo girar em torno de 10 dólares por missão. Os primeiros resultados obtidos por Souza (1999), relatados em sua dissertação de mestrado, mostram que esses sistemas podem, de uma maneira simples e com baixo custo, substituir os meios convencionais utilizados, até então, para a realizaçāo deste tipo de missão.

Este trabalho faz parte da fase II do projeto ARARA (Aeronaves de Reconhecimento Assistidas por Rádio e Autônomas) em desenvolvimento no Laboratório de Computação de Alto Desempenho do Instituto de Ciências Matemáticas e de Computação. Seu objetivo principal é incorporar ao STT (Sistema de Telemetria e Telecomando) um enlace de dados digital para a transmissão de telecomandos, telemetria e imagens de vídeo entre um UAV do projeto ARARA e uma estação em solo.

Para realizar a transmissāo de dados entre o UAV e a estação de solo, foi especificado e im.plementado um protocolo de comunicação específico. Esse protocolo tem a função de coordenar a transmissão dos dados através de um canal de comunicação digital sem fio, possibilitando, assim, a comunicação bi-direcional entre o UAV e a estação de solo. Os dados transmitidos do UAV para a estação de solo (telemetria), são úteis para o acompanhamento das missões. Os dados transmitidos da estação de solo para o UAV (telecomandos), são utilizados quando o usuário desejar pilotar remotamente o UAV ou modificar algum parâmetro de configuração do UAV.

Apesar de não ter submetido o sistema desenvolvido a ensaios em vôo, ele foi extensivamente testado em bancada, tendo se mostrando-se confiável e pronto para utilização a bordo das aeronaves do projeto ARARA.

\subsection{Estrutura do Texto}

O presente texto é composto por seis capítulos. O capítulo 2 apresenta as tecnologias pesquisadas para o desenvolvimento deste trabalho, como a transmissão de dados via-rádio e a manipulação de vídeo (captura, digitalização e compressão). Este capítulo também apresenta uma introdução ao projeto ARARA. 
No capítulo 3, é apresentada a análise de requisitos do STT. Nesse capítulo, os requisitos atuais são comparados com os requisitos da versão anterior do STT. O capítulo 4, apresenta a modelagem do STT, utilizando a notação de análise estruturada. O capítulo 5, descreve o ambiente de implementação do STT, o projeto de hardware, os testes com os programas de transmissão de vídeo, a especificação do protocolo de comunicação, os detalhes de implementação e os testes realizados com o STT.

Finalmente, o capítulo 6 apresenta as conclusões finais, sugestões para trabalhos futuros e as contribuições deste trabalho.

Os apêndices $\mathrm{A}$ e $\mathrm{B}$ descrevem respectivamente a aeronave utilizada no projeto ARARA e o dicionário de dados do sistema implementado. 


를

\section{Revisão Bibliográfica}

Este capítulo tem como objetivo apresentar os diversos assuntos pesquisados para o desenvolvimento deste trabalho. Neste sentido, são apresentados na seção 2.1 o projeto $A R A R A$, seus objetivos e suas fases. A seção 2.2, mostra alguns aspectos importantes da transmissão de dados via-rádio, bem como uma lista de equipamentos de transmissão relevantes para o projeto proposto. Finalmente, a seção 2.3 apresenta alguns aspectos básicos de captura e digitalização de vídeo e algumas técnicas e padrões de compressão de vídeo.

\subsection{O Projeto 'ARARA}

O projeto ARARA (Aeronaves de Reconhecimento Assistidas por Rádio e Autonomas ou Autonomous and Radio-Assisted Reconnaissance Aircraft), em que este trabalho está inserido, está centrado no desenvolvimento e uso de UAVs, de escala reduzida, para monitoramento aéreo. Seu principal objetivo é a substituição de aeronaves convencionais utilizadas para monitoramento, por UAVs de pequeno porte, que realizam missões pré-estabelecidas pelos usuários. O projeto $A R A R A$ está sendo desenvolvido em parceria com a EMBRAPA-CNPDIA de São Carlos.

O projeto está dividido em quatro fases. Cada fase representa um marco na direção do objetivo final do projeto que consiste no desenvolvimento de aplicações automáticas, incluindo por 
exemplo, a inspeção de linhas de transmissão de energia elétrica e a contagem de animais em propriedades rurais.

Na fase I, o UAV é baseado em componentes utilizados em aeromodelos. O controle de vôo é feito a partir do solo, utilizando um equipamento de rádio controle convencional, limitando a distância de vôo do UAV a um raio de até $1 \mathrm{Km}$. Uma câmera fotográfica (química ou digital), é adaptada ao UAV e pode ser disparada via-rádio controle. É possível a instalação de uma câmera de vídeo com transmissor para o monitoramento em tempo real ou para posicionar o UAV sobre a área de interesse para a obtenção de fotografias. A fase I do projeto já foi completada por Souza (1999) e apresenta o menor custo entre todas as fases definidas no projeto ARARA.

A fase II, da qual este trabalho faz parte, cnvolve o projeto $e$ a construção de um UAV rádiocontrolado com vários sensores. Entre esses sensores estão incluídos GPS, giroscópio, altímetro, horizonte artificial, bússola, etc. Os dados gerados pelos sensores são transmitidos para uma estação de solo, possibilitando a realização do vôo sem visada direta do UAV. Nessa fase, o UAV ainda é controlado via-rádio, mas sua distância de vôo é ampliada de acordo com a potência do amplificador do rádio-controle. Duas câmeras de vídeo estão incluídas e suas imagens são transmitidas para um computador em solo. Uma câmera instalada na frente do UAV permite ao usuário ter a visão similar a de um piloto, enquanto uma câmera voltada para baixo permite ao usuário visualizar a área de interesse. As imagens da câmera do piloto são sobrepostas por um painel de instrumentação. O resultado dessa combinaçāo é semelhante aos simuladores de vôo, tal como o Flight Simulator '. A fase II foi parcialmente completada por Ribeiro (2000). O apêndice A mostra detalhes da aeronave utilizada na fase II.

A fase III utiliza o mesmo tipo de UAV da fase II. O vôo, nesse ,caso é autônomo e o UAV deve ser capaz de realizar missões de forma completamente automática. O usuário pode programar a rota de vôo e as tarefas para cumprir a meta de uma missão, tais como fotografar ou filmar uma área pré-definida. Barbosa (2001) já completou parte desta fase desenvolvendo o SINACOM (Sistema de Navegação e Controles de Missão do Projeto ARARA). Neris (2001) também contribuiu para essa fase do projeto, desenvolvendo um piloto automático para os UAVs do projeto ARARA.

A fase IV irá utilizar os sistemas desenvolvidos na fase III para a realização de missões complexas de forma totalmente automática. Nessa fase, serão necessários computadores mais potentes para a execução de missões que envolvam a tomada de decisōes baseadas no processamento das imagens obtidas.

\footnotetext{
${ }^{1}$ O Flight Simulator é marca registrada da Microsoft Corp.
} 


\subsection{Transmissão de Dados via-Rádio}

A transmissão sem fio e a comunicação digital tiveram início no Havaí, onde os usuários ficavam separados por ilhas e o sistema de telefonia era inadequado. O primeiro sistema de computador a utilizar rádio, ao invés de ligações ponto-a-ponto por cabo, foi o sistema Aloha, da Universidade do Havaí, em 1971. O Aloha ć o ancestral de todos os sistemas de difusão por rádio (Tanenbaum, 1996).

\subsubsection{Espectro Eletromagnético}

Quando se movem, os elétrons criam ondas eletromagnéticas que podem se propagar pelo espaço (mesmo no vácuo). Essas ondas foram descobertas pelo físico britânico James Clerk Maxwell, em 1865 e produzidas e observadas pelo físico alemão Heinrich Hertz, em 1887. O número de oscilações por segundo de uma onda eletromagnética é chamado frequiência ( $f$ ), e é medido em $\mathrm{Hz}$ (em homenagem a Heinrich Hertz). A distância entre dois pontos máximos (ou mínimos) consecutivos na onda é chamada de comprimento de onda $(\lambda)$.

Anexando uma antena de tamanho apropriado a um circuito elétrico, as ondas eletromagnéticas podem ser transmitidas e recebidas com eficiência à longa distância. Todas as comunicações sem fio são baseadas nesse princípio (Tanenbaum, 1996).

No vácuo, todas as ondas eletromagnéticas se propagam na mesma velocidade, independentemente da sua freqüência. Essa velocidade, geralmente chamada de velocidade da luz, c, é aproximadamente $3 \times 10^{8} \mathrm{~m} / \mathrm{seg}$, aproximadamente $1 \mathrm{ft}$. $(30 \mathrm{~cm})$ por nanosegundo. No cobre ou na fibra óptica, essa velocidade decresce aproximadamente para $\frac{2}{3}$ desse valor e se torna, ligeiramente dependente da freqüência (Yacoub, 1993).

A relação fundamental entre $f, \lambda$ e $c$ (no vácuo) é:

$$
\lambda f=c
$$

Como $c$ é uma constante, sabendo-se $f$, pode-se encontrar $\lambda$ e vice versa. Por exemplo, ondas de $1 \mathrm{MHz}$ têm aproximadamente 300 metros c ondas de $1 \mathrm{~cm}$ têm uma frequência de $30 \mathrm{GHz}$.

O espectro eletromagnético é mostrado na figura 2.1. As ondas de rádio, microondas, infravermelho e porções de luz visíveis do espectro, podem ser utilizadas para a transmissão de informações através da modulação da amplitude, frequiência ou fase das ondas. A luz ultravioleta, o raio-X e os raios gama, deveriam ser melhores devido às suas altas freqüências; mas eles são difíceis de produzir, modular, não se propagam bem através de construções e são nocivos para os seres vivos 
(Tanenbaum, 1996). As bandas relacionadas na parte inferior da figura 2.1, são nomes oficiais do ITU (International Telecommunication Union). Esses nomes são baseados no comprimento de onda. Os termos LF, MF e HF se referem a Low, Medium e High Frequency, respectivamente. Quando esses nomes foram associados, ninguém esperava superar freqüências acima de $10 \mathrm{MHz}$; por isso, as bandas superiores posteriormente foram chamadas de Very, Ultra, Super, Extremely, e Tremendously High Frequency.

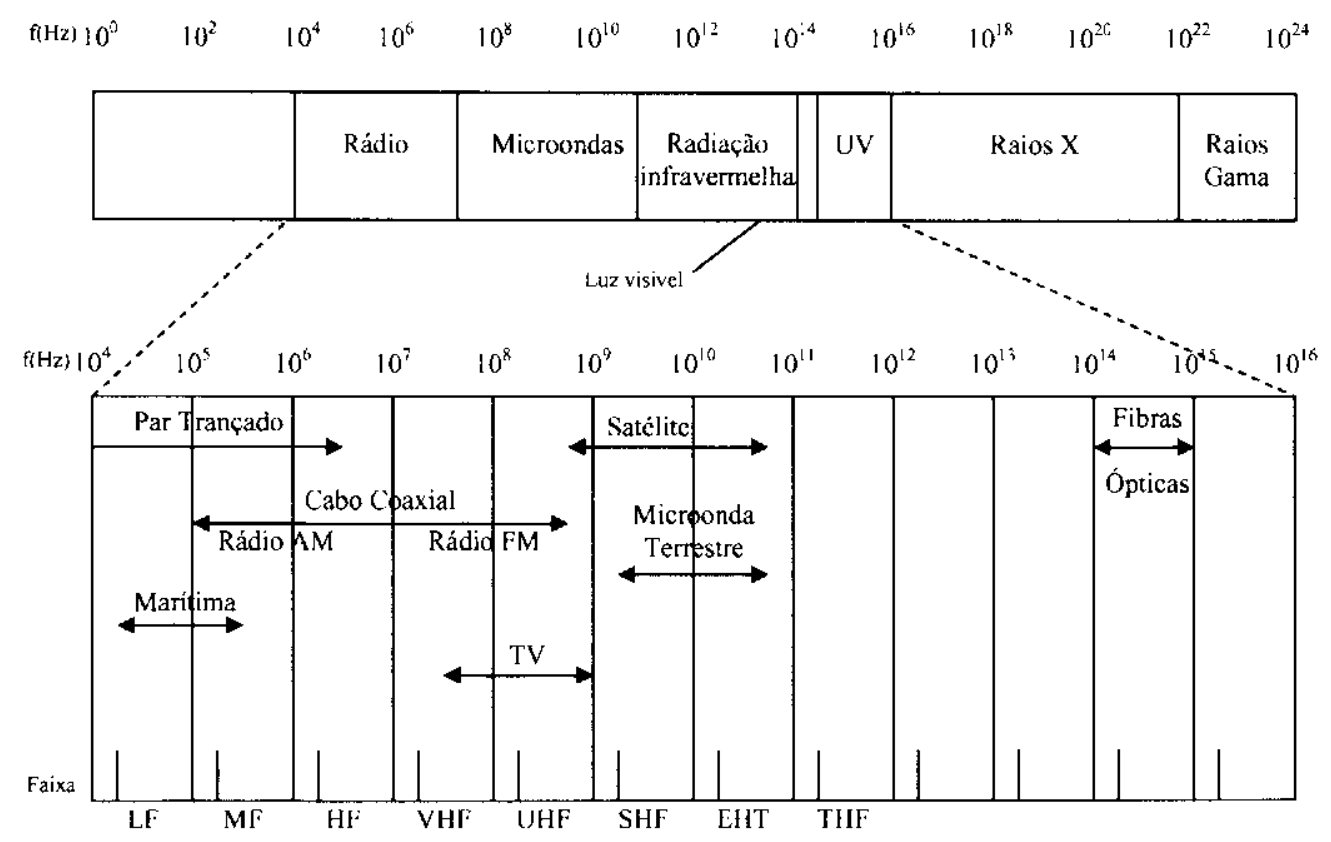

Figura 2.1: O espectro eletromagnético e o seu uso na comunicação (Tanenbaum, 1996).

O volume de informação que uma onda eletromagnética pode transportar está diretamente relacionado com a sua largura de banda. Utilizando tecnologias atuais, é possível codificar alguns bits por Hertz em baixas freqüências; no entanto, esse número pode subir para 40 sob determinadas condições em altas frequiências. Um cabo com $500 \mathrm{MHz}$ de largura de banda pode transportar muitos gigabits por segundo (Tanenbaum, 1996).

Se a equação 2.1 for resolvida para $f$ e derivada em relação a $\lambda$ é obtido:

$$
\frac{d f}{d \lambda}=-\frac{c}{\lambda^{2}}
$$

Se for aplicado o método de diferenças finitas ao invés da derivação, e somente for observado os valores absolutos, obtém-se:

$$
\Delta f=\frac{c \Delta \lambda}{\lambda^{2}}
$$


Com base na largura de uma banda de comprimento de onda $\Delta \lambda$, é possível calcular a banda de frequiência correspondente, $\Delta f$, e, a partir daí, a taxa de dados que a banda pode transportar. Quanto mais larga a banda, mais alta a taxa de dados. Como um exemplo: se for considerada uma banda de 1,30 microns tem-se: $\lambda=1,3 \times 10^{-6}$ e $\Delta \lambda=0,17 \times 10^{-6}$, resultando em um $\Delta f$ de 30 THz.

Foram criadas organizações nacionais e internacionais para regulamentar o uso do espectro eletromagnético. Nos Estados Unidos, o FCC (Federal Communications Commission) aloca espectro para rádios AM e FM, televisão, telefonia celular, operadoras de telefonia, polícia, militares, navegação, governo c muitos outros usuários. No Brasil, essa responsabilidade é delegada à ANATEL (Agência Nacional de Telecomunicações). Em âmbito mundial, uma agência do ITU-R (International Telecommunication Union - Radiocommunication Sector) é responsável por essa regulamentação: a WRC (World Radiocommunications Conference), antiga WARC (World Administrative Radio Conference). Muitas vezes, as agências nacionais não seguem as recomendações da WRC. Conseqüentemente, dispositivos que utilizam rádio freqüência, podem funcionar apenas em um certo país ou região.

\subsubsection{Transmissão de Rádio}

As ondas de rádio são relativamente fáceis de gerar, percorrem longas distâncias e atravessam construções com certa facilidade. Devido a essas características, elas são largamente utilizadas para comunicação, tanto em interiores como em espaço aberto. As ondas de rádio também são omnidirecionais, o que significa que elas podem trafegar em todas as direçōes a partir da sua origem. O transmissor e o receptor não precisam estar cuidadosamente alinhados.

As propriedades das ondas de rádios dependem da frequiência. Em baixas freqüências, as ondas de rádio atravessam bem os obstáculos, mas a potência cai rapidamente com o aumento da distância entre o transmissor e o receptor. Em altas frequiências, as ondas de rádio tendem a percorrer linhas retas, mas são refletidas por obstáculos. As ondas de rádio também são absorvidas pela chuva. Em todas as freqüências, as ondas de rádios estão sujeitas à interferências de motores e outros equipamentos elétricos.

Devido à capacidade que as ondas de rádio de percorrer longas distâncias, a interferência entre os usuários é um problema. Por essa razão, todos os governos exercem um controle sobre os transmissores de rádio, concedendo apenas algumas exceções (discutidas na seção 2.2.3).

Em bandas VLF, LF e MF, as ondas de rádio seguem a superfície terrestre, como é ilustrado na figura 2.2(a). Em baixas frequiências, essas ondas podem ser detectadas a até $1000 \mathrm{~km}$ de distância; em altas frequiências, esse raio de ação é bem menor. Ondas de rádio que operam nessas 
bandas facilmente atravessam construções. O principal problema na utilização dessas frequiências em comunicação de dados é a baixa largura de banda que elas oferecem (ver equação 2.1).

Nas bandas HF e VHF, as ondas tendem a ser absorvidas pela terra. Entretanto, as ondas que chegam à ionosfera, uma camada de partículas carregadas que circunda a terra a uma altitude de 100 a $500 \mathrm{~km}$, são refratadas por ela e enviadas de volta para a terra, como mostrado na figura 2.2(b). Em determinadas condições atmosféricas, os sinais podem ser refletidos várias vezes. Operadores de rádio amador utilizam essas bandas para comunicação em longas distâncias.

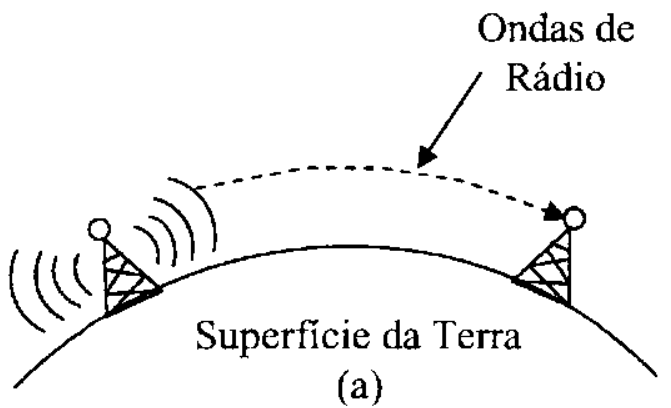

(a)

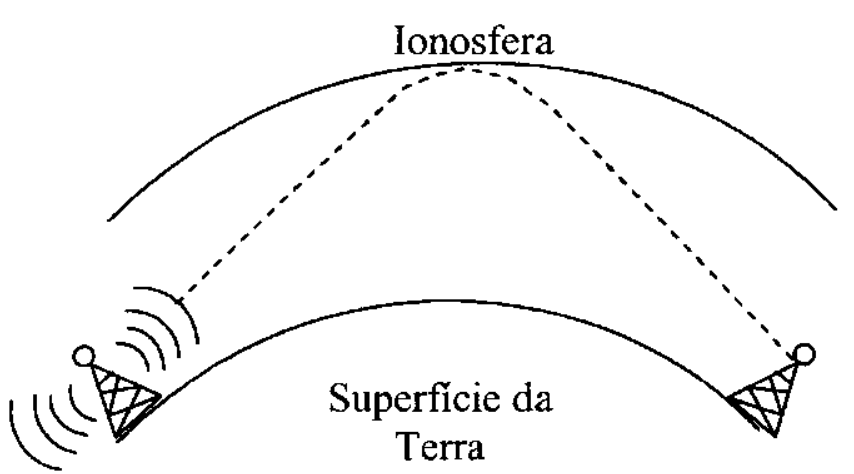

(b)

Figura 2.2: (a) Comportamento das bandas VLF, VF e MF. (b) Comportamento da ondas HF e VHF (Tanenbaum, 1996).

\subsubsection{Transmissão de Microondas}

Acima de $100 \mathrm{MHz}$, as ondas trafegam em linha reta, e por essa razão, podem ser captadas com mais facilidade. Ao contrário das ondas de rádio de frequiências mais baixas, as microondas não atravessam os prédios. Algumas ondas podem ser refratadas nas camadas atmosféricas mais baixas e, conseqüentemente, a sua chegada pode ser mais demorada do que as ondas diretas. Esse efeito é chamado de multipath fading, ou fadding por múltiplos caminhos, e costuma provocar sérios problemas. Ele depende do tempo e da frequiência (Tanenbaum, 1996).

Atualmente é muito comum a utilização de bandas até $10 \mathrm{GHz}$. A partir de $8 \mathrm{GHz}$ surge um novo problema: a absorção pela água. 


\section{A faixa de freqüência ISM}

Para aumentar a flexibilidade e diminuir a burocracia na alocação do espectro eletromagnético, as organizações responsáveis pela regulamentação do seu uso, criaram bandas (faixas de frequiência) de uso livre, ou seja, não é necessário obter nenhum tipo de licença para utilizar essas bandas. Elas sāo chamadas de bandas ISM (Industrial, Scientific and Medical). Uma das bandas ISM é alocada em escala mundial ( $2400 \mathrm{a} 2484 \mathrm{MHz}$ ). Além dela, existem outras bandas ISM como a de 902 a $928 \mathrm{MHz}$ e a de 5725 a $5850 \mathrm{MHz}$; contudo elas podem ser utilizadas somente em alguns países, dentre eles o Brasil. (ANATEL, 2001).

Logicamente, para prevenir abusos, essas organizações impuseram um conjunto de regras para a utilização dessas bandas e somente produtos certificados são permitidos. Essas regras especificam a máxima potência transmitida na banda e fora dela (para não poluir as faixas de frequiência adjacentes).

As faixas de freqüência ISM são as que melhor se enquadram no projeto proposto, pois possuem largura de banda aceitável para transmissão de vídeo e dados, grande alcance, baixo custo (comparado com o de outras tecnologias), e grande disponibilidade no mercado.

Vale ressaltar que as faixas de frequiência mais indicadas para a utilização no projeto ARARA são as de $902-928$ e de $2400-2484 \mathrm{MHz}$, devido às suas características de serem pouco direcionais e oferecerem largura de banda satisfatória. Faixas de frequiência mais altas, como a de 5725-5850 $\mathrm{MHz}$, estão descartadas do projeto devido à necessidade de alinhar, precisamente, o transmissor $\mathrm{e}$ o receptor, o que não é possível no projeto ARARA.

\subsubsection{Técnica Spread Spectrum}

Spread Spectrum ou Espalhamento Espectral, é uma técnica de comunicação sem fio $\mathrm{cm}$ que a frequiência do sinal transmitido é variada intencionalmente. Isso resulta na obtenção de uma largura de banda maior que o sinal poderia ter, se a freqüência não fosse variada.

A técnica SS (Spread Spectrum) tem sido amplamente usada em sistemas de comunicação comerciais e militares. Nos sistemas SS, o sinal de informação utiliza uma banda de RF (Rádio Freqüência) muito maior do que um sinal convencional. A expansão da banda propicia certas vantagens desejáveis e determinadas características que, dificilmente, seriam obtidas de outro modo (Casella, 1998).

Um sinal de rádio convencional possui uma frequiência que não é modificada conforme o tempo (exceto quando ocorrem pequenas e rápidas flutuações como resultado da modulação). Um sinal de $103.1 \mathrm{MHz}$, em um reccptor de FM, terá, sempre, 103.1 MHz. Ele não aumentará para 105.1 
MHz nem diminuirá para 99.1 MHz. A frequiência de sinais convencionais de rádio é mantida o mais constante possível. Por isso, a largura de banda pode ser mantida dentro de certos limites e o sinal pode ser facilmente encontrado por alguém que deseje receber a informação.

Existem, ao menos, dois problemas com transmissões convencionais de rádio que podem ocorrer em ccrtas circunstâncias:

- Um sinal com freqüência constante está muito mais sujeito à interferência. Isso ocorre quando outro sinal é transmitido na, ou muito perto, da frequiência do sinal desejado. A interferência pode ser acidental, como em comunicações de radioamador, ou pode ser intencional, como na guerra;

- Um sinal de frequiência constante é fácil de interceptar, e, conseqüentemente, não é apropriado para aplicações em que as informações devam ser confidenciais.

Para minimizar problemas como os citados acima, a freqüiência do sinal transmitido pode ser intencionalmente variada em um segmento significativamente grande do espectro eletromagnético. Essa variação é feita utilizando-se uma função matemática específica. Para interceptar o sinal, um receptor deve ser sintonizado em freqüências que variam precisamente de acordo com essa função. $O$ receptor deve conhecer a função de tempo/freqüência empregada pelo transmissor e o ponto de início dessa função. Segundo Casella (1998), dentre as razões para o emprego da técnica SS, pode-se citar:

1. Capacidade de rejeitar interferências;

2. Capacidade de reduzir os efeitos de atenuação;

3. Baixa probabilidade de interceptação;

4. Sincronismo universal de precisão;

5. Sigilo.

Existem várias técnicas SS que podem ser empregadas em sistemas de comunicação. Normalmente cada técnica apresenta características intrínsecas que facilitam o seu emprego em determinados campos de atuação. As técnicas SS mais difundidas são descritas, brevemente, a seguir. 


\section{Direct Sequence}

A técnica SS Direct Sequence (DSSS - Direct Sequence Spread Spectrum), também conhecida como Spread Spectrum Pseudo-Aleatório, utiliza uma sequiência de código para modular, diretamente, um sinal de informação modulado. A portadora modulada pelo sinal de informação é modulada novamente por um sinal de código digital pseudo-aleatório, cuja taxa é muito maior que a taxa do sinal de informação. Em princípio, qualquer técnica de modulação digital pode ser empregada. Entretanto, a mais empregada é a modulação digital BPSK (Casella, 1998; Rappaport, 1996). A figura 2.3 exemplifica a técnica Direct Sequence.

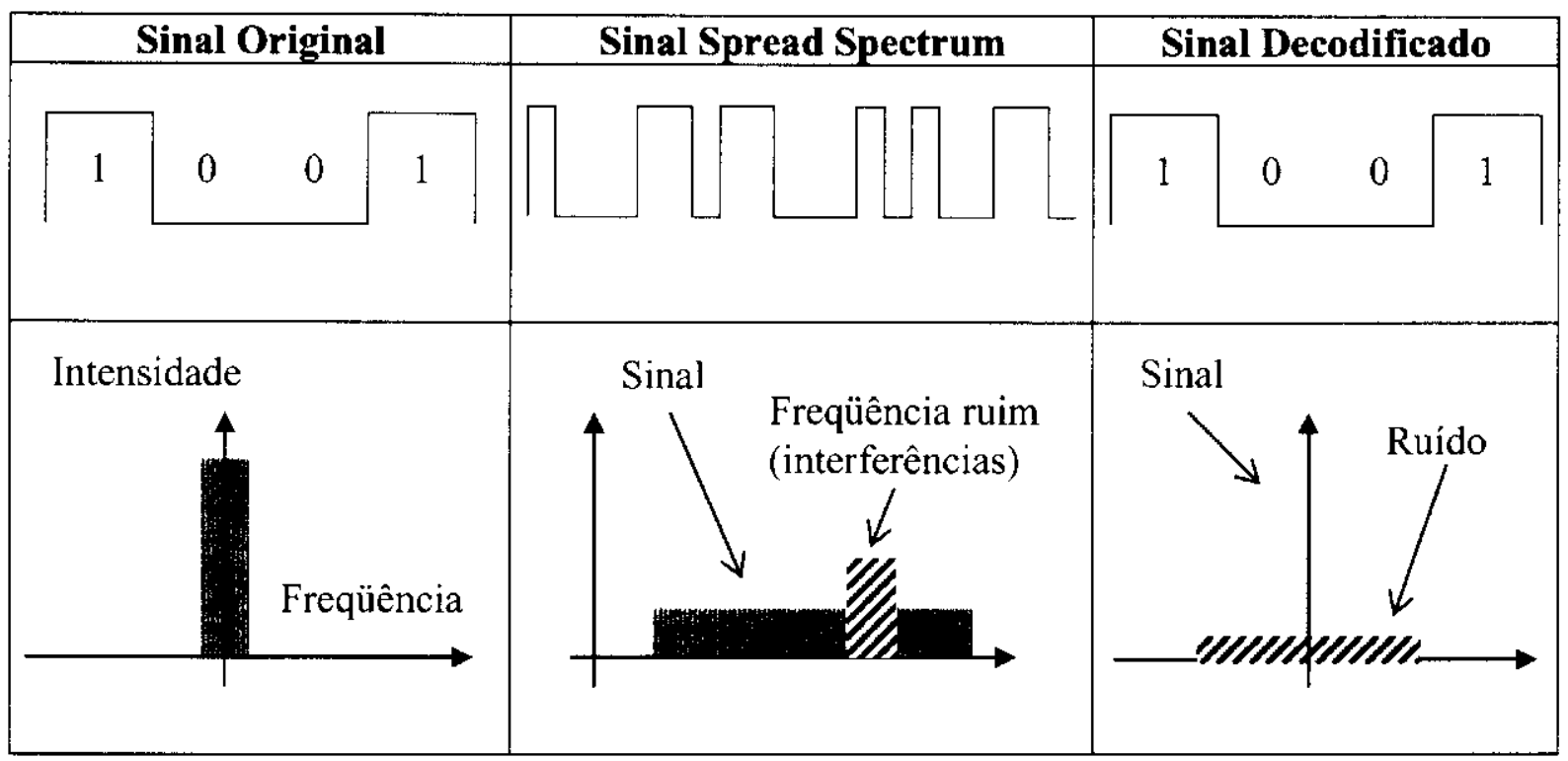

Figura 2.3: Direct sequence spread spectrum.

Vantagens:

- Melhor desempenho contra ruídos e interferências;

- Mais difícil de ser detectado;

- Melhor desempenho contra sinais multipath.

Desvantagens:

- Requer um canal de banda larga com distorção mínima;

- Necessita de um gerador de código de alta velocidade. 


\section{Frequency Hopping}

Essa técnica utiliza uma série de canais estreitos. Esses canais são utilizados em uma seqüiência pré-determinada. Por exemplo, a banda de $2400 \mathrm{MHz}$ ISM é dividida em 79 canais, de $1 \mathrm{MHz}$. Periodicamente (geralmente de 20 até $400 \mathrm{~ms}$ ), o sistema troca de canal, seguindo um padrão de troca cíclico pré-determinado. Com essa técnica, é possível evitar interferências porque o transmissor não utiliza sempre um mesmo canal. Caso um canal possua ruído, e o sistema não possa utilizá-lo, o sistema irá esperar pelo próximo canal sem ruído. Como o sistema troca de canal periodicamente, ele também aproveita para fazer uma média da qualidade de todos os canais a fim de evitar que os piores canais sejam utilizados (Martinez, 1997). A figura 2.4 mostra o funcionamento da técnica Frequency Hopping.

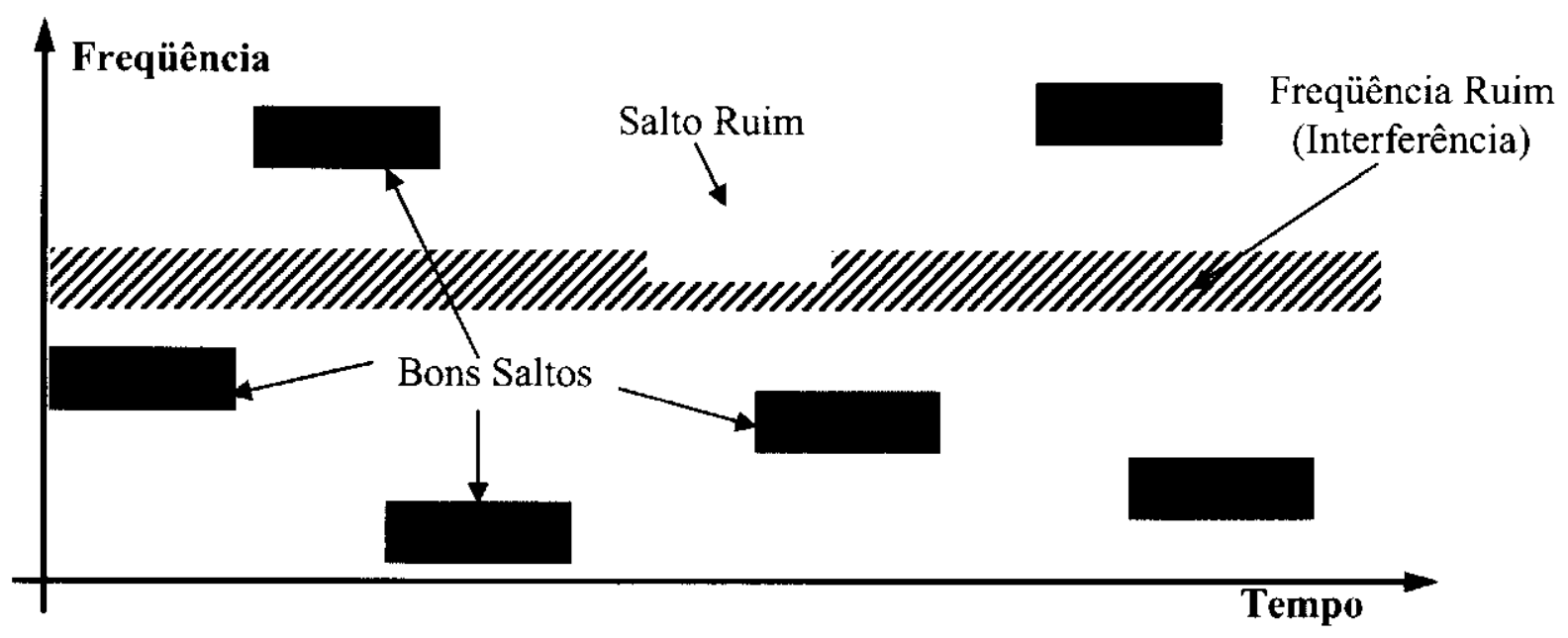

Figura 2.4: Frequency hopping spread spectrum.

Vantagens:

- Pode ser programada para evitar porções do espectro;

- Melhor desempenho quando existem canais com pouco ruído.

Desvantagens:

- Necessário um sintetizador de frequiências complexo;

- Necessário o emprego de códigos corretores de erro. 


\subsubsection{Tópicos de Redes de Computadores}

A arquitetura de uma rede de computadores é um sistema complexo que envolve subsistemas de hardware e software. Uma tentativa de padronização de tais sistemas é representada pelo modelo de referência ISO/OSI (Tanenbaum, 1996). Esse modelo é dividido em sete camadas que se comunicam através de uma interface bem definida. Tudo se passa como se camadas de mesmo nome em computadores diferentes, se comunicassem, diretamente, através de um conjunto de primitivas de serviço e protocolos de comunicação. As funções de cada uma das sete camadas do modelo são sumarizadas a seguir:

Camada Física - a camada física é responsável pela transmissão de um fluxo bruto de bits de um computador até outro. Os bits são representados por uma tensão/corrente elétrica ou tempo de duração de um pulso. Nessa camada, são definidas as direções da transmissão (simplex, duplex, half-duplex), como são iniciadas e liberadas as conexões e a distância máxima do canal de comunicação;

Camada de Enlace de Dados - a camada de enlace de dados provê uma interface bem definida para a camada de rede. Os bits são agrupados em frames e os algoritmos utilizados na implementação dos serviços de comunicação, permitem que se obtenha uma comunicação eficiente e confiável entre dois computadores que estejam conectados por um canal de comunicação que atua como se fosse um fio. A função principal da camada de enlace de dados é transferir dados da camada de rede do computador fonte para a camada de rede do computador destino, tratando os erros de transmissão e regulando o fluxo de frames. A camada de enlace de dados provê comunicação ponto-a-ponto entre os computadores fonte e destino;

Camada de Rede - a camada de rede controla a operação da subrede fazendo o roteamento dos pacotes entre subredes. As rotas são baseadas em tabelas estáticas (inseridas na rede e raramente modificadas) ou dinâmicas, normalmente gerenciadas por um protocolo de roteamento dinâmico. A camada de rede trata, também, dos problcmas de congestionamento (quando existem muitos pacotes na subrede). Ela implementa serviços de contabilidade de custos no envio de pacotes, bytes ou bits. Resolve, ainda, problemas de pacotes trafegando por redes heterogêneas, permitindo que elas possam ser interconectadas;

Camada de Transporte - a camada de transporte recebe os dados da camada de sessão, divide esses dados em unidades menores, se necessário, e entrega os dados para a camada de rede. A camada de transporte estabelece uma conexão distinta para cada conexão de transporte solicitada pela camada de sessão. Ela permite a multiplexação de várias conexões de transporte em uma mesma conexão de rede; 
Camada de Sessão - a camada de sessão permite que usuários em máquinas distintas estabeleçam sessões entre eles. Permite também uma série de serviços, entre eles o estabelecimento de sessões remotas e transferência de arquivos. Permite gerenciar o controle de diálogos, por exemplo, em duas direções ou em turnos. Faz o gerenciamento de tokens e provê serviço de sincronização;

Camada de Apresentação - a camada de apresentação cuida da sintaxe e da semântica das informações transmitidas, ou seja, os dados são codificados/decodificados em um padrão preestabelecido. Ela também se preocupa com a compressão dos dados, utilizada para reduzir o número de bits transmitidos e utiliza a criptografia para garantir a privacidade e autenticação;

Camada de Aplicação - a camada de aplicação fornece uma variedade de protocolos necessários na utilização do sistema. Nessa camada, os usuários podem definir os serviços a serem incluídos. Por exemplo: um editor de tela, usado em milhares de terminais físicos distintos (terminal virtual de rede). A camada de aplicação permite a transferência de arquivos entre sistemas diferentes, serviço de correio eletrônico e consultas remotas a diretórios.

A comunicação entre um UAV e a estação de solo é caracterizada por ser uma comunicação ponto-a-ponto. A camada de enlace de dados oferece esse tipo de serviço em diversas modalidades: serviço sem conexão e sem confirmação, serviço sem conexão e com confirmação e serviço com conexão e com confirmação (Tanenbaum, 1996).

No serviço sem conexão e sem confirmação, nenhuma conexão é estabelecida antecipadamente ou liberada posteriormente. A fonte transmite frames independentes para o destino e não há confirmação. Essa classe de serviço é adequada quando a taxa de erros é pequena e a recuperação é feita pelas camadas superiores. Também é utilizada para tráfego em tempo real, por exemplo, voz, onde o recebimento de dados com atraso excessivo não é melhor que o recebimento de dados com erros.

No serviço sem conexão e com confirmação, não há conexão entre a fonte e o destino; cada frame é individualmente confirmado e, se a confirmação não chegar dentro de um intervalo de tempo especificado, o frame é retransmitido. Esse tipo de serviço é mais utilizado quando os meios de comunicação não são confiáveis; por exemplo, enlaces via-rádio ou microondas.

O serviço com conexão e com confirmação é o serviço mais sofisticado da camada de enlace de dados. Os computadores precisam estabelecer previamente uma conexão antes de transmitir qualquer dado. Cada frame enviado é numerado e a camada de enlace de dados garante que cada frame enviado seja recebido corretamente e sem duplicação. Este serviço tem 3 fases: conexāo, onde existe a preparação do ambiente, ou seja, a conexão é estabelecida e ambos os lados iniciam as variáveis e os contadores necessários para o controle dos frames; transmissão, onde os frames são efetivamente transmitidos e; finalmente, liberaçāo, onde se encerra a conexão, liberando as variáveis, buffers e outros recursos utilizados. 
A comunicação entre a camada de rede e a camada de enlace de dados pode utilizar as primitivas de serviço do modelo OSI: pedido, indicação, resposta e confirmação (Tanenbaum, 1996). A primitiva de pedido é utilizada pela camada de rede para fazer uma solicitação para a camada de enlace de dados, tal como liberar uma conexão ou enviar um frame. A primitiva de indicação é utilizada para indicar, para a camada de rede, que aconteceu algum evento como, por exemplo, um outro computador querendo estabelecer ou desfazer uma conexão ou o recebimento de um frame. A primitiva de confirmação permite que a camada de enlace de dados possa indicar ao solicitante se o seu pedido foi executado corretamente e, caso contrário, qual foi o motivo.

Os métodos mais utilizados para assinalar o início e o fim de cada frame são: contagem de caracteres, caracteres de início e final de frame, preenchimento de caracteres, flags de início e final, preenchimento de bits e violações de codificação da camada física.

O controle de erros na camada de enlace de dados é feito pela introdução de timers (sincronização). Quando o transmissor emite um frame, ele inicia um timer, que é ajustado para disparar após um intervalo de tempo longo o suficiente para que o frame chegue ao destino, seja processado e a confirmação de recebimento seja enviada de volta ao transmissor. Se o frame for recebido corretamente, a confirmação será obtida de volta antes que o timer dispare e ele é cancelado. Se o frame ou a confirmação se perderem, o timer irá disparar, alertando o transmissor quanto ao problema. Nesse caso é necessário retransmitir o frame, correndo-se o risco de que esse frame seja entregue à camada de rede mais de uma vez. Para evitar que isso aconteça, é necessário que sejam atribuídos números de sequiência aos frames para que o receptor possa distinguir as retransmissões dos frames originais.

O controle de fluxo é outro ponto importante, tanto na camada de enlace de dados como nas camadas superiores. Muitas vezes, o transmissor quer transmitir frames de modo mais rápido do que o receptor pode aceitá-los. O controle desse fluxo requer um mecanismo de realimentação, onde o transmissor seja informado se o receptor está apto ou não para receber novos dados.

A camada de enlace de dados utiliza códigos para detectar e corrigir erros. Por exemplo, o bit de paridade pode indicar a presença de erros em um número ímpar de bits. Códigos de correção e detecção de erros mais avançados como o de Hamming e o CRC (Cyclic Redundancy Check), podem detectar erros em múltiplos bits e corrigir, automaticamente, alguns tipos de erros.

Diversos protocolos podem ser definidos para regulamentar a troca de dados entre a camada física e a de enlace de dados. Os protocolos de janelas deslizantes são altamente robustos e funcionam apropriadamente, mesmo sob condições desfavoráveis. Eles diferem entre si em termos de eficiência, complexidade e necessidades de buffer, permitindo o controle de fluxo e de erros na transmissăo. Eles podem ser associados com a técnica conhecida por pipelining, permitindo aumentar a eficiência de utilização de canais com tempo de latência elevado. 


\subsubsection{Equipamentos para Transmissão de Dados}

Os equipamentos adequados para a utilização neste projeto, devem apresentar as seguintes características:

- Dimensōes e peso pequenos;

- Baixo consumo de energia;

- Utilização de antenas omnidirecionais ou pouco direcionais;

- Alcance na ordem de $10 \mathrm{Km}$;

- Bidirecionalidade na transmissão dos dados;

- Largura de banda suficiente para a transmissão de vídeo digital comprimido.

Diversos equipamentos podem ser encontrados no mercado para o estabelecimento de comunicação ponto-a-ponto, no nível da camada de enlace de dados. Muitos desses equipamentos utilizam antenas direcionais, operando na faixa de microondas, sendo inadequados para o projeto proposto. Para a transmissão de imagens de vídeo, fica ainda mais difícil encontrar equipamentos com todas as características necessárias. As principais limitações encontradas são o peso ou dimensões do equipamento, o alto consumo de energia, a transmissão utilizando antenas direcionais ou as baixas taxas de transmissão de dados.

Os equipamentos encontrados, que mais atendem às necessidades do projeto são conhecidos como modems de RF (Rádio Freqüência). Os modems de RF ou modems wireless, possibilitam comunicação de dados sem meios físicos de transmissão. Os sistemas wireless são suscetíveis a ruído, o que pode resultar em erros na transmissão. Um modem wireless inteligente, garante dados livres de erros do transmissor até o receptor. Um microprocessador incorporado no equipamento empacota e endereça os dados, verifica erros nos pacotes recebidos e requisita, automaticamente, a retransmissão dos pacotes caso seja necessário. Todas essas operações são transparentes ao usuário. A utilização de modems de RF é similar à utilização de modems convencionais. Outra vantagem da utilização de modems de RF é que, os pacotes endereçados para mais de dois modems, podem compartilhar uma única frequiência.

Vale ressaltar que os modems pesquisados se enquadram nas faixas de freqüência ISM, cuja utilização foi justificada na seção 2.2.3. A tabela 2.1, descreve diversas características de alguns modems de RF disponíveis no mercado: 


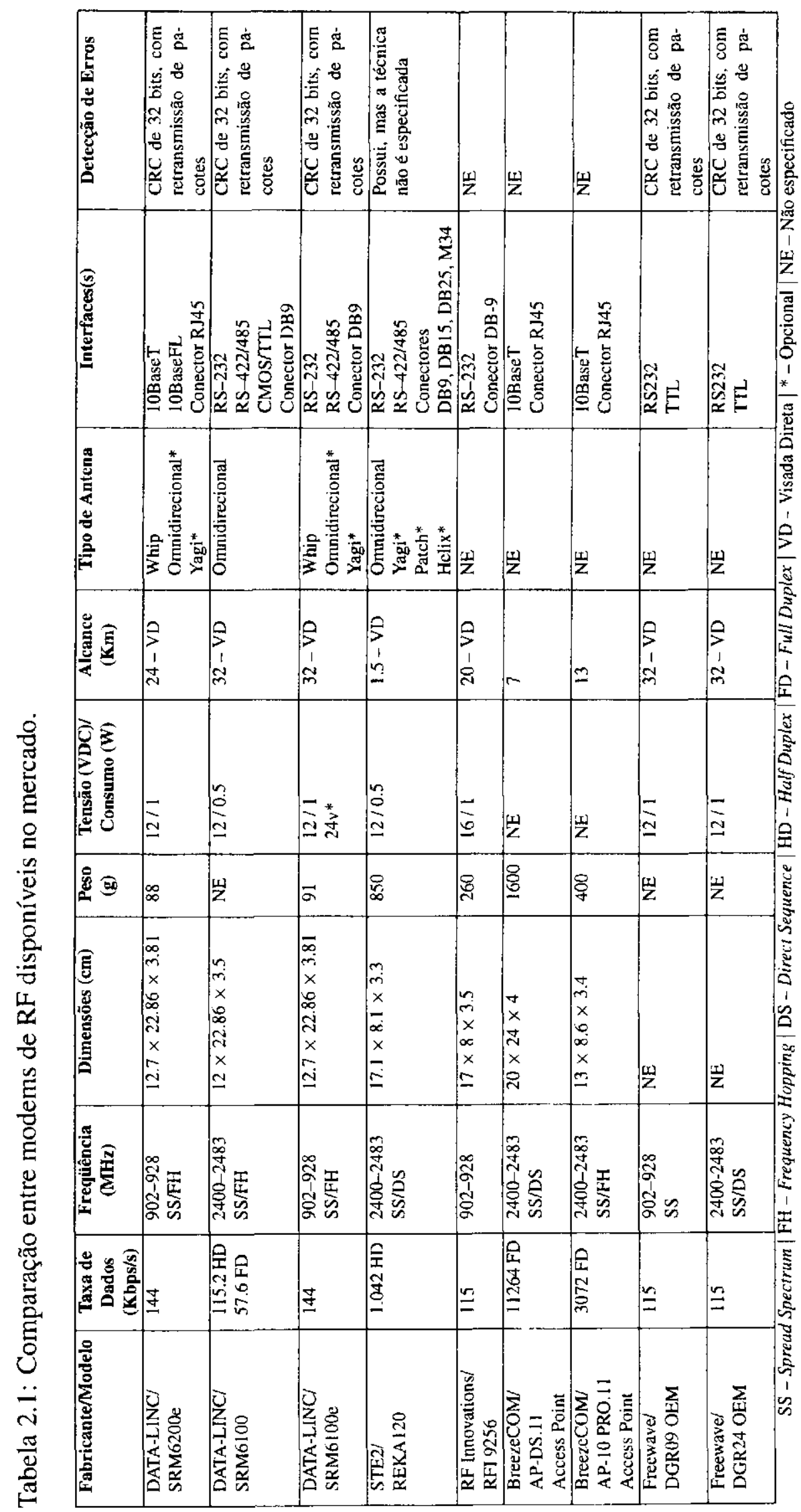




\subsection{Vídeo Digital}

Vídeo é uma entidade analógica conhecida como imagem. Para ser utilizada em um computador, a imagem deve ser transformada de sua representação mecânica/óptica, para uma representação eletrônica (analógica) e, então, de analógica para digital.

\subsubsection{Câmeras de Vídeo}

As câmeras de vídeo são equipamentos utilizados para a captura de imagens. Elas podem ser monocromáticas, reproduzindo somente imagens em preto-e-branco, ou podem reproduzir imagens coloridas, utilizando a combinação das três cores primárias (vermelho, verde e azul) para a reprodução de cor (Luther, 1995).

Uma câmera de vídeo monocromática consiste em uma lente e uma superfície sensível à luz (fotossensível), que converte uma imagem luminosa em um padrão de cargas elétricas. Por meio da técnica de rastreamento, o padrão de cargas elétricas é lido, utilizando-se um feixe disparado por um canhão de elétrons, que se encontra no interior de um tubo a vácuo. O rastreamento passa sobre cada ponto da superfície da imagem e, a carga do ponto é convertida para um sinal elétrico na linha de saída (Luther, 1995). A figura 2.5, mostra o resultado de um rastreamento em uma figura retangular.

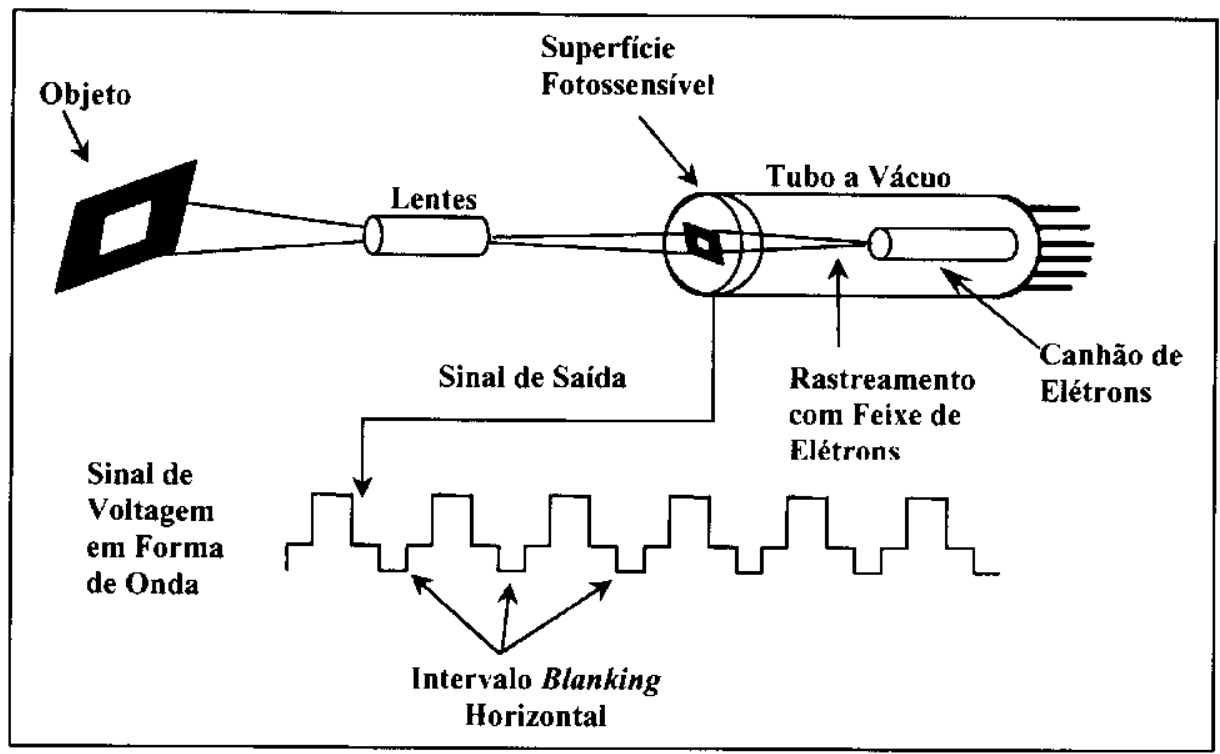

Figura 2.5: Câmera de vídeo monocromática e seu sinal de saída (Luther, 1995).

Câmeras coloridas realizam a reprodução de vídeo utilizando três câmeras que focalizam a mesma imagem. Cada câmera possui um filtro apropriado para uma determinada cor primária. 
Um prisma é utilizado para dividir a luz de maneira idêntica entre as câmeras, de modo que cada câmera veja a mesma imagem. Esse esquema é denominado câmera RGB $^{2}$ de três sensores (Luther, 1995) (figura 2.6).

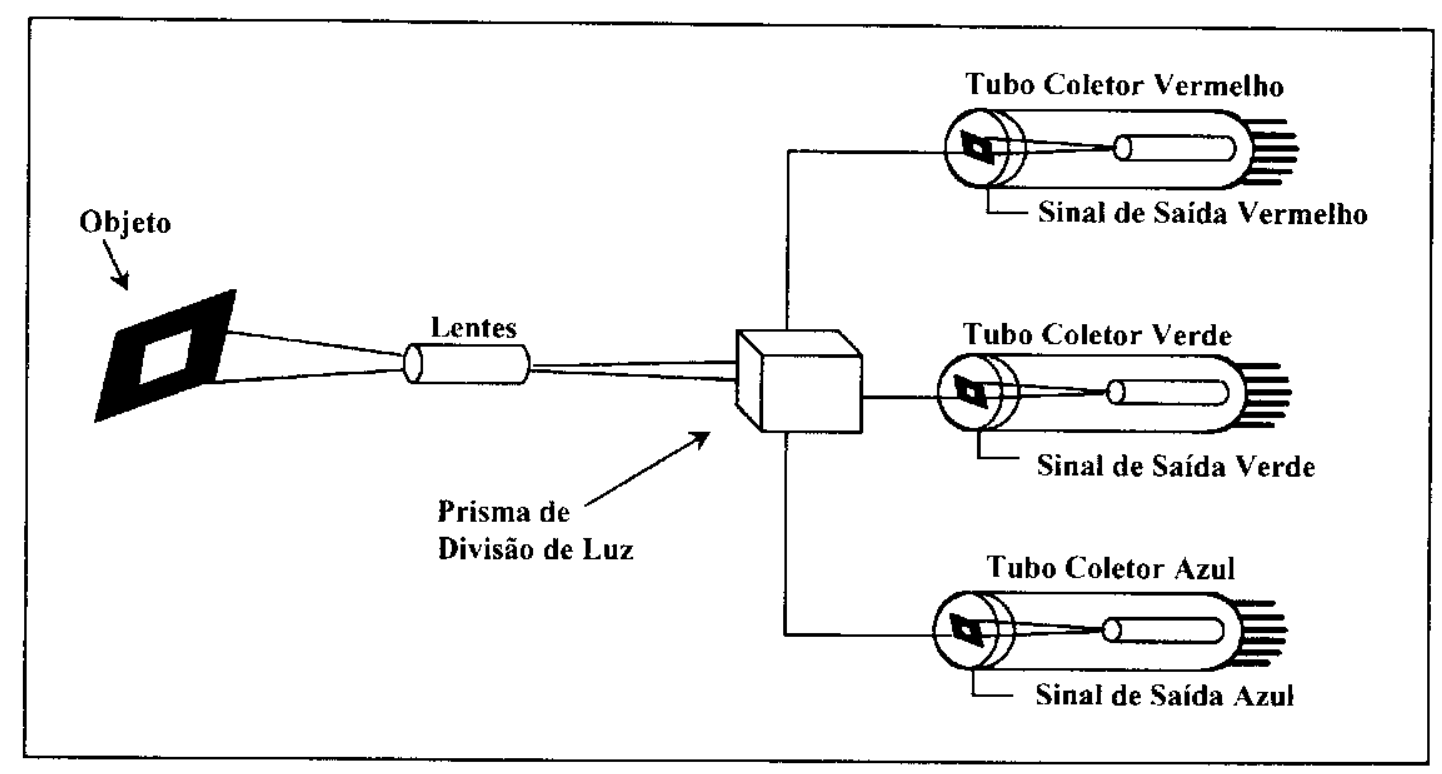

Figura 2.6: Câmera de vídeo colorida com três sensores (Luther, 1995).

Os dispositivos eletrônicos mais utilizados em câmeras de vídeo digitais, são conhecidos como CCD (Charge Coupled Device). Um dispositivo CCD converte as intensidades de luz que incidem sobre ele em valores digitais armazenáveis, na forma de bits e bytes (Cappelaro et al., 1997). Esse dispositivo pode ser visto na figura 2.7 .

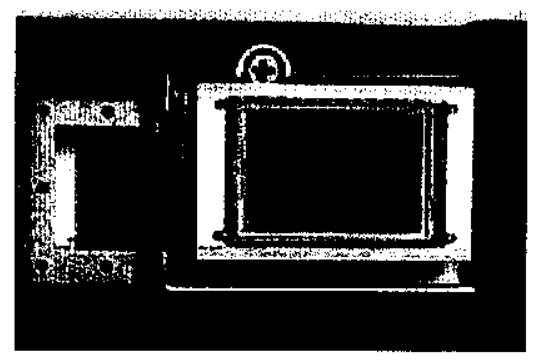

Figura 2.7: CCD de uma câmera fotográfica digital.

Existem dois tipos básicos de CCD, que podem ser utilizados em câmeras digitais:

CCD linear - é uma fileira composta de milhares de elementos fotossensíveis que varrem a área onde a imagem se forma na câmera, capturando uma coleção de linhas que formam o quadro

\footnotetext{
${ }^{2}$ RBG, do inglês, Red, Greem e Bluc. É um padrão que utiliza a combinação das três cores primárias para obter outras cores.
} 
de vídeo. Esse dispositivo pode fornecer uma resolução bem alta e gerar quadros bem grandes. A geração de uma imagem leva um bom tempo para ser completada. As câmeras que usam este tipo de CCD são, geralmente, utilizadas em estúdios para fotografias estáticas de alta definição. Não são câmeras indicadas para objetos em movimento e podem apresentar resultados ruins quando utilizadas em iluminação piscante, como lâmpadas fluorescentes.

CCD do tipo array - é uma matriz com milhares, ou até milhões de elementos fotossensíveis que capturam simultaneamente os pixels da imagem convencional. Esse dispositivo produz resultados equivalentes ao de uma imagem fotográfica comum, com relação ao tempo de captura, mas normalmente produz imagens com qualidade inferior às conseguidas com o CCD linear. $\mathrm{O}$ CCD linear permite capturar uma quantidade maior de pixels que o CCD tipo Array. As câmeras que utilizam este tipo de CCD (retangular) são as mais populares do mercado e apresentam, não somente preços mais acessíveis, como também facilidade de uso e portabilidade.

Outro tipo de sensor similar ao CCD é o CMOS (Complementary Metal - Oxide Semicondutor). A principal vantagem que o CMOS apresenta é o baixo custo. Além disso, consome menos energia que os dispositivos CCD, embora a qualidade da imagem seja inferior podendo apresentar mais ruído (Zoran, 2001).

\subsubsection{Vídeo Analógico}

O ser humano percebe imagens de uma forma paralela, isto é, todos os objetos da imagem, refletem luz ao mesmo tempo e o olho humano capta tais reflexões paralelamente. O nervo óptico possui milhões de conexões que levam a informação, paralelamente, até o cérebro. No mundo eletrônico, é impraticável construir uma conexão com milhares de circuitos; por isso, é utilizada uma única conexão ou algumas poucas conexões e um sensor de vídeo (câmera) que converte a imagem paralela em um sinal de vídeo (Goularte \& Moreira, 1998).

\section{Rastreamento}

O processo de rastreamento (scanning), consiste em capturar eletricamente uma imagem através de uma leitura seqüencial dos valores de brilho de uma série de pontos (figura 2.5). O rastreamento produz, como saída, um sinal analógico (elétrico), representando o brilho de um ponto da imagem. Se o processo for realizado a uma velocidade variando de 30 a 60 vezes por segundo, os olhos perceberão uma imagem contínua.

A figura 2.8, mostra um padrão típico de rastreamento. O movimento de leitura inicia-se no canto superior esquerdo, realizando sucessivos retraços horizontais. Quando a leitura atinge o 
canto inferior direito da imagem, ocorre um retraço vertical e a leitura recomeça no canto superior esquerdo, completando um quadro de rastreamento. Maiores informações podem ser obtidas em Luther (Luther, 1995).

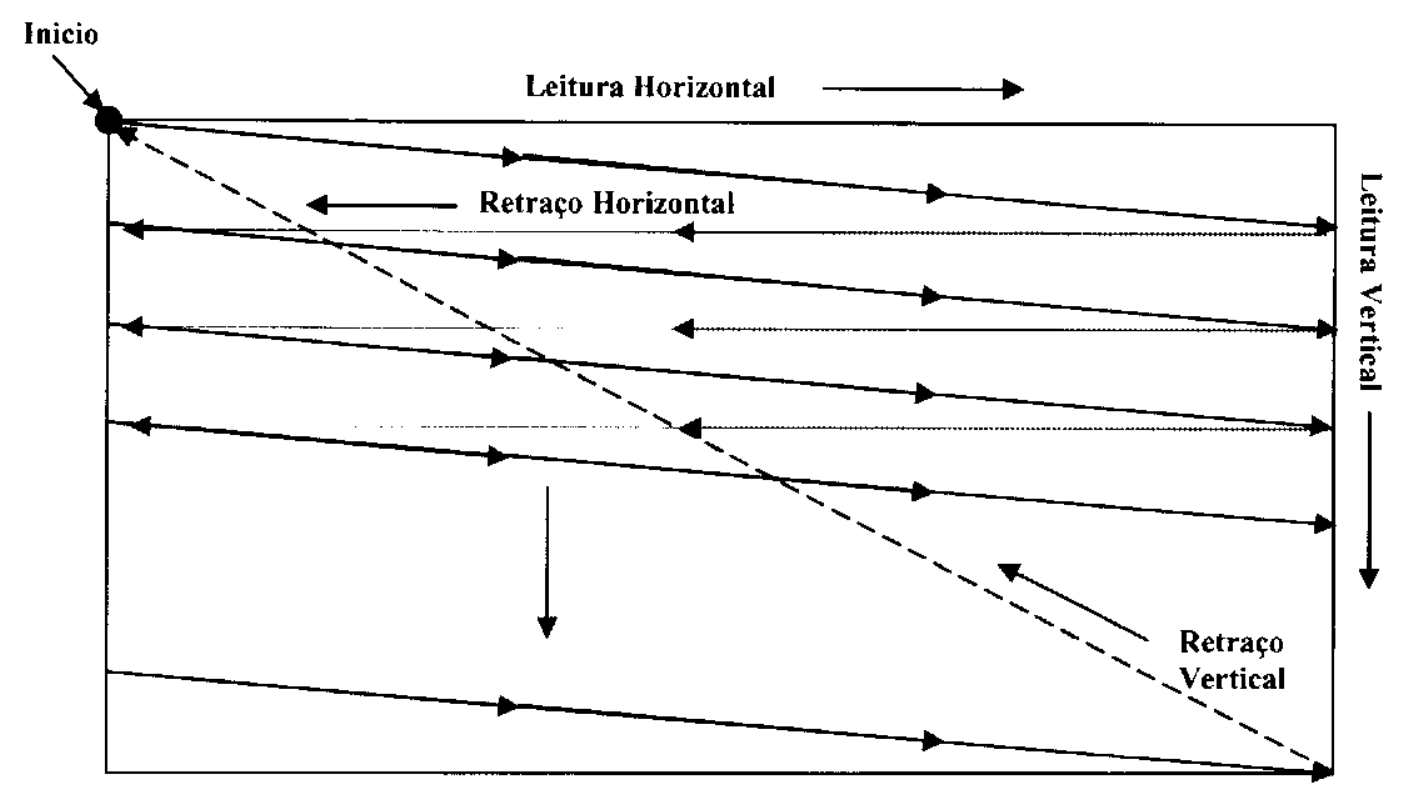

Figura 2.8: Rastreamento progressivo (Luther, 1995).

\section{Padrōes de Sinais de Vídeo}

Televisores preto-e-branco recebem um único sinal chamado luminância (também conhecido como sinal Y). Cada pixel é definido como alguma variação de intensidade entre branco (intensidade total) e preto (nenhuma intensidade). Em 1953, o padrão NTSC (National Television Standards Committee) surgiu para possibilitar a manipulação de cores. Para manter a compatibilidade com o padrão preto-e-branco, o NTSC utiliza um padrão de cores que mantém o sinal de luminância separado do sinal requerido para os televisores a cores (Cisco, 2001). No mundo digital, as cores são tipicamente expressadas utilizando vermelho, verde e azul (RGB). O mundo analógico também utiliza o padrão RGB, pelo menos no que se refere à aquisição de imagens, onde a maioria das câmeras quebram o sinal analógico em componentes RGB.

Infelizmente, o NTSC não poderia utilizar o RGB como padrão de cores para televisores, porque o padrão preto-e-branco não poderia decodificar os sinais RGB. Ao invés disso, o NTSC envia um sinal de luminância (para os televisores preto-e-branco) e utiliza outros sinais para enviar as informações de cores, chamados hue e saturation (matiz e saturação), também conhecidos com sinais U e V. Por essa razão, a tecnologia digital utiliza como padrão de cores o RGB e a tecnologia analógica, especialmente o sistema de televisão broadcast, utiliza YUV. (os sinais Y, U e V). 
O RGB, entretanto, é um formato ineficiente para armazenamento de vídeo analógico por duas razões:

- Para utilizar o padrão RGB, todos os três sinais de cores devem ter disponível no sistema a mesma largura de banda, o que é freqüentemente ineficiente do ponto de vista de projeto do sistema;

- Cada pixel é a soma dos valores de vermelho, verde e azul. As modificações de pixel forçam o ajuste dos três valores. Em contraste, quando imagens são armazenadas com formatos de luminância e cor (no formato YUV), um pixel pode ser alterado pela modificação de um único valor.

A figura 2.9 mostra um sinal de vídeo analógico da captura até à saída NTSC.

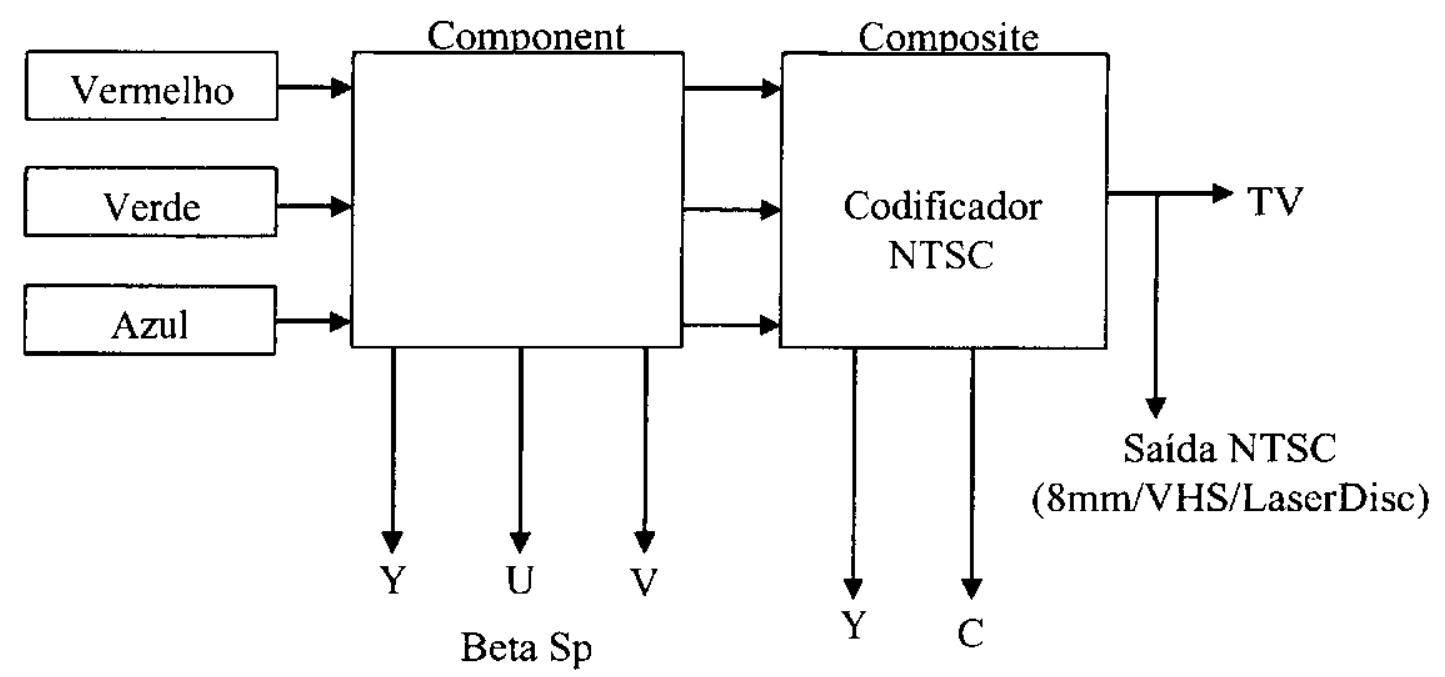

HI-8/S-VHS

Figura 2.9: Codificação de RGB para NTSC (Cisco, 2001).

Um sinal de vídeo pode ser transmitido como composto (composite), S-Video ou component video (Cisco, 2001). O component video mantém canais separados para cada valor de cor, tanto no dispositivo de gravação quanto no meio de armazenamento. O component video provê a fidelidade mais alta porque ele elimina o ruído que deveria aparecer quando dois sinais são combinados em um único canal.

Na codificaçāo NTSC, os canais de matiz e saturação (sinais U e V), são combinados em um único canal de crominância, o canal $\mathrm{C}$. Um sinal de vídeo, chamado $S$-Video, mantém canais separados para os sinais de luminância e crominância. O S-Video é também conhecido como $Y / C$ Video. 
Todas as cores e outras informações podem ser combinadas em um único canal YUV, chamado também de sinal composto, para ser mostrado nos televisores preto-e-branco. Tecnicamente, um sinal composto é qualquer sinal que contenha toda informação necessária para mostrar vídeo. Qualquer canal individual de um component video ou Y/C video não é suficiente para mostrar vídeo.

O tipo de sinal de vídeo define o conector que é utilizado. O sinal composto, utiliza um único pino chamado de conector RCA. O sinal S-Video, composto de dois sinais elétricos utiliza um conector de quatro pinos chamado conector mini-DIN; já o sinal component, utiliza três conectores (Cisco, 2001).

\subsubsection{Vídeo Digital}

O vídeo digital tem crescido muito nos últimos anos por uma série de razões. A informação digital é mais robusta e pode ser codificada para eliminar erros. Isso significa que, perdas na gravação e na transmissão, podem ser eliminadas. Outra razão desse crescimento está relacionada com a manipulação de vídeo. As técnicas de gravação e transmissão digital permitem um nível de manipulação de conteúdo impossível de ser feito utilizando as técnicas analógicas (Tektronix, 2001).

Como visto anteriormente, antes de obter um vídeo digital, é preciso transformá-lo de sua representação analógica para uma representação digital. Esse processo é conhecido como digitalização. O processo de digitalização envolve a conversão do sinal de vídeo analógico em um fluxo de vídeo (video stream) digital, utilizando circuitos para captura de vídeo, como o mostrado na figura 2.10 .

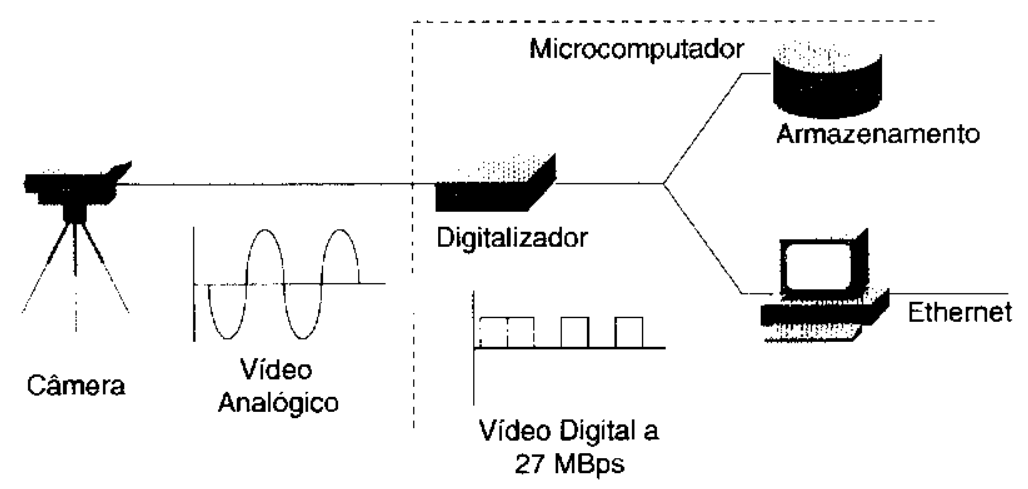

Figura 2.10: Conversão de vídeo analógico para digital (Cisco, 2001). 
Na captura e digitalização de vídeo, é importante observar os seguintes parâmetros:

Resolução - São as dimensões vertical e horizontal de uma sessão de vídeo. Um vídeo em tela cheia possui normalmente 640 pixels horizontais por 480 pixels verticais. O vídeo em tela cheia utiliza essas dimensōes para se enquadrar no padrão 4:3 da televisão, o que significa que o número de linhas horizontais é $25 \%$ menor que o número de linhas verticais (colunas).

Profundidade de Cor (Color Depth) - O número de bits utilizados para expressar cor. Por exemplo, com 24 bits é possível mostrar 16.7 milhões de cores ( 8 bits para representar o vermelho, 8 bits para o verde e 8 bits para o azul). Cada conjunto de 8 bits é utilizado para expressar a intensidade da cor, que varia entre 0 e 255 . Outras profundidades de cor comuns são de 16 bits e 8 bits, que conseguem mostrar respectivamente 65536 e 256 cores.

Taxa de quadros (Frame Rate) - É o número de quadros mostrados por segundo. Para produzir vídeo com qualidade NTSC, é necessário mostrar 30 quadros por segundo. O PAL (Phase Alternation Line) e o SECAM (Sequential Couleur avec Memoire), mostram 25 quadros por segundo. Vale ressaltar que existem variações dos padrões de vídeo. Por exemplo, o padrão PAL, na maioria das variações, transmite 25 quadros por segundo, mas uma de suas variações transmite 30 quadros por segundo. Essa variação é conhecida com PAL-M e é utilizada no Brasil. O sufixo após o nome do padrão, nesse caso o M, define como será a transmissão do sinal. Maiores informações sobre os padrões de vídeo podem ser encontradas em Faroudja (1988) e em Jack (1996).

Através de uma operação matemática simples é possível determinar a quantidade de largura de banda que um determinado fluxo de vídeo requer. Por exemplo, para enviar um vídeo digitalizado em tela cheia $(640 \times 480)$ não comprimido em uma rede, é necessário uma largura de banda de aproximadamente 27 megabytes por segundo (27 MBps). Esse número é derivado do cálculo abaixo:

$640 \times 480 \times 3 \times 30=27.648 \mathrm{MBps}$ (ou 221.184 megabits por segundo [Mbps])

onde: 640 e 480 representam a resolução em pixels, 3 representa 24 bits de cor ( 3 bytes), e 30 representa o número de quadros por segundo.

Como indicado nesse cálculo, um vídeo digital de movimento completo (full-motion) e cores reais (true-color), requer mais banda que as redes de pacotes mais comumente utilizadas podem oferecer. Felizmente, existem duas técnicas para reduzir o consumo de banda: Manipulação de Captura de Vídeo e Compressão de Vídeo.

Manipulação de Captura de Vídeo - Os parâmetros de manipulação de captura de vídeo envolvem mudanças de resolução, profundidade de cores e taxa de quadros. Para reduzir o consumo de banda/espaço de armazenamento, as três variáveis sāo freqüentemente modificadas. Por exemplo, algumas aplicações multimídia capturam vídeo com resolução de $320 \times 240$, com 8 bits de 
cor e taxa de quadros de 15 quadros por segundo. Com esses parâmetros, o consumo de banda cai para $9.216 \mathrm{Mbps}$. Na prática, essa taxa de transmissão dificilmente pode ser conseguida em uma rede Ethernet de 10-Mbps.

Compressão de Vídeo - Como visto anteriormente, a manipulação de captura de vídeo não resolve totalmente os problemas de armazenamento e largura de banda; por isso, aliado à manipulação de captura de vídeo é possível utilizar a compressão de vídeo como meio de resolver os problemas citados. Essa técnica se caracteriza por substituir as redundâncias de pixels em um quadro por representações mais "econômicas", ou seja, que ocupem menor espaço de armazenamento ou banda de transmissão. A compressão de vídeo também trabalha na substituição de redundâncias que ocorrem em uma seqüência de quadros. Maiores detalhes na seção 2.3.4.

\section{Requisitos de Qualidade de Serviço}

Dados e aplicações multimídia têm diferentes requisitos de qualidade de serviço. Ao contrário dos serviços tradicionais de dados de "melhor esforço" (best effort), como o FTP (File Transfer Protocol) e o SMTP (Simple Mail Transfer Protocol), onde variações de latência passam freqüentemente despercebidas, dados de áudio e vídeo são úteis somente se eles chegam ao seu destino em um período de tempo pré-estabelecido. Em geral, latência e jitter são os dois principais problemas encontrados na transmissão de vídeo digital.

Latência - Em uma rede, latência é um sinônimo para atraso (delay). Ela expressa quanto tempo é necessário para um pacote de dados ir de um ponto a outro. Em alguns casos, a latência é medida pelo tempo de envio e retorno do pacote de dados ao ponto de origem. Isso também é chamado de round-trip time. Redes de telefonia são projetadas para oferecer menos que 400 milisegundos (ms) de round-trip time. Redes multimídia, projetadas para a transmissão de áudio e videoconferência, também devem oferecer uma latência máxima de $400 \mathrm{~ms}$ de round-trip time. A rede contribui para a latência de várias maneiras:

- Atraso de Transmissão: É o tempo que um pacote leva para cruzar o meio. O atraso de transmissão é determinado pela velocidade do meio e o tamanho do pacote;

- Atraso de Store-and-Forward: É o tempo que um dispositivo de interligação de redes (como um switch, bridge ou roteador) leva para retransmitir um pacote;

- Atraso de Processamento: É o tempo necessário para um dispositivo de interligação de redes encontrar a rota, mudar o cabeçalho do pacote e realizar outras tarefas de chaveamento. Em alguns casos, o pacote também deve ser modificado. Por exemplo, na mudança do tipo de 
encapsulamento ou no contador de hops (saltos). Cada um desses passos contribui para aumentar $\mathrm{o}$ atraso de processamento.

Jitter - Se uma rede entrega dados com uma latência variável, isso introduz jitter. Jitter são interrupções perceptíveis ao usuário em transmissões de áudio/vídeo. Muitas aplicações multimídia são projetadas para minimizar jitter. A técnica mais comum é armazenar todos dados recebidos em um buffer antes de apresentá-los ao usuário. Variações no fluxo de chegada dos dados devem ser menores que o tamanho total do buffer para que as interrupções de apresentação do vídeo/áudio não sejam percebidas.

\subsubsection{Compressão de Vídeo Digital}

Compressão de vídeo digital é o processo onde um conjunto de técnicas e algoritmos codificam um pixel de imagem com representaçōes matemáticas mais compactas. A descompressão é o processo reverso onde as representações matemáticas são transformadas em pixels.

O sucesso inicial do vídeo digital se deu em aplicações de pós-produção, onde o alto custo do vídeo digital era compensado pela quantidade e qualidade dos efeitos produzidos. Entretanto, o volume de dados gerado era acima de $200 \mathrm{Mbps}$, ocasionando a necessidade de grandes capacidades de armazenamento e uma extensa largura de banda para transmissão. $O$ vídeo digital somente poderia ser utilizado em larga escala se as necessidades de armazenamento e banda fossem reduzidas. Reduzir essas necessidades é o propósito da compressão.

Um esquema de compressão de vídeo ideal é aquele que reduz as taxas de dados de vídeo sem afetar a qualidade do vídeo. Para realizar a compressão de vídeo, um CODEC (Codificador/Decodificador ou Compressor/Descompressor) deve ser utilizado. O CODEC, o qual pode ser implementado em hardware ou software, é responsável pela compressão/descompressāo de um fluxo de vídeo digital.

Em todos os fluxos de vídeo existem dois tipos de componentes de sinal: aqueles que são "novos" e imprevisíveis e aqueles que podem ser previstos. Os componentes novos săo chamados de entropy. O restante é chamado de redundância porque não é essencial. A redundância pode ser espacial, quando as redundâncias ocorrem no mesmo quadro, ou seja, quando pixels adjacentes possuem semelhanças. A redundância também pode ser temporal, quando as semelhanças ocorrem entre quadros sucessivos (Tektronix, 2001). Os conceitos de redundância temporal e espacial são melhor explicados em seções posteriores.

Os sistemas de compressão trabalham separando a entropy da redundância através do codificador (encoder). Somente a entropy é armazenada ou transmitida. O decodificador computa a redundância a partir do sinal transmitido. 
Um codificador ideal deveria extrair toda entropy e somente ela deveria ser transmitida para o decodificador. Um decodificador ideal deveria reproduzir o sinal original. Na prática, esse ideal é dificilmente alcançado. Um codificador ideal seria muito complexo, caro e causaria um atraso (delay) muito grande. Em algumas aplicações, como gravação ou broadcast, algum atraso é aceitável, mas em vídeo conferência, não é (Tektronix, 2001).

Ebrahimi \& Kunt (1998) discutem várias técnicas de compressão de vídeo e de imagens estáticas utilizadas pelos algoritmos de compressão de vídeo atuais. Lu et al. (1999) descrevem um sistema de compressão de vídeo desenvolvido para veículos remotamente controlados e as características que devem consideradas nesse tipo de aplicação.

É importante ressaltar que algumas técnicas/padrões de compressão de vídeo também possuem especificações para compressão de áudio. As técnicas de compressão de áudio não serão abordadas porque não serão aplicadas no projeto proposto.

\section{Compressão Lossless/Lossy}

Lossless são as técnicas de compressão onde não ocorre nenhuma perda de dados. Um arquivo comprimido com essa técnica será exatamente igual ao original após sua descompressão. As técnicas lossless são tipicamente utilizadas para arquivos executáveis (aplicações) e arquivos de dados, ou seja, onde qualquer modificação torna o arquivo inutilizável. Em geral, as técnicas lossless identificam e utilizam os padrões dos arquivos para descrever o conteúdo dos mesmos de maneira mais eficiente. Isso funciona bem para arquivos com uma redundância significativa, como bancos de dados e planilhas. As técnicas lossless conseguem taxas de compressão de aproximadamente 2:1. A compressão lossless é utilizada por produtos como o Double Space ${ }^{3}$ para expandir, de forma transparente ao usuário, a capacidade do disco rígido, e por produtos como o PKZIP ${ }^{4}$, para armazenar mais dados em um meio de armazenamento;

As técnicas de compressão lossy são muito utilizadas em imagens e vídeo, pois recuperam uma representação próxima à original. Uma imagem comprimida com essas técnicas será parecida com a original, mas será diferente da representação digital, ou seja, o arquivo original será diferente do qual foi descomprimido. Essa perda (loss) permite obter taxas de compressão de 2:1 até 300:1. Uma ampla gama de técnicas de compressão lossy estão disponíveis para vídeo digital e uma regra simples se aplica a todas elas: quanto maior for a taxa de compressão, maior será a perda de dados (Furht, 1995).

\footnotetext{
${ }^{3}$ O Double Space é marca registrada da Microsoft Corp.

${ }^{4} O$ PKZIP é marca registrada da PKWARE, Inc.
} 


\section{Compressão Interframe/Intraframe}

Compressão Interframe é a compressão entre quadros, também conhecida como compressão temporal pelo fato de ser aplicada ao longo do tempo, ou seja, trabalha na eliminação da redundância temporal. As técnicas de compressão interframe utilizam um sistema de quadros chave e quadros delta para eliminar a informação redundante entre quadros. Os quadros chave armazenam o quadro completo e os quadros delta armazenam somente as mudanças ocorridas entre os quadros. Algumas implementações comprimem os quadros chave e outras não. Em ambas as maneiras, o quadro chave serve como uma referência para os quadros delta. Os quadros delta contêm somente os pixels, que são diferentes do quadro chave ou do quadro delta imediatamente anterior. Durante a descompressão, os quadros delta são comparados com seus respectivos quadros de referência (delta ou chave) para preencher as informações que estão faltando.

Diferentes técnicas de compressão interframe utilizam diferentes seqüências de quadros chave e quadros delta. Por exemplo, algumas implementações calculam as diferenças interframe entre quadros delta seqüenciais, durante a compressão. Nesse caso, somente o primeiro quadro delta é comparado com o quadro chave. Em outras implementações, como a do MPEG (Moving Pictures Expert Group), todos os quadros delta são relacionados com o quadro chave anterior.

As técnicas de compressão interframe derivam sua eficácia da redundância existente entre os quadros. Um vídeo que possui poucos movimentos (low-motion), como cabeças e ombros de uma pessoa em uma sessão de videoconferência, tem um alto grau de redundância.

Compressão Intraframe é a compressão de quadros individuais, também conhecida como compressão cspacial. Essas técnicas trabalham na eliminação da redundância espacial. Embora exista uma maior preocupação com as técnicas intraframe, o desempenho dos CODECs está mais relacionado com a técnica compressão interframe utilizada do que com a técnica intraframe. A seguir, são citadas as principais técnicas de compressão intraframe:

- RLE (Run Length Encoding) - Uma técnica lossless simples originalmente projetada para compressão de dados e posteriormente modificada para fac-símile. O RLE comprime uma imagem baseada em "séries" de pixels. Embora ela funcione bem em fac-símiles preto-ebranco, o RLE não é eficiente para imagens em cores, que possuem poucas "séries" grandes de pixels coloridos exatamente iguais;

- JPEG (Joint Photographic Experts Group) - Um padrão que tem sido adotado por duas organizações de padrões internacionais: o ITU (formalmente CCITT) e a ISO (International Standards Organization). O JPEG utiliza a DCT (Discrete Cosine Transform) para comprimir imagens (Pennebaker \& Mitchell, 1993); 
- VQ (Vector Quantization) - É um padrão similar ao JPEG. A diferença entre o VQ e o JPEG está no processo de quantização. A compressão no VQ é altamente complexa. Entretanto, seu processo de descompressão, que envolve obter valores de uma tabela, é simples e rápido (Rabbani \& Jones, 1991). O VQ é um algoritmo de domínio público.

\subsubsection{Algoritmos e Padrões de Compressão de Vídeo}

A seguir são apresentados os algoritmos e padrões de compressão de vídeo relevantes ao projeto proposto:

\section{MPEG-2}

O padrão MPEG-2 (formalmente padrão internacional ISO/IEC 13818) é um sistema de codificação de vídeo genérico para vários tipos de aplicações. Segundo Tudor (1995) o MPEG-2 tem sido utilizado com sucesso desde aplicações que necessitem de vídeo de alta definição até aplicações que necessitem de baixas taxas de bits. Basso et al. (1999) mostra que a transmissāo de fluxos MPEG-2 sobre redes IP, utilizando o protocolo RTP e hardware e sistemas operacionais comerciais, permite a entrega de audio e vídeo de boa qualidade com pouca perda de pacotes.

O MPEG-2 utiliza tanto a compressão intraframe como a compressāo interframe para reduzir a taxa de bits. Para realizar a compressão intraframe, o MPEG-2 utiliza uma combinação de DCT, Quantização e VLC (Variable-length Code). O DCT codifica blocos de $8 \times 8$ pixels, em blocos de coeficientes DCT. Para transmitir os blocos DCT de maneira mais eficiente para o decodificador, é aplicado o processo de quantização reduzindo o número de valores a serem transmitidos. O VLC tem a função de serializar os coeficientes DCT quantizados para a transmissão.

A técnica de compressão interframe utilizada pelo MPEG-2 é chamada Motion-compensated interframe prediction. Essa técnica explora a redundância temporal tentando prever o quadro a ser codificado a partir de um quadro de referência anterior, posterior ou ambos.

Diferentes algoritmos têm sido integrados ao padrão MPEG-2. Implementar todos esses algoritmos em todos os decodificadores, os tornariam muito complexos. Para resolver esse problema foram criados subconjuntos do MPEG-2, conhecidos como profiles e levels. Um profile é um subconjunto de algoritmos e um level identifica um conjunto de restrições de parâmetros (como o tamanho do quadro e a taxa de bits).

O MPEG-2 está sendo considerado, por empresas de telecomunicações e empresas de TV a cabo, como o padrão para a entrega de vídeo-sob-demanda e de HDTV (High-Definition Television). Vale ressaltar que os decodificadores MPEG-2 também decodificam fluxos de bits MPEG-1. 


\section{MPEG-4}

O padrão MPEG-4 (formalmente padrão internacional ISO/IEC 14496) define um sistema multimídia que contem cenas complexas compostas de áudio, vídeo, áudio sintético e material gráfico. Além do MPEG-4 combinar algumas características típicas de outros padrões MPEG, ele visa fornecer um conjunto de tecnologias para satisfazer à necessidade de autores, provedores de serviço e usuários finais.

Para autores, o MPEG-4 possibilita a produção de conteúdo com maior reusabilidade, flexibilidade, melhor gerenciamento e melhor proteção de direitos de propriedade do que as tecnologias individuais, como televisão digital, animação gráfica, páginas Web e suas extensões.

Para provedores de serviço, o MPEG-4 oferece um descritor de QoS (Quality of Service) genérico para diferentes tipos de mídia MPEG-4. A tradução exata dos parâmetros de QoS de cada tipo de mídia para o QoS da rede excede o escopo do MPEG-4 e fica a cargo dos provedores de serviço.

Para usuários finais, o MPEG-4 oferece um nível de interatividade com o conteúdo, dentro dos limites permitidos pelo autor.

O MPEG-4 atinge esses objetivos, oferecendo maneiras padronizadas para:

- Codificação - representando unidades de áudio, visuais, ou conteúdo audiovisual, chamados de objetos de mídia (Média Objects). Esses objetos são naturais ou sintéticos, o que significa que eles podem ser gravados com uma câmera ou microfone ou gerados por um computador;

- Composição - descrevendo a composição desses objetos para criar objetos de mídia compostos que formam cenas audiovisuais;

- Multiplexação - Multiplexado e sincronizando os dados associados aos objetos de mídia para transmiti-los por canais de rede e oferecendo uma QoS apropriada para a natureza dos objetos de mídia;

- Interação - Interagindo com a cena audiovisual no receptor, ou através de um canal de retorno, no transmissor.

A estrutura do padrāo MPEG-4 consiste em seis partes: sistemas, visual, áudio, teste de conformidade, software de referência e DMIF (Delivery Multimedia Integration Framework). Mais informações sobre o MPEG-4 podem ser encontradas em (Battista et al., 1999, 2000; Pereira, 2000; Avaro et al., 2000). 


\section{M-JPEG (Motion-JPEG)}

Um fluxo de vídeo M-JPEG é equivalente a apresentar uma série de imagens comprimidas pelo padrão JPEG em seqüência. Devido ao M-JPEG não possuir compressão interframe, o que reduz a taxa de bits de maneira mais significativa em relação à compressão intraframe, ele não é tão eficiente quanto os outros algoritmos apresentados.

Böröczky \& Ngai (1999) fazem uma comparação do MPEG-2 com o M-JPEG em baixas taxas de dados (1 até $8 \mathrm{Mbits} / \mathrm{s}$ ). Nessa comparação, é concluído que o MPEG-2, comparado ao MJPEG, apresenta imagens de melhor qualidade na mesma taxa de bits ou imagens de qualidade equivalente em menores taxas de bits. Portanto, em baixas taxas de bits, tanto quando se deseja melhorar a qualidade da imagem ou quando se deseja diminuir a taxa de bits, o MPEG-2 é mais indicado que o M-JPEG.

\section{CELL}

Existem dois tipos de compressão por células: CellA e CellB. CellA é uma técnica assimétrica onde se utiliza mais computação para compressão do que para descompressão. A técnica CellB é mais simétrica computacionalmente, sendo adequada para utilização em tempo real, como por exemplo, em videoconferência. O CellA utiliza o padrão RGB como entrada, enquanto o CellB utiliza o padrāo YUV.

A técnica de codificação Cell baseia-se no método de truncamento de bloco, mais conhecido como BTC (Block Truncation Coding). A imagem de entrada é dividida em blocos de $4 \times 4$ pixels chamados de células. A diferença entre o CellA e o CellB está no modo como as intensidades são escolhidas. O CellA, cataloga os valores através de um mapa de cores enquanto o CellB utiliza uma tabela de quantização vetorial. Ambas as técnicas utilizam VQ e RLE;

\section{H.261}

O H.261 (recomendação ITU-T H.261) é um padrão de compressão de vídeo destinado à videoconferência sobre redes ISDN (Integrated Services Digital Network) e é baseado no padrão H.320. O H.261 visa larguras de banda de comunicação entre $64 \mathrm{Kbps}$ e $2 \mathrm{Mbps}$, variando em intervalos de 64 Kbps. Essa técnica também é conhecida como "px64" onde "p" varia de 1 até 30.

O Padrāo H.261 utiliza codificação temporal interframe e codificação espacial intraframe. No modo de codificação intraframe, um processo de compensação de movimento (motion compensation), é executado para calcular a diferença entre os quadros, que são então codificados em DCT. 
Segundo Mitchell et al. (1996), o algoritmo de codificação atual do H.261 é similar ao MPEG, mas não é compatível com o mesmo. Entretanto, o H.261 necessita, substancialmente, de menor poder de CPU para codificação em tempo-real, do que o MPEG;

O H.261 define dois formatos para imagens:

- CIF (Common Intermediate Format) - Especifica 288 linhas de informação de luminância (com 360 pixels por linha) e 144 linhas de informação de crominância (com 180 pixels por linha);

- QCIF (Quarter Common Intermediate Format) - Especifica 144 linhas de informação de luminância (com 180 pixels por linha) e 72 linhas de informação de crominância (com 90 pixels por linha). A escolha entre o CIF e QCIF depende da capacidade do canal de transmissão. O QCIF é normalmente utilizado quando p é menor que 3.

\section{H.263}

O padrão H.263 (recomendação ITU-T H.263) foi projetado para comunicação em baixas taxas de dados (menores que $64 \mathrm{Kbits} / \mathrm{s}$ ). Entretanto, essa limitação foi retirada pelo ITU-T esperando que o H.263 seja utilizado para várias taxas de dados. Cote et al. (1998) descreve uma nova versão do H.263, o H.263 + (ou H.263 versão 2), e suas vantagens de sua utilização em baixas taxas de bits.

$\mathrm{O}$ algoritmo de codificação do H.263 é similar ao usado pelo H.261; contudo, as mudanças introduzidas resultaram em melhora de desempenho e em maior eficiência na recuperação de erros. As principais diferenças entre o H.263 e o H.261 sāo listadas abaixo:

- Algumas partes da estrutura hierárquica do fluxo de vídeo são opcionais possibilitando que o CODEC possa ser configurado para baixas taxas de dados ou melhor recuperação de erros;

- Existem quatro opções negociáveis para melhorar o desempenho: Vetores de movimento sem restrições, codificação aritmética baseada na sintaxe, predição avançada e predição bidirecional (similar aos quadros P e B do MPEG);

- H.263 disponibiliza cinco resoluções além das duas já disponibilizadas pelo H.261 (QCIF e CIF). Elas são SQCIF, 4CIF e 16CIF. SQCIF possui metade da resolução do QCIF. 4CIF e $16 \mathrm{CIF}$ possuem ,respectivamente, 4 e 16 menos resolução que o CIF. 


\subsection{Sumário}

O objetivo deste capítulo foi descrever alguns conceitos importantes de transmissão de vídeo e dados via-rádio e sua relação com os UAVs. Neste sentido, foram apresentados vários conceitos e tecnologias relacionadas com a transmissão de dados. Foi mostrada, também, uma pesquisa que descreve algumas características de vários equipamentos para transmissão via-rádio. Vale ressaltar que essa pesquisa foi baseada nas restrições impostas pelo projeto ARARA como: custo, largura de banda, consumo de energia e alcance, entre outras.

Também foram apresentados alguns conceitos básicos de vídeo, seja ele analógico ou digital. Nesse contexto, foram apresentados também, tópicos sobre a manipulação de vídeo (captura, digitalização e compressão) e a sua importância para o projeto proposto.

No próximo capítulo são apresentados os requisitos do STT e uma comparação com os requisitos da primeira versão do STT. 


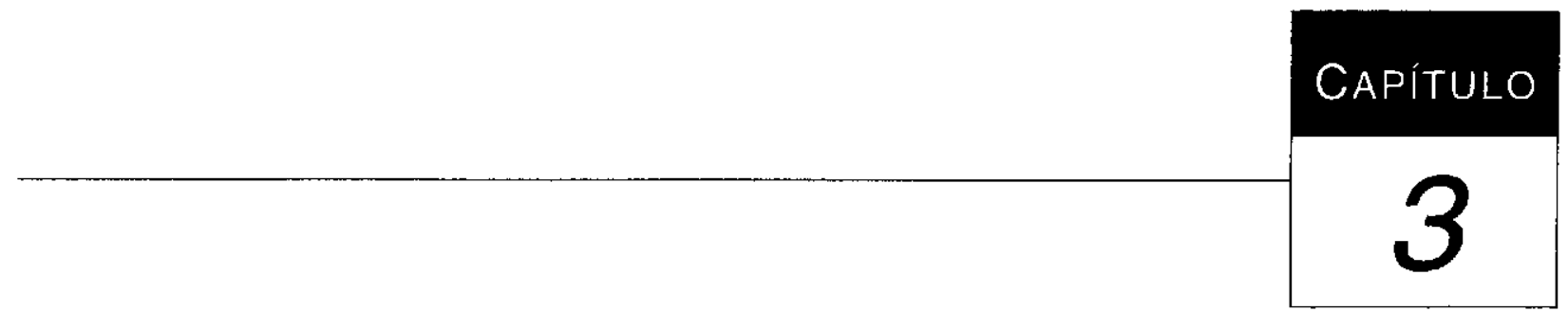

\section{Análise de Requisitos}

O sistema de telemetria e telecomandos do projeto ARARA permite a interação entre um usuário e um UAV, remotamente pilotado ou autônomo. Utilizando esse sistema o usuário pode acompanhar um vôo observando as mudanças de estado da aeronave (e.g. Altitude, Direção, etc...), transmitir comandos para a mesma e assistir ao vídeo transmitido pela aeronave. O objetivo do STT é fazer com que o usuário interaja com a aeronave da mesma maneira que ele interage com um jogo de simulador de vôo.

A primeira versão do STT foi desenvolvida por Ribeiro (2000), em seu trabalho de mestrado. Ela realiza a transmissão dos dados obtidos dos sensores embarcados na aeronave para um estação de monitoramento localizada, no solo. Essa versão também faz a transmissão do vídeo analógico capturado das câmeras instaladas na aeronave para a estaçāo de solo. O vídeo e os dados são enviados para a estação de solo através de um transmissor de vídeo que opera na freqüência de UHF. O canal de áudio do transmissor de vídeo é utilizado para a transmissão dos dados dos sensores.

O STT de Ribeiro (2000) não possui nenhum módulo para realizar a transmissão de comandos à aeronave. A aeronave é controlada da mesma maneira que um aeromodelo convencional, ou seja, utilizando um transmissor de R/C (Rádio Controle). Alguns canais do transmissor R/C eram utilizados para controlar dispositivos não relacionados à aeronaves, como por exemplo a câmera 
fotográfica e a chave eletrônica utilizada para selecionar a câmera de vídeo (câmera frontal ou câmera inferior).

Para facilitar a compreensão do funcionamento da primeira versão do STT, é apresentado na figura 3.1 o diagrama de blocos dos componentes de hardware utilizados:

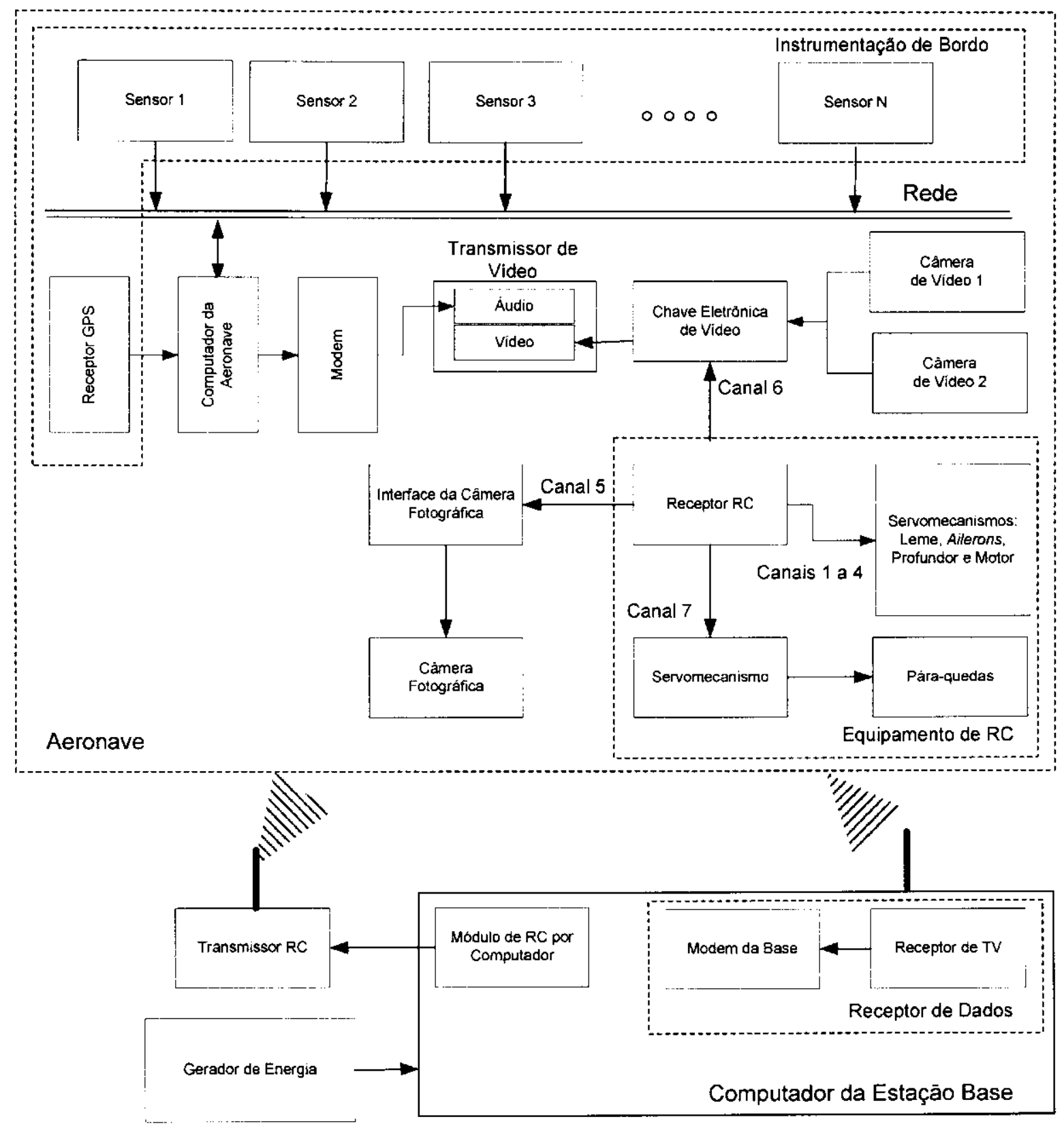

Figura 3.1: Componentes de hardware da primeira versão do STT (Ribeiro, 2000). 
Ribeiro (2000) dividiu a arquitetura de hardware e software do STT em dois módulos: Módulo Aéreo (MA) e Módulo Base (MB). No MA, encontram-se os componentes embarcados na aeronave e, no $\mathrm{MB}$, encontram-se os componentes da estação de solo.

Baseado nos requisitos do STT especificados por Ribeiro (2000), foi realizada uma análise para determinar quais requisitos deveriam ser mantidos, quais deveriam ser alterados, quais deveriam ser incluídos e quais deveriam ser retirados para adequar o STT às novas necessidades do projeto ARARA. Este capítulo apresenta a especificação de requisitos de hardware (seção 3.1) e software (seção 3.2) do STT destacando as diferenças em relação aos requisitos levantados por Ribeiro (2000).

\subsection{Hardware do Sistema}

A figura 3.2 mostra os componentes de hardware em seus respectivos módulos (MA ou $\mathrm{MB}$ ) e as interligaçōes existentes entre eles. O projeto detalhado de hardware é apresentado no capítulo 5. Gerenciando a maioria dos componentes de hardware do MA, a placa-mãe padrão IBM-PC é o principal componente de hardware embarcado na aeronave. Ela está ligada ao modem de RF, à câmera fotográfica, à interface dos servomotores, ao codificador de vídeo, ao GPS e à rede de comunicação. Ao contrário do MA, o MB é composto por componentes convencionais de hardware como um microcomputador padrão IBM-PC, um joystick e um modem de RF.

\subsubsection{Requisitos de Hardware}

Os seguintes requisitos de hardware devem ser atendidos pelo hardware do STT:

- O modem de RF deve ter alcance de pelo menos $10 \mathrm{~km}$, utilizando uma antena omnidirecional no UAV e uma antena direcional na estação solo. O objetivo da utilização de uma antena direcional na estação de solo é possibitar a captação do sinal de rádio transmitido pelo UAV em distâncias maiores; (alterado)

- Os modems de RF devem transmitir dados, em modo full duplex, permitindo no canal de comunicação, o trafego simultâneo de telemetria, telecomandos e vídeo; (incluído)

- A estaçāo de solo deve ser dotada de um sistema para rastreamento do UAV. Nesse sistema, a antena da estação de solo deve receber um sinal que indique a direção para qual ela deve apontar. Esse sinal será provido pelo software da estação de solo (MB) a partir de cálculos que utilizam as coordenadas da aeronave; (incluído) 


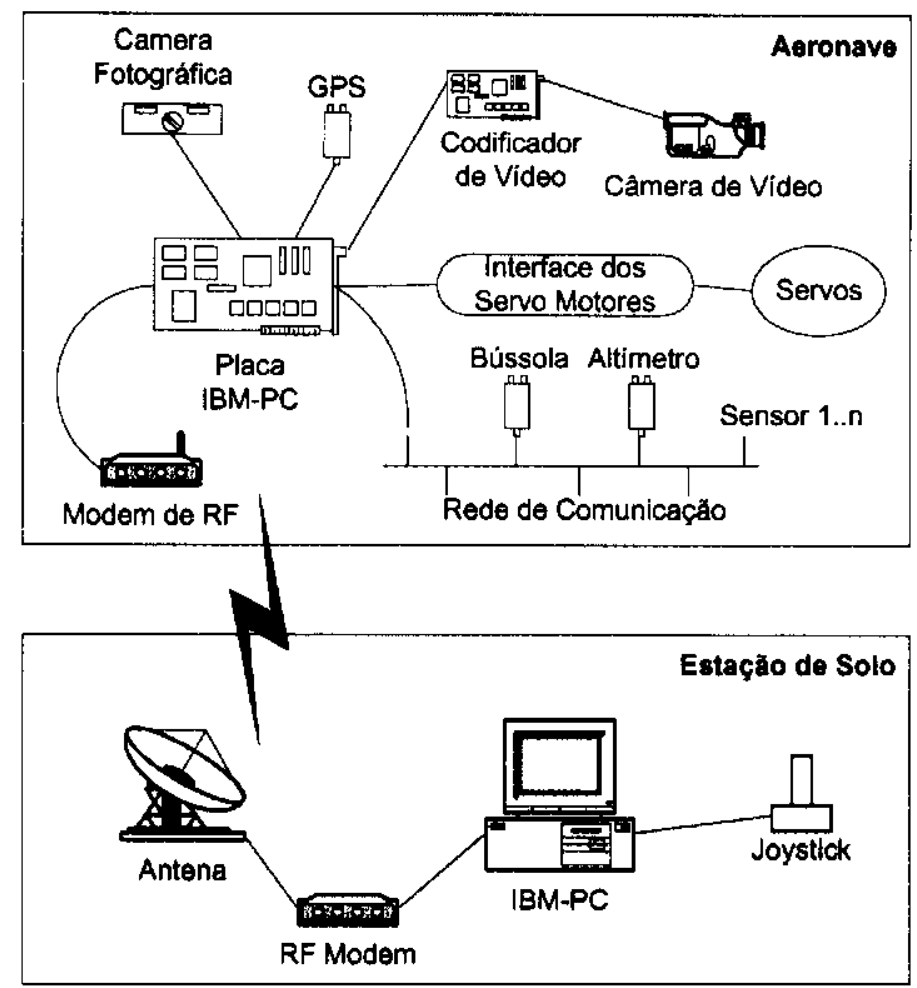

Figura 3.2: Hardware do projeto ARARA.

- Os seguintes sensores devem estar disponíveis na aeronave:

- indicador de combustível; (mantido)

- tacômetro; (mantido)

- temperatura do motor; (mantido)

- temperatura dos gases do escapamento; (mantido)

- temperatura do ambiente; (mantido)

- indicador de velocidade do ar; (mantido)

- altímetro; (mantido)

- sensor de variação de altitude (climb); (incluído)

- bússola magnética; (mantido)

- bússola giroscópica; (incluído)

- sensor de tensão das baterias; (mantido)

- horizonte artificial; (mantido) 
- O computador a bordo da aeronave deve ter baixo consumo de energia e potência computacional suficiente para executar o software que realiza a aquisição e a transmissão dos dados; (alterado)

- $O$ receptor GPS a bordo da aeronave deve ter precisão melhor que 25 metros; (mantido)

- Devem estar disponíveis duas câmeras de vídeo e uma câmera fotográfica. Opcionalmente, podem estar disponíveis um gravador de vídeo e uma câmera fotográfica convencional; (alterado)

\subsection{Software do Sistema}

As próximas duas subseções apresentam, respectivamente, os requisitos funcionais e não funcionais do software do STT.

\subsubsection{Requisitos Funcionais de Software}

- Todos os sensores devem ser continuamente monitorados pelo MA, para a detecção de falhas. As falhas detectadas pelo MA devem ser transmitidas para o MB e apresentadas na forma de um aviso sonoro e um indicador luminoso, mostrando qual sensor não está funcionando corretamente; (alterado)

- Os dados de telemetria e vídeo digital devem ser continuamente transmitidos pelo MA; (alterado)

- Os dados de telecomando devem ser continuamente transmitidos pelo MB; (incluído)

- Deve existir algum método de detecção de erros na transmissāo dos dados. Os pacotes que apresentarem erros devem ser descartados; (alterado)

- Não deve haver nenhum mecanismo de retransmissão para os dados transmitidos; (incluído)

- Como a aeronave possui duas câmeras de vídco, uma localizada no bico e outra localizada na parte inferior, o operador poderá selecionar a câmera desejada; (mantido)

- O operador poderá acionar a câmera fotográfica digital da aeronave, a partir do MB; (incluído) 
- O sistema deve apresentar, ao operador, uma interface gráfica intuitiva semelhante ao painel de um aviāo convencional. No painel devem ser mostrados os instrumentos necessários para a realização de vôo por instrumentos. Os instrumentos devem ter a seguinte apresentação:

- Indicador de Combustível: A escala desse mostrador deve ser graduada em porcentagem de combustível restante, entre 0 e $100 \%$. O mostrador deve ser do tipo analógico para facilitar a leitura; (alterado)

- Rotação do Motor (tacômetro): Informa o número de rotações, por minuto, do motor. A escala do mostrador deve variar de 0 a 20.000 RPM. O mostrador deve ser do tipo analógico; (mantido)

- Indicador de Temperatura do Motor: A escala deste mostrador deve estar graduada em graus Celsius e variar entre $0^{\circ}$ e $450^{\circ} \mathrm{C}$. O mostrador deve ser do tipo analógico; (alterado)

- Indicador de Temperatura dos Gases do Escapamento: A escala deste mostrador deve estar graduada em graus Celsius e deve variar entre $0^{\circ}$ e $500^{\circ} \mathrm{C} . \mathrm{O}$ mostrador deve ser do tipo analógico; (mantido)

- Indicador de Temperatura Externa: A escala deste mostrador deve estar graduada em graus Celsius, podendo variar de $-50^{\circ}$ a $50^{\circ} \mathrm{C}$. O mostrador deve ser do tipo digital, para melhor precisão de leitura; (mantido)

- Indicador de velocidade do ar: A escala desse mostrador deve variar entre 0 e 300 $\mathrm{km} / \mathrm{h}$. O mostrador deve ser do tipo analógico; (alterado)

- Altímetro: Indica a altitude, em pés, em relação ao nível do mar. A escala desse mostrador deve estar entre -5000 e 5000 metros. O mostrador deve ser do tipo analógico; (alterado)

- Indicador de Velocidade Vertical: Indica as mudanças de altitude da aeronave. A escala deste instrumento deve variar entre $-5000 \mathrm{e}+5000$ metros por minuto; (incluído)

- Bússola: Indica ao piloto onde está o norte magnético. O mostrador deve representar uma bússola analógica convencional; (mantido)

- Bússola Giroscópica: Semelhante à bússola, porém, não é afetada pelo balanço da aeronave. O mostrador deve ter o formato de uma bússola giroscópica; (mantido)

- Indicador de Bateria do Sistema: A escala desse mostrador deve apresentar o nível de tensão da bateria principal do sistema, variando entre 0 e $100 \%$. A escala deve ser apresentada na forma de um gráfico de barras colorido, indicando em vermelho, a condição de nível baixo de tensão; (alterado) 
- Indicador de Bateria do Motor: A escala desse mostrador deve apresentar o nível de tensão da bateria utilizada pelo motor da aeronave, variando em uma escala entre 0 e $100 \%$. A escala deve ser apresentada na forma de um gráfico de barras colorido, indicando, em vermelho, a condição de nível baixo de tensão; (alterado)

- Indicadores de Baterias Auxiliares: A escala desse mostrador deve apresentar o nível de tensão das baterias auxiliares, variando em uma escala entre 0 e $100 \%$. Foi definido que a aeronave utilizará, no máximo, três baterias auxiliares. A escala deve ser apresentada na forma de um gráfico de barras colorido, indicando, em vermelho, a condição de nível baixo de tensão; (alterado)

- Horizonte Artificial ou Indicador de Atitude: Indica as posições de arfagem e rolamento (pitch e roll) do avião em relação ao horizonte. Os eixos de arfagem e rolamento devem ser representados, graficamente, por um avião em miniatura, visto em relação à linha do horizonte; (mantido)

- GPS: As informações disponíveis no painel do GPS devem ser:

* Latitude: em graus, minutos e segundos; (mantido)

* Longitude: em graus, minutos e segundos; (mantido)

* Velocidade: $\mathrm{cm} \mathrm{km} / \mathrm{h}$; (alterado)

* Altitude: em metros; (mantido)

* Horário: em hora, minutos e segundos; (incluído)

* Distância da Estação Base: em metros; (incluído)

* Posição da Aeronave: em graus; (incluído)

- A partir do MB, o operador poderá ajustar alguns parâmetros de configuração do MA e transmiti-Ios. O MA deve confirmar se esse dados foram recebidos, transmitindo uma confirmação ao MB (incluído). Os parâmetros de configuração do MA são:

- Tamanho do quadro de vídeo;

- Taxa de quadros (frame rate);

- Profundidade de cores;

- Altitude da estação de solo;

- Latitude da estação de solo;

- Longitude da estação de solo;

- Pressão Local; 
- O software deve fornecer, ao operador, uma interface para a visualização de fotos armazenadas no disco do computador da Estação Base. A interface deve permitir a visualização de fotos nos formatos JPEG ou BMP; (mantido)

- A distância entre a aeronave e a estação de base deve ser verificada constantemente pelo MB para evitar que a aeronave saia do raio de alcance do modem de RF. Um aviso sonoro e um indicador luminoso devem ser acionados no $\mathrm{MB}$ quando a aeronave estiver em uma distância crítica, ou seja, quando estiver prestes a sair do alcance do transmissor. Deve existir a possibilidade de configuração dessa distância; (alterado)

- O nível de combustível da aeronave deve ser constantemente monitorado. Um indicador luminoso deve ser acionado no MB informando, ao operador, que o sistema está abaixo do nível mínimo. Deve existir a possibilidade de configuração do nível mínimo de combustível; (alterado)

- A temperatura do motor da aeronave deve ser constantemente monitorada. Um indicador sonoro $\mathrm{c} u m$ indicador luminoso devem ser acionados no MB quando a temperatura do motor da aeronave exceder ao seu limite máximo. Esse limite deve ser configurado pelo operador; (incluído)

- Quando alguma das baterias auxiliares estiverem em uso, um indicador luminoso deve ser acionado no MB; (incluído)

- Sempre que o operador inicia uma sessão de vôo, o sistema deve iniciar o processo de gravação dos valores da telemetria dos instrumentos na estação de solo (MB). A cada vôo, deve ser gerado um arquivo de $\log$ desses valores. O log deve ser continuamente gravado até o operador finalizar a sessão de vôo. Com a sessão de vôo inativa, o operador poderá visualizar qualquer arquivo de $\log$ anteriormente gravado; (alterado)

- A interface usada para mostrar o arquivo de log deve ser uma tabela onde é permitida a troca das colunas de lugar. A interface do arquivo de log somente pode ser chamada quando o sistema estiver inoperante; (mantido)

- Um relatório estatístico deve estar disponível para o operador após a abertura do arquivo de log. A análise estatística deve conter o valor mínimo, o valor máximo e a média aritmética de cada instrumento durante uma sessão de vôo da aeronave; (alterado)

- A interface do painel deve ocupar 1/3 da tela. Durante o vôo, o operador deve poder escolher um outro painel onde são mostrados somente os instrumentos indispensáveis para o 
acompanhamento do vôo da aeronave, ocupando apenas $1 / 5$ da tela disponível. (alterado) Os instrumentos disponíveis nesta configuração devem ser:

- Nível de Combustível; (mantido)

- GPS; (mantido)

- Tensão das Baterias do Sistema. (mantido)

\subsubsection{Requisitos Não Funcionais de Software}

- Durante uma sessão de vôo, deve ser reservado, no mínimo, 1 Mbyte de espaço em disco por minuto de sessão, para o armazenamento do arquivo de log; (mantido)

- Para utilização do ARARA, na fase II, é necessário que o operador tenha conhecimento de pilotagem de aeromodelos; (mantido)

- O sistema não deve utilizar nenhum recurso de banco de dados para armazenar os registros de log. O arquivo de $\log$ deverá ser gerado a partir das funções básicas da linguagem de programação utilizada; (mantido)

- O sistema operacional que equipa o computador de bordo da aeronave deve ser configurado para executar somente serviços estritamente necessários, devido à limitação de memória e hardware. (mantido)

\subsection{Sumário}

Este capítulo apresentou uma breve descrição da primeira versão do STT e os motivos que levaram a criação de uma nova versão do STT.

O objetivo principal desse capítulo, foi descrever os requisitos de hardware e software do STT. Nesse sentido, foi realizada uma análise nos requisitos da primeira versão do STT, para determinar se os mesmos seriam retirados, alterados ou mantidos na nova versão. Além dos requisitos da primeira versão, houve a necessidade de incluir novos requisitos para a versão atual.

No próximo capítulo será apresentada a modelagem do STT utilizando a análise de requisitos, apresentada neste capítulo. 


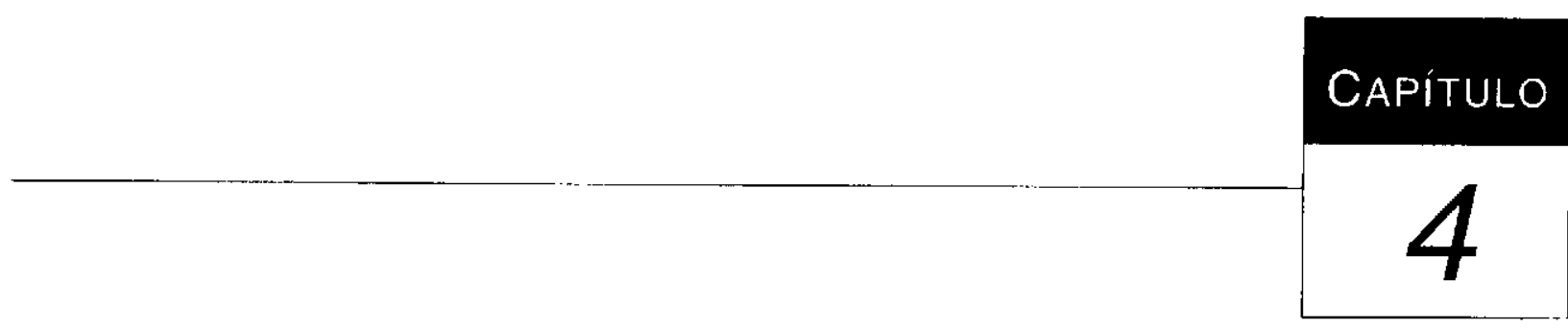

\section{Modelagem do Sistema}

Este capítulo apresenta a modelagem do STT utilizando a notação de análise estruturada. Nesse sentido, a seção 4.1, apresenta a notação estendida de Ward c Mellor, utilizada nos DFDs (Diagramas de Fluxo de Dados), a seção 4.2, apresenta o diagrama de contexto do STT e a seçâo 4.3, apresenta o diagrama de contexto do STT dividido em dois módulos: MA e MB. As seções 4.4, 4.5 e suas subseçōes, apresentam os DFDs nível 1 e 2 correspondentes ao MA e ao MB respectivamente.

A análise estruturada foi selecionada para manter o padrão de modelagem utilizado no projeto $A R A R A$, facilitando uma posterior integração. Ao longo deste capítulo, os requisitos apresentados no capítulo anterior são traduzidos em DFDs. Os DFDs, além de auxiliar na compreensão do sistema, fornecem uma notação padronizada para a modelagem de sistemas.

Para detalhar a modelagem do sistema e fornecer mais subsídios para a fase de implementação, todos os elementos do DFDs são descritos em um dicionário de dados. O apêndice B apresenta o dicionário de dados do STT.

O levantamento das atualizações necessárias da nova versão do STT foi realizado com base na modelagem da primeira versão do STT, desenvolvida por Ribeiro (2000), e nos requisitos do capítulo anterior. Esses requisitos, juntamente com a modelagem de Ribeiro (2000), também forneceram subsídios para realizar uma nova modelagem do STT. É importante destacar que a 
modelagem do STT foi totalmente refeita, visto que as modificações necessárias para atender aos novos requisitos, alteram o modo de funcionamento do sistema em vários aspectos.

Para facilitar a compreensão das atualizações necessárias da nova versão do STT, são apresentados a seguir os DFDs nível 1, da primeira versão do STT.

A figura 4.1 apresenta o DFD nível 1 do MA, da primeira versão do STT, desenvolvida por Ribeiro (2000). Analisando esse DFD, juntamente com a análise de requisitos apresentada no capítulo anterior, foi possível determinar as principais modificações necessárias do MA:

- Recebimento e execução de telecomandos;

- Redefinição dos dados da telemetria;

- Compressão e transmissão de vídeo digital;

- Configuração remota dos parâmetros de vídeo a partir do MB;

- Configuração remota dos parâmetros do sistema a partir do MB.

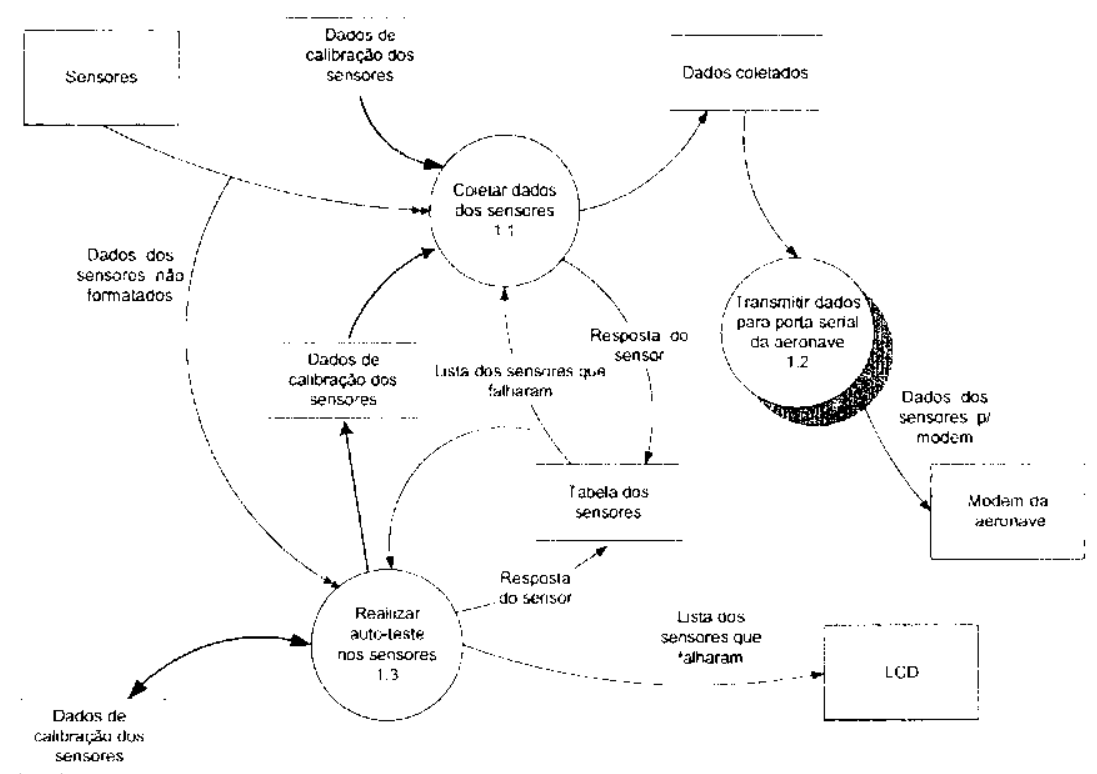

Figura 4.1: Diagrama de fluxo de dados do MA (nível 1) (Ribeiro, 2000). 


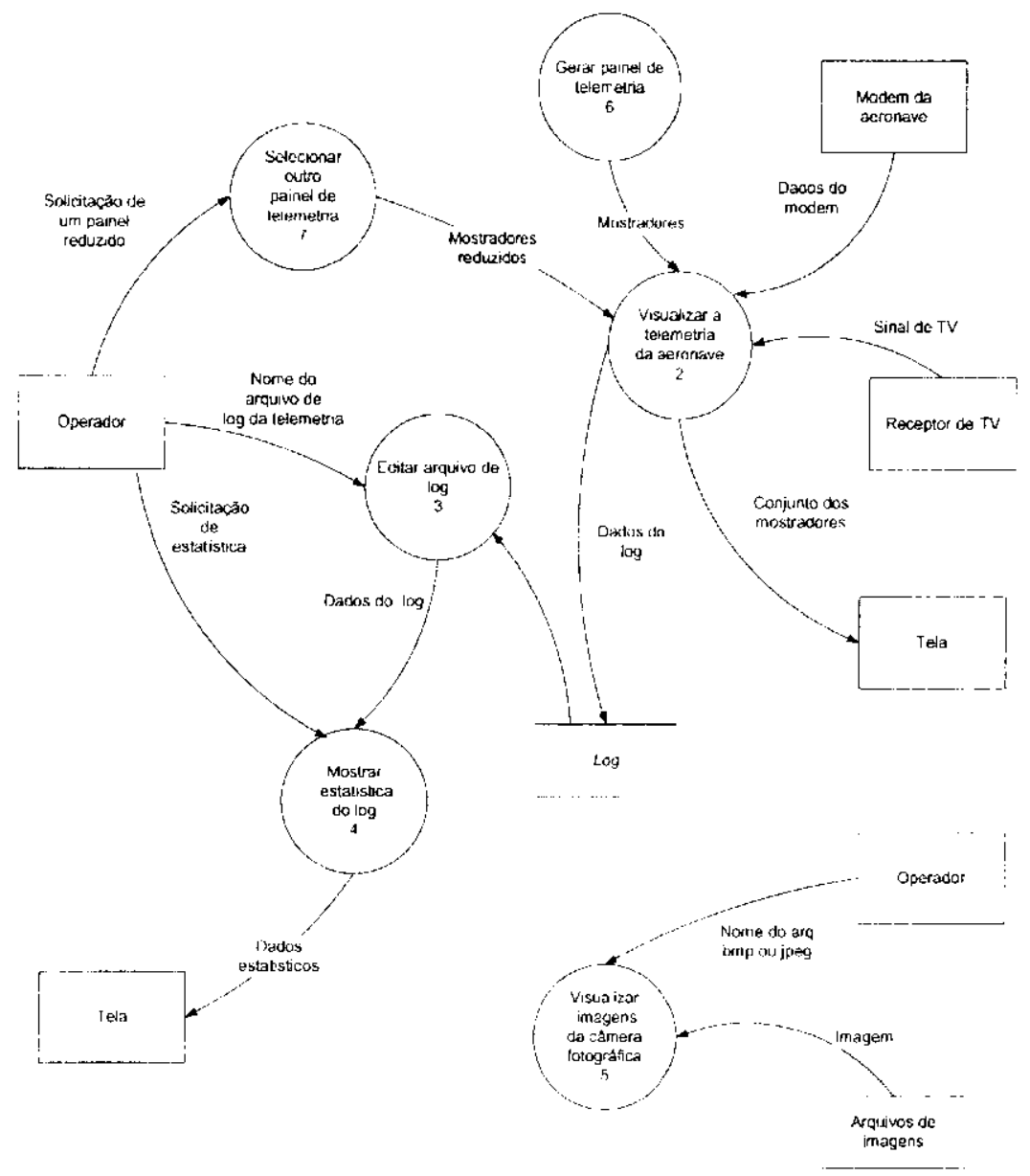

Figura 4.2: Diagrama de fluxo de dados do MB (nível 1) (Ribeiro, 2000).

A figura 4.2 apresenta o DFD nível 1 do $\mathrm{MB}$, da primeira versão do STT, desenvolvida por Ribeiro (2000). Analisando esse DFD, juntamente com a análise de requisitos apresentada no capítulo anterior, foi possível determinar as principais modificações necessárias do MB:

- Transmissão de telecomandos;

- Redefinição dos dados de telemetria;

- Inclusão de novos alertas;

- Cálculo da posição e distância da aeronave;

- Configuração dos parâmetros do MB;

- Redefinição dos dados de log;

- Redefinição dos dados estatísticos; 
- Transmissão do posicionamento da aeronave para a antena;

- Configuração de parâmetros do sistema;

- Configuração remota dos parâmetros do MA;

- Recebimento, descompressão e apresentação de vídeo digital.

\subsection{Notação Estendida de Ward e Mellor}

Apesar da análise estruturada atender às necessidades de muitas aplicações, ela falha em aplicações dependentes do tempo e que processam informações orientadas a controle, que é o caso do STT. Para resolver esse problema, Ward \& Mellor (1985), desenvolveram uma extensão para a análise estruturada que supre essas falhas.

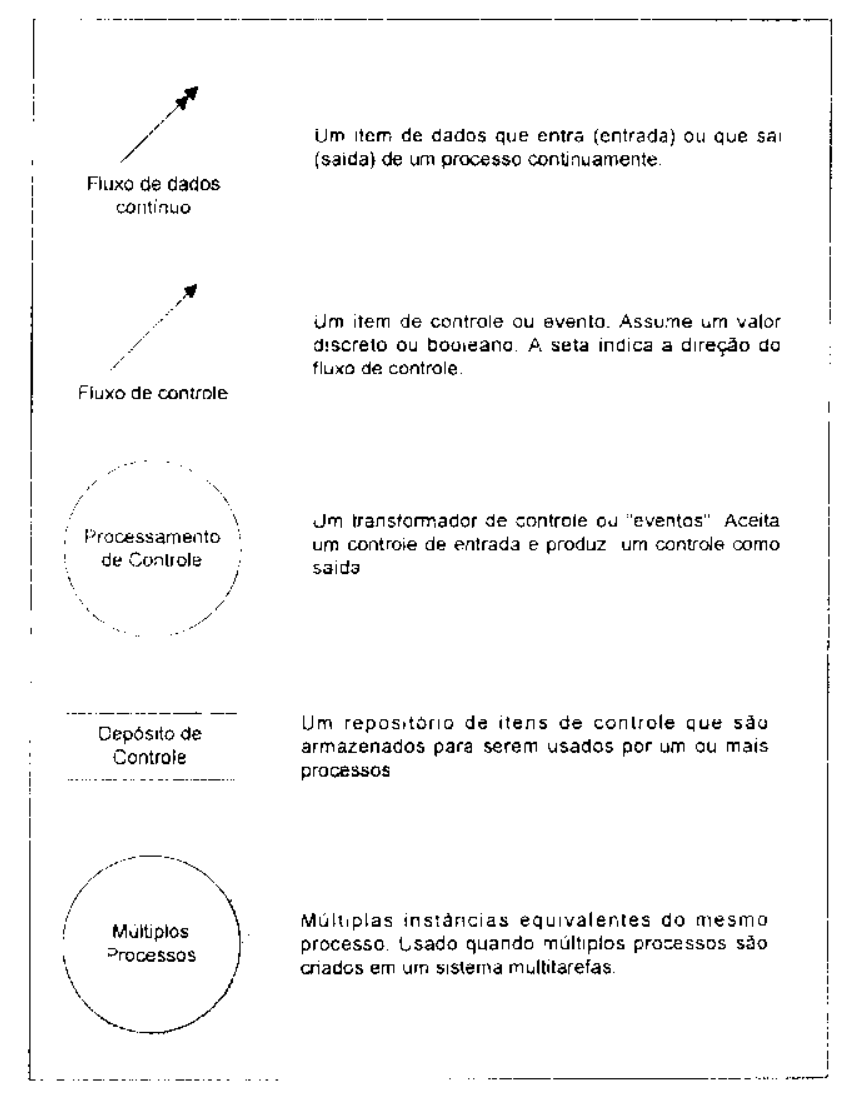

Figura 4.3: Notação estendida de Ward e Mellor.

A análise estruturada falha por nāo trazer uma notação específica para representar questões relacionadas a controle ou eventos que ocorrem, simultaneamente, como é o caso de sistemas de tempo real (Pressman, 1997). 
Para acomodar a análise de sistema de tempo real, uma série de extensões foi adicionada ao modelo clássico da análise estruturada. Estas extensões foram desenvolvidas por Ward \& Mellor (1985) e são ilustradas na figura 4.3. Elas permitem que o analista possa representar o fluxo de controle e o processamento do controle tão bem quanto o fluxo de dados e o processamento de dados.

As próximas seçōes apresentam os diagramas de fluxo de dados da nova versão do do STT, utilizando as extensões de Ward \& Mellor (1985).

\subsection{Diagrama de Contexto}

Na figura 4.4 é apresentado o diagrama de contexto do STT do projeto ARARA. Esse diagrama apresenta todas as entradas, saídas e entidades do sistema, possibilitando uma visão geral do mesmo. É importante ressaltar que esse diagrama engloba tanto as funções do software da aeronave como as funções do software da estação de solo.

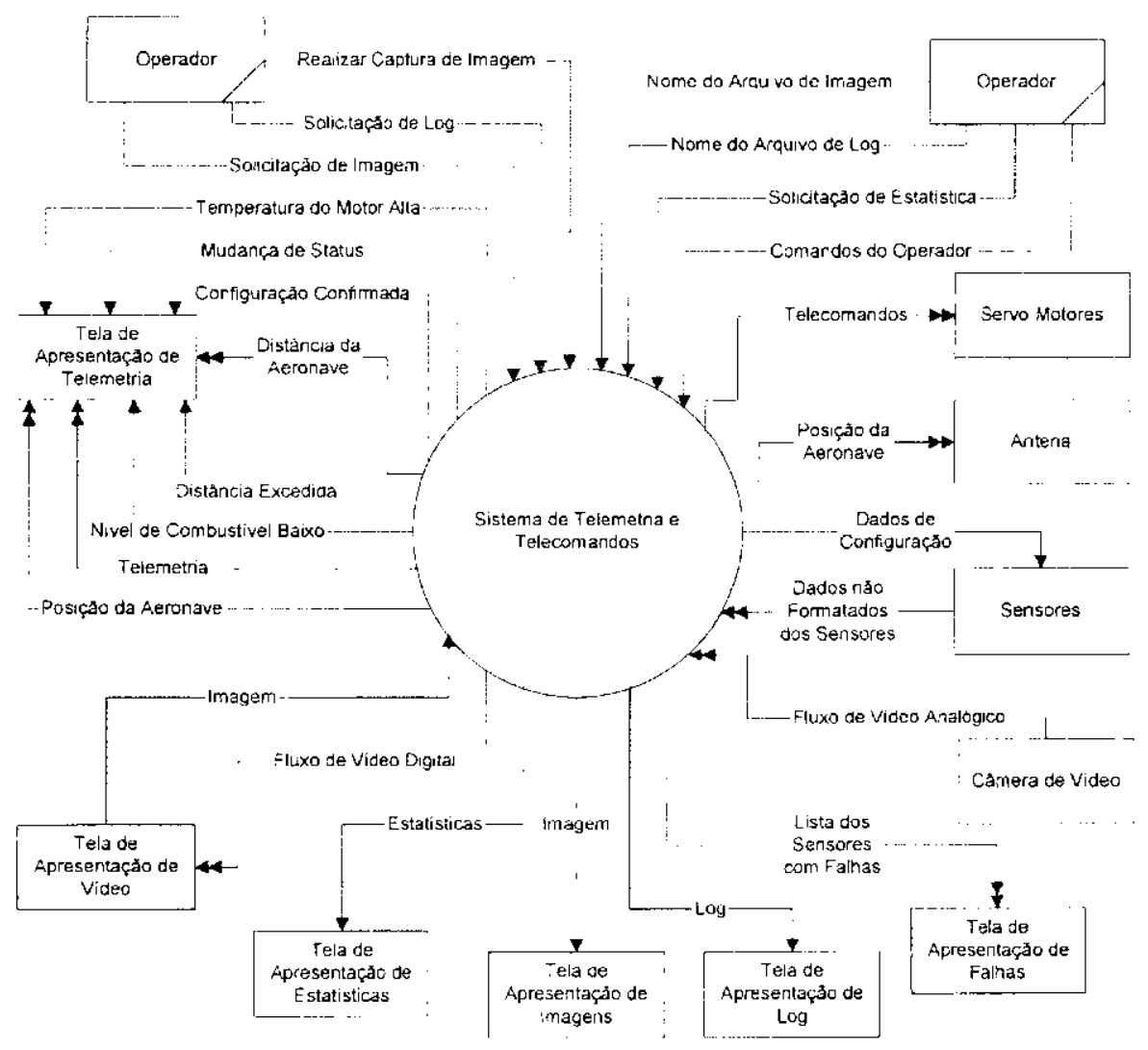

Figura 4.4: Diagrama de contexto. 


\subsection{Diagrama de Contexto MA e MB}

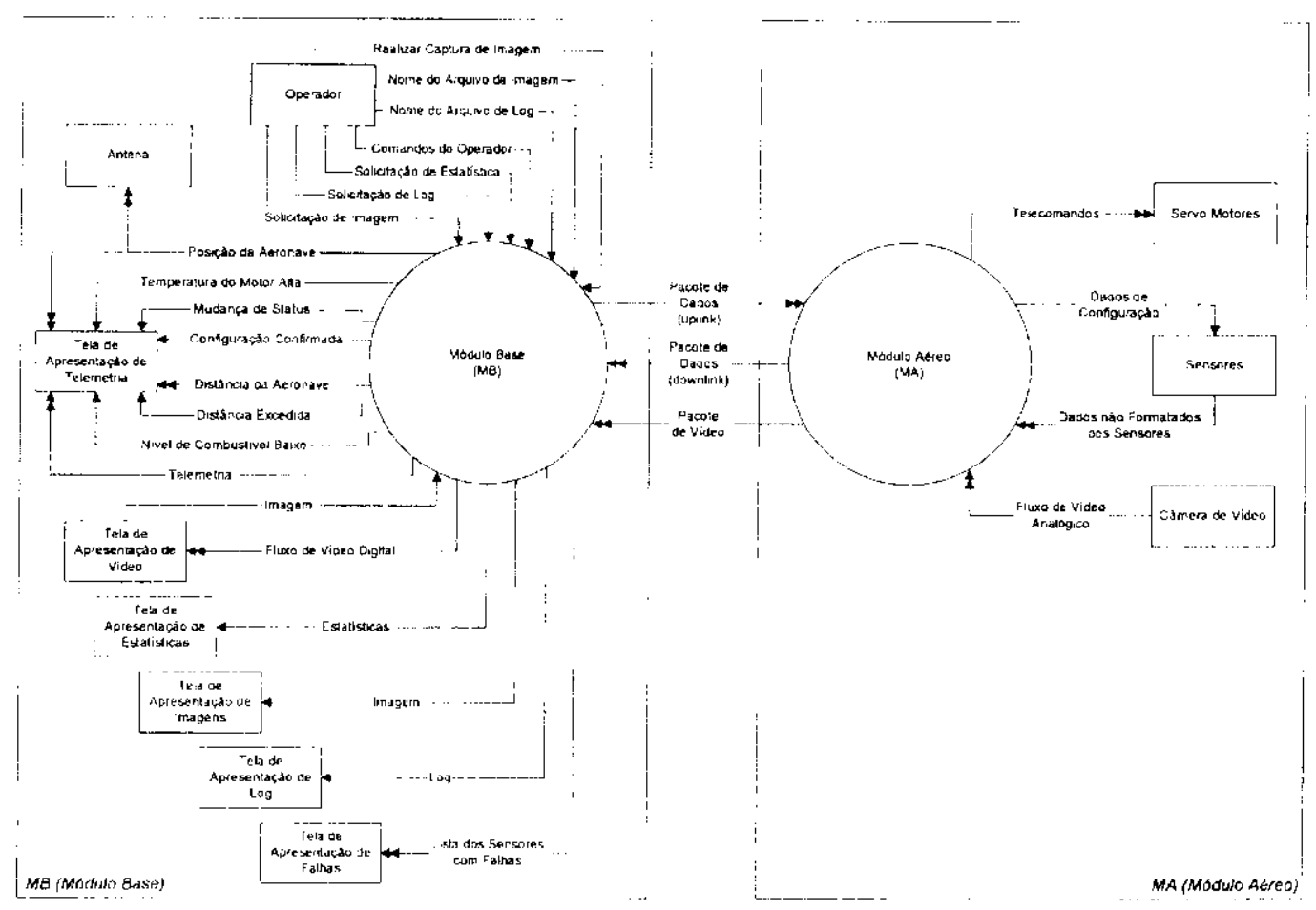

Figura 4.5: Diagrama de contexto MA e MB.

A figura 4.5 apresenta o diagrama de contexto do STT de uma mancira diferente da seção anterior. Nesse caso, o diagrama apresentado é dividido em dois módulos, MA e MB, ressaltando a interação existente entre esses módulos.

\subsection{Diagramas de Fluxo de Dados do MA}

Na figura 4.6 é apresentado o diagrama de fluxo de dados (nível 1) do MA. Nesse DFD, o MB é apresentado como um entidade externa. A seguir são apresentadas as principais funções do MA, as quais podem ser observadas na figura 4.6:

- Comprimir o fluxo de vídeo recebido da câmera de vídeo e enviar pacotes de vídeo comprimido para o $\mathrm{MB}$;

- Coletar os dados dos sensores, transformá-los em dados de telemetria e enviá-los para o MB;

- Executar os comandos recebidos do MB. Esses comandos podem manipular um dispositivo físico da aeronave, como por exemplo, acionar uma câmera fotográfica ou mover alguma 
superfície de controle (e.g. flaps), ou somente modificar algum parâmetro de configuração do MB, como a pressão atmosférica que é usada para calibrar o sensor de altitude da aeronave.

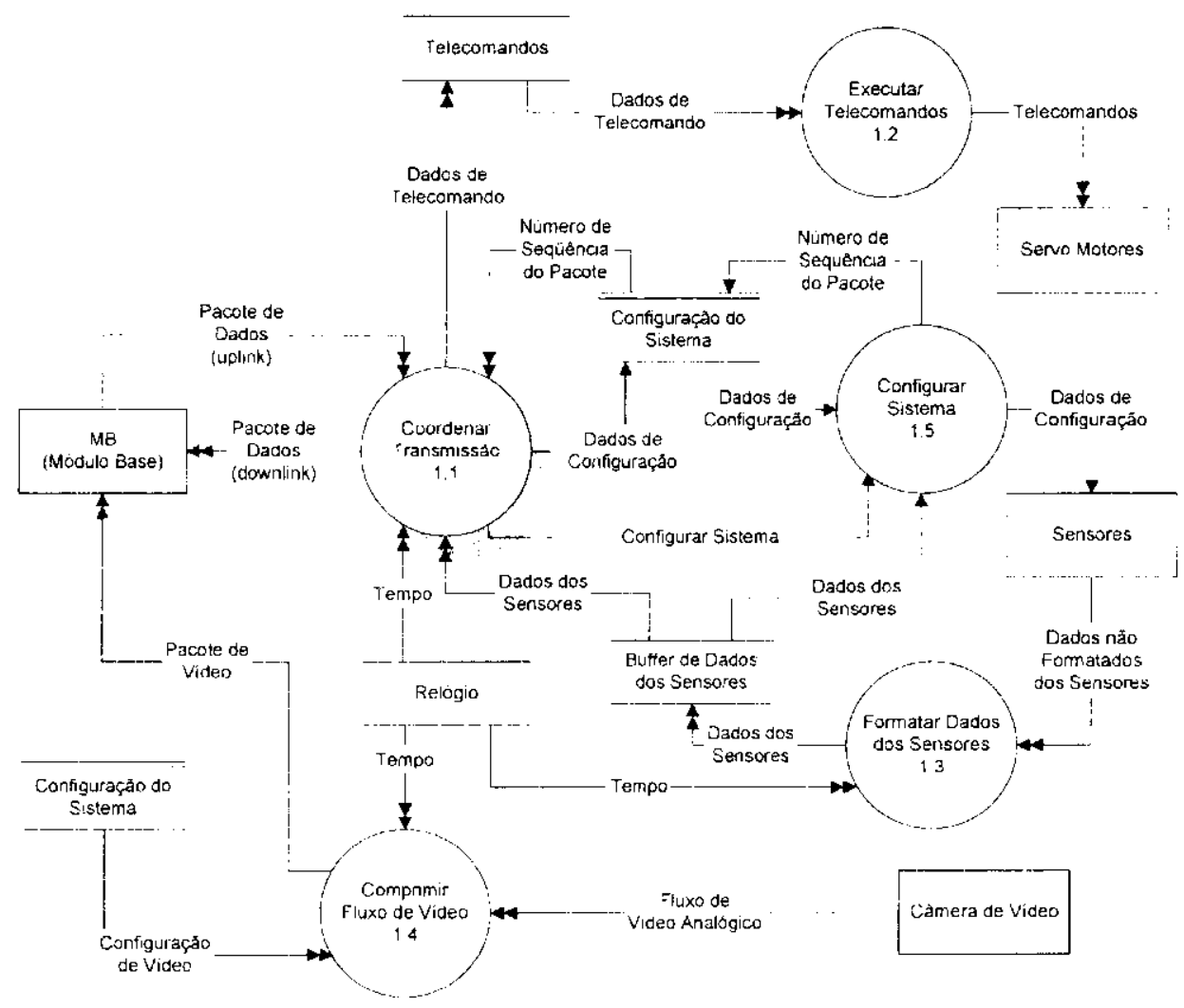

Figura 4.6: Diagrama de fluxo de dados do MA (nível 1).

As próximas subseções apresentam os DFDs nível 2 do MA. Esses DFDs oferecem mais detalhes e possibilitam uma melhor compreensão do sistema.

\subsubsection{DFD 1.1 - Coordenar Transmissão}

O DFD apresentado na figura 4.7 mostra como é realizado o processo de transmissão e recepção de dados no MA. Quando um pacote de dados (uplink) chega ao MA, ele precisa ser identificado. Esse pacote pode carregar dois tipos de dados: dados de telecomando e dados de configuração.

Os dados de telecomando, depois de convertidos em pulsos elétricos, agem sobre os dispositivos de hardware da aeronave, como por exemplo, os servomotores. Os dados de configuração são utilizados para modificar os parâmetros de configuração do MA.

Depois de identificados, a integridade dos pacotes de dados (uplink) é verificada utilizando uma rotina de cálculo de CRC. Se o cálculo do CRC indicar que o pacote está corrompido, ele será descartado. 


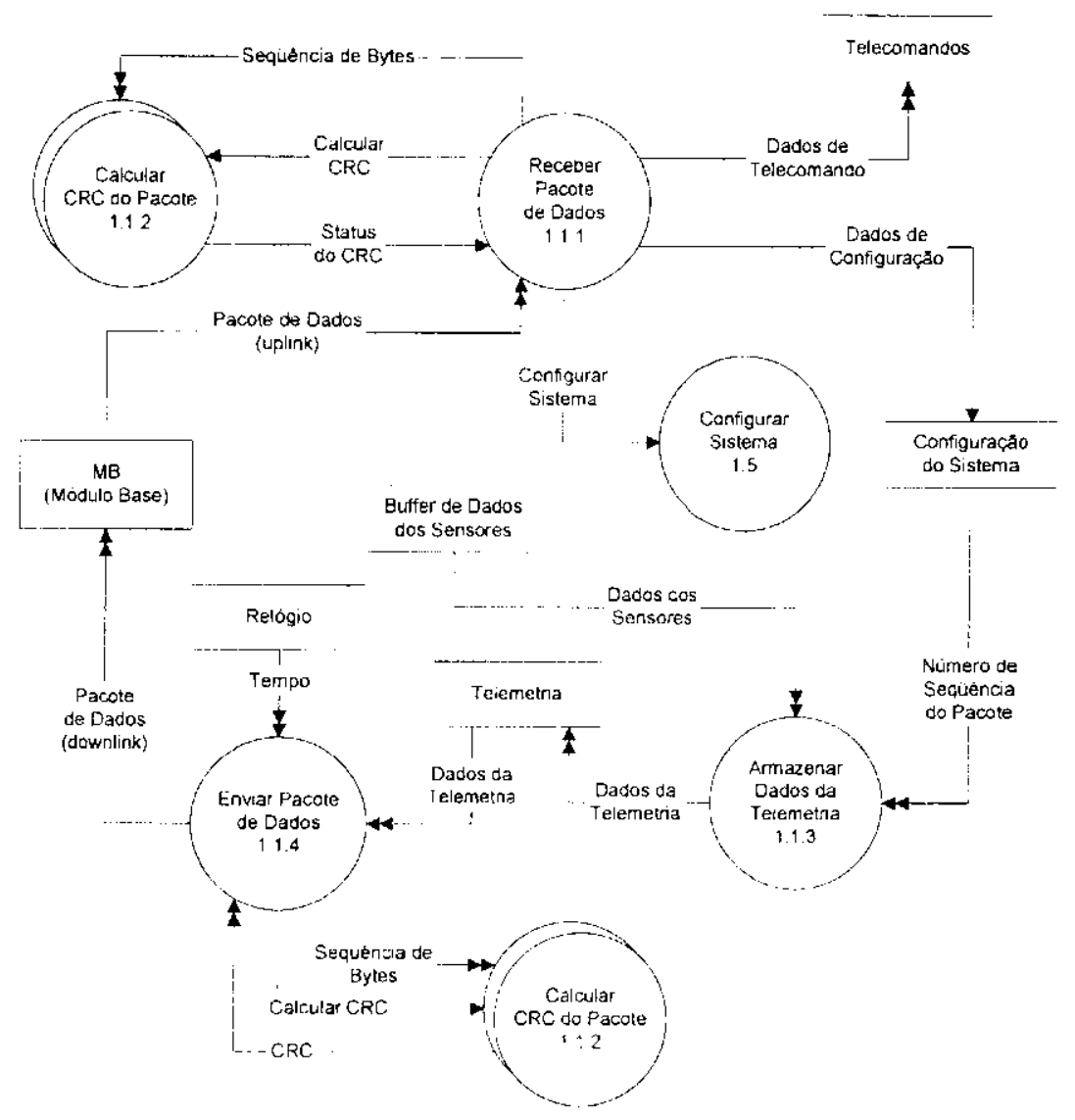

Figura 4.7: DFD 1.1 - Coordenar transmissão.

Os dados da telemetria são enviados para o $\mathrm{MB}$ em intervalos de tempo fornecidos pelo relógio do computador da aeronave. A cada urn desses intervalos é realizado o cálculo do CRC dos dados de telemetria. O resultado deste cálculo (número correpondente ao $\mathrm{CRC}$ do pacote de telemetria) deve ser enviado junto aos dados de telemetria.

Vale ressaltar que as tarefas de enviar e receber dados são executadas concorrentemente. Isso pode ser observado no DFD nível 1, do MA, apresentado na figura 4.6, onde o processo coordenar transmissão (1.1) é representado como múltiplos processos, segundo a notação estendida de Ward \& Mellor (1985), apresentada anteriormente. 


\subsubsection{DFD 1.2 - Executar Telecomandos}

Para movimentar os servomotores da aeronave é necessário aplicar pulsos clétricos nos mesmos. A largura desses pulsos elétricos determina o curso do movimento; quanto maior a largura do pulso, maior o curso do movimento que o servomotor irá realizar (pulsos entre 1 e $2 \mathrm{~ms}$ com largura de banda de $30 \mathrm{~Hz}$ ). O DFD, apresentado na figura 4.8, mostra como os dados de telecomando sāo transformados em pulsos elétricos.

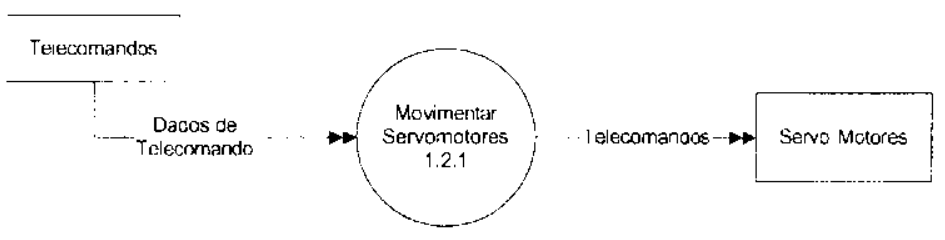

Figura 4.8: DFD 1.2 - Executar telecomandos.

\subsubsection{DFD 1.3 - Formatar Dados dos Sensores}

O DFD da figura 4.9 mostra como os dados dos sensores são coletados e transformados. É interessante observar que o MA coleta os dados dos sensores em determinados intervalos de tempo fornecidos pelo relógio da acronave e os formata segundo a especificação protocolo de transmissão. Depois de formatados, os dados dos sensores são armazenados em variáveis de memória para que sejam posteriormente transmitidos.

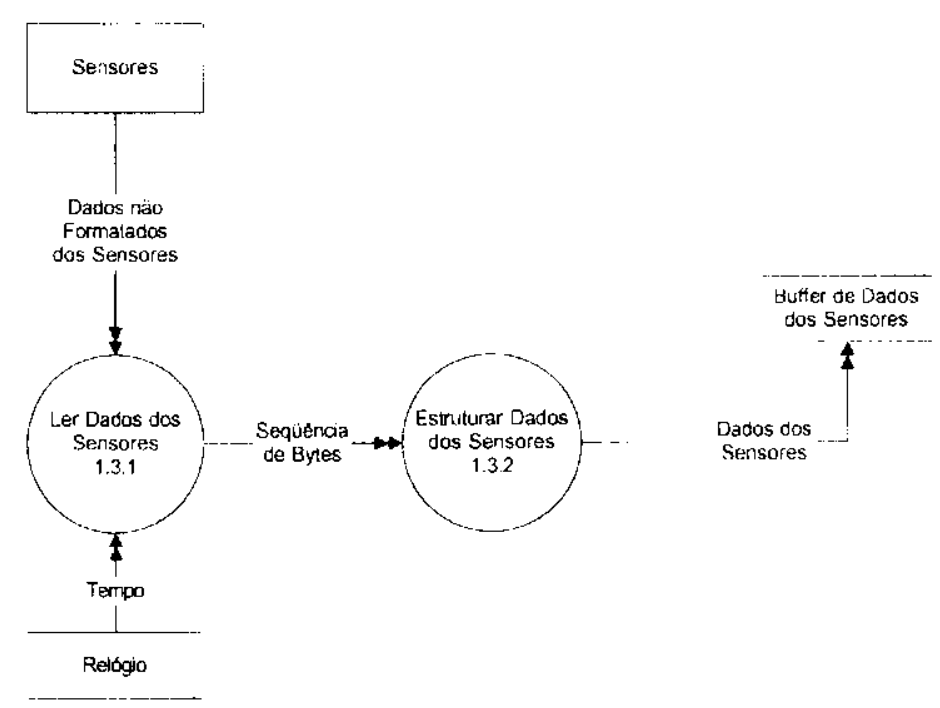

Figura 4.9: DFD 1.3 - Formatar dados dos sensores. 


\subsubsection{DFD 1.4 - Comprimir Fluxo de Vídeo}

O DFD da figura 4.10 ilustra o processo de compressão de vídeo realizado pelo MA. Apesar da implementação do algoritmo de compressão de vídeo estar fora do escopo deste trabalho, foi decidido modelar o processo de compressão de vídeo para facilitar a compreensão do mesmo.

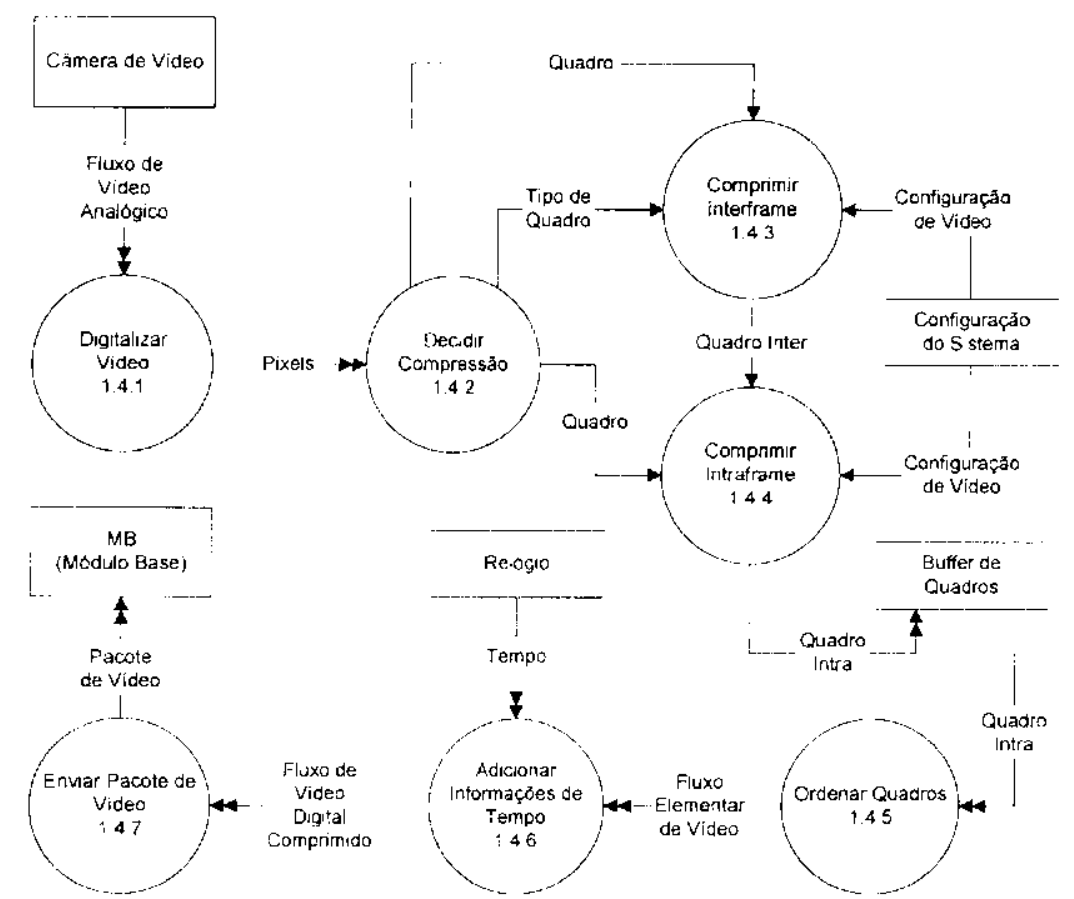

Figura 4.10: DFD 1.4 - Comprimir fluxo de vídeo.

O processo de compressão de vídeo se inicia com a digitalização do fluxo de vídeo analógico que é convertido em uma sequiência de pixels. Os pixels são utlizados para formar os quadros de vídeo. Os quadros de vídeo poderão ser comprimidos de duas formas já apresentadas no capítulo 2 : interframe e intraframe.

O tipo de compressão deve ser decidido pelo compressor de vídeo, levando-se em conta a quantidade de diferença entre quadros sucessivos. Se existir muita diferença entre os dois quadros, a compressāo deve ser intraframe; se as diferenças forem pequenas, então a compressão interframe deve ser aplicada.

Depois que os quadros foram comprimidos, eles devem ser armazenados em um buffer. Todos os quadros devem ser comprimidos com a técnica intraframe, inclusive os quadros interframe.

O passo final da compressão é criar um fluxo de vídco digital comprimido. Para tanto, os quadros de vídeo são ordenados conforme a sequiência de descompressão e colocados em um fluxo elementar (fluxo contínuo de vídeo sem informações de tempo). O fluxo elementar é acrescido de informações de tempo e, finalmente, empacotado para que seja transmitido para o MB. 


\subsubsection{DFD 1.5 - Configurar Sistema}

A figura 4.11 apresenta o DFD responsável pela configuração do MA. O processo de configuração é iniciado quando o evento configurar sistema ativa o processo configurar sensores (1.5.2). Esse processo utiliza os dados de configuração para configurar os sensores da aeronave.

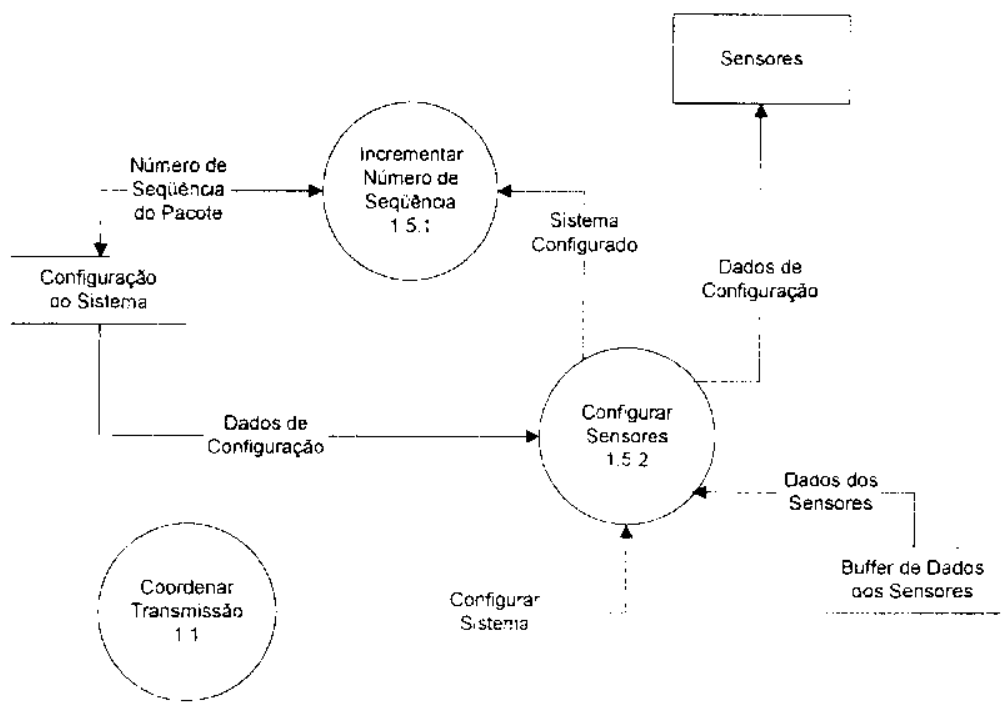

Figura 4.11: DFD 1.5 - Configurar sistema.

Depois que os dados de configuração foram enviados aos sensores, são realizadas leituras dos dados dos sensores em intervalos de tempo determinados. Essas leituras têm a função de confirmar se os sensores foram configurados corretamente. Se houve sucesso na configuração, o número de sequência do pacote é incrementado.

É importante observar que o número de sequiencia do pacote faz parte dos dados de telemetria. Quando esse número chegar ao MB incrementado de 1, significa que o MA foi corretamente configurado.

\subsection{Diagramas de Fluxo de Dados do MB}

A figura 4.12 mostra o diagrama de fluxo de dados (nível 1) do MB. É importante destacar que nesse DFD, o MA é apresentado como um entidade externa. A seguir são apresentadas as principais funções do MB:

- Coletar e enviar os comandos do operador. Esses comandos são obtidos a partir de dispositivos de entrada conectados à estação de solo como joystick, mouse, teclado entre outros: 
- Apresentar no monitor de vídeo e armazenar no arquivo de log os dados de telemetria recebidos do MA;

- Descomprimir e apresentar o fluxo de vídeo, recebido do MA.

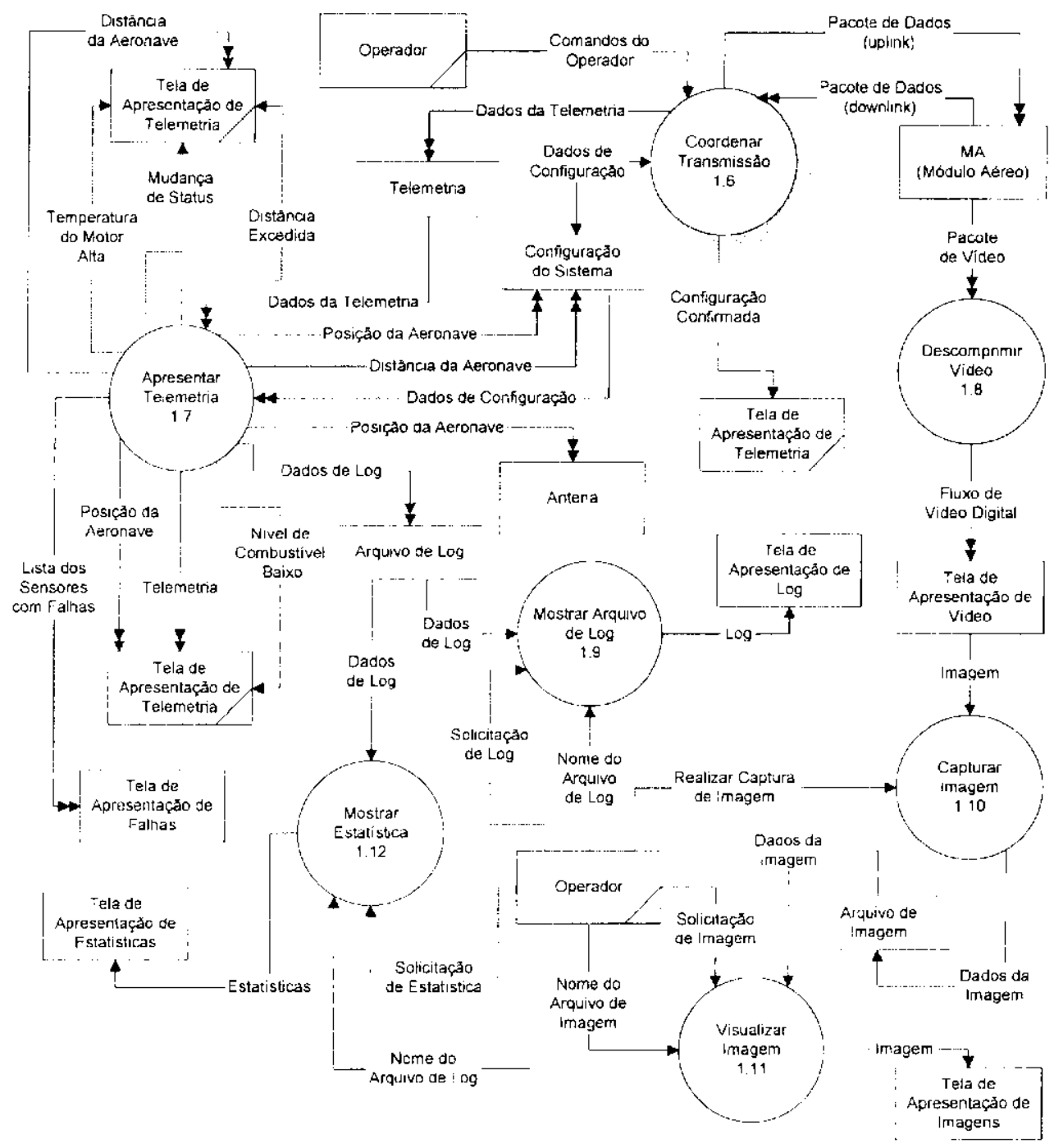

Figura 4.12: Diagrama de fluxo de dados do MB (nível 1).

\subsubsection{DFD 1.6 - Coordenar Transmissão}

O DFD apresentado na figura 4.13 mostra como é realizada a transmissão/recepção de dados do MB. Nesse DFD é possível identificar três tarefas principais, realizadas de maneira concorrente: a obtenção dos comandos do operador, o envio de dados e a recepção de dados. 


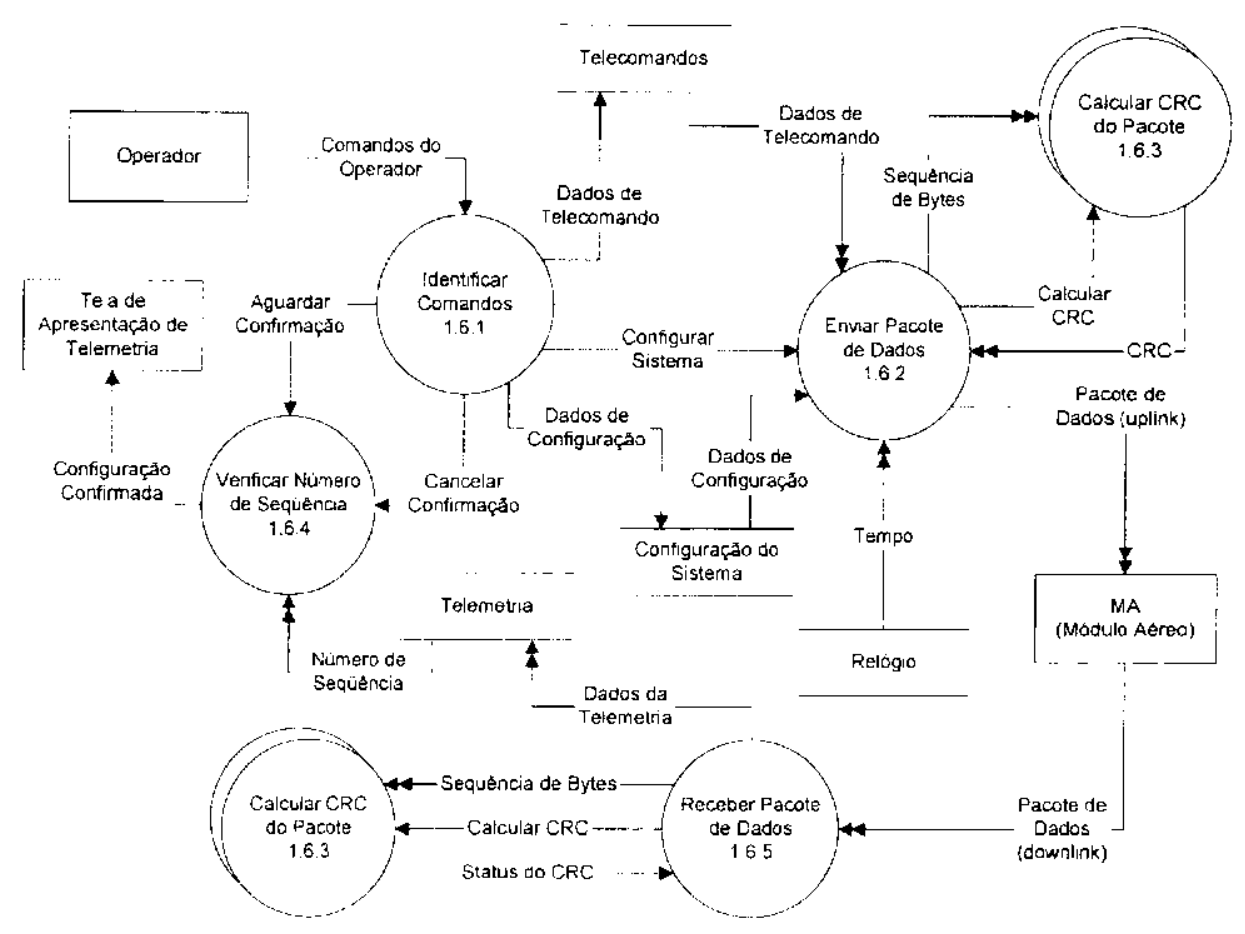

Figura 4.13: DFD 1.6 - Coordenar transmissão.

Os comandos do operador são obtidos a partir de dispositivos de entrada, conectados ao computador da estação de solo, como joystick, mouse e teclado. Quando o operador modifica o estado de um desses dispositivos de entrada, como por exemplo a posição da alavanca do joystick, o MB recebe um evento notificando essa mudança e altera os dados de telecomando de acordo com o movimento do joystick.

O pacote de dados (uplink) enviados ao MA podem conter dois tipos de dados: dados de telecomando e dados de configuração. Os dados de telecomando são transmitidos em curtos intervalos de tempo enquanto que os dados de configuração são transmitidos somente após uma solicitação do operador. As configurações do sistema podem ser tanto configurações da estação de solo como configurações da aeronave.

Quando é solicitado o envio de um pacote de dados de configuração, é necessário aguardar uma confirmação para verificar se os dados de configuração foram recebidos com sucesso pelo MA. Essa confirmação se dá quando o número de seqüência dos dados de telemetria é incrementado.

Tanto os dados de configuração como os dados de telecomando, antes de serem enviados ao MA, devem ser empacotados segundo o protocolo de transmissão especificado. Esse pacote de dados deve conter um número de CRC que será utilizado pelo MA para verificar a integridade dos dados. 
O pacote de dados (downlink) transporta os dados de telemetria. Antes de retirar os dados de telemetria desse pacote, é importante que seja aplicada a verificação de CRC no mesmo para determinar, se durante a transmissāo do pacote, a integridade dos dados foi preservada. Se os dados estiverem corrompidos, o pacote de dados é descartado.

\subsubsection{DFD 1.7 - Apresentar Telemetria}

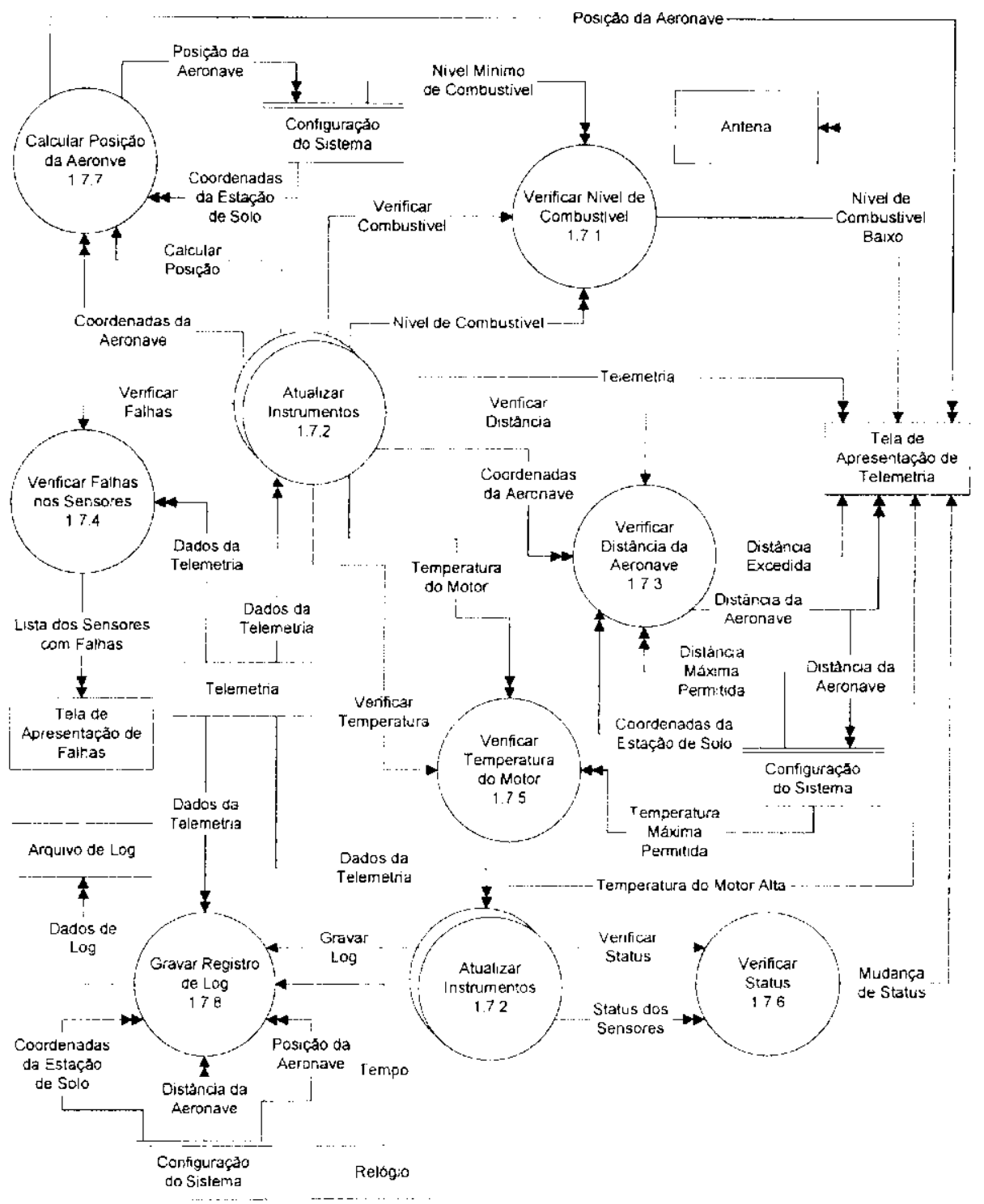

Figura 4.14: DFD 1.7 - Apresentar telemetria. 
DFD apresentado na figura 4.14 mostra como é realizada a apresentação da telemetria da aeronave. O principal elemento desse DFD é o processo atualizar instrumentos (1.7.2), que além de apresentar a telemetria, ativa os processos que realizam as seguintes funçōes:

- Calcular, apresentar e enviar para a antena, a posição da aeronave (em graus) em relação à estação de solo. Essa posição é calculada a partir das coordenadas da estação de solo e das coordenadas da aeronave;

- Verificar o nível de combustível no tanque da aeronave. Quando esse nível está abaixo do nível mínimo, um sinal luminoso é acionado;

- Verificar falhas nos sensores da aeronave. No caso de falha, para cada sensor um sinal luminoso e sonoro deve ser ativado;

- Verificar a distância da aeronave em relaçāo à estação de solo. Se a distância máxima for excedida, um sinal luminoso e sonoro deve ser acionado;

- Verificar se a temperatura do motor está acima da temperatura permitida. Caso esteja, um sinal luminoso será acionado;

- Verificar e apresentar o estado dos sensores da aeronave. Um exemplo de estado é se a bateria auxiliar está ou não em uso;

- Gravar Registro de Log. Todos os dados apresentados ao usuário devem ser gravados em um arquivo de $\log$. 


\subsubsection{DFD 1.8 - Descomprimir Vídeo}

O DFD apresentado na figura 4.15 mostra como o MB realiza a descompressão do vídeo recebido do MA. O processo de descompressão basicamente ć o processo de compressão realizado de modo inverso.

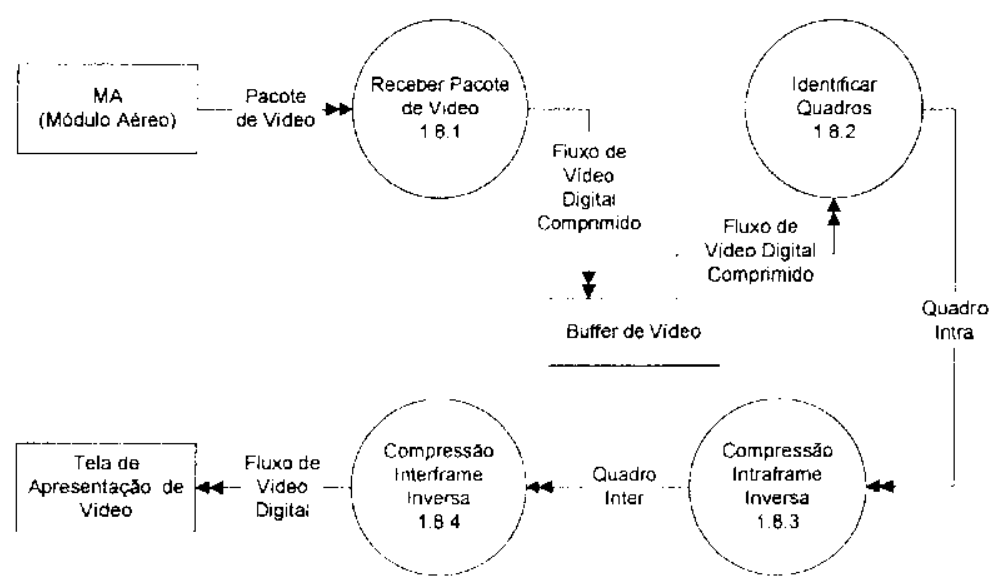

Figura 4.15: DFD 1.8 - Descomprimir vídeo.

\subsubsection{DFD 1.9 - Mostrar Arquivo de Log}

O DFD apresentado na figura 4.16 mostra como o MB apresenta os arquivos de log. Este processo envolve somente a abertura do arquivo de log e suá apresentação na tela, após uma solicitação do usuário.

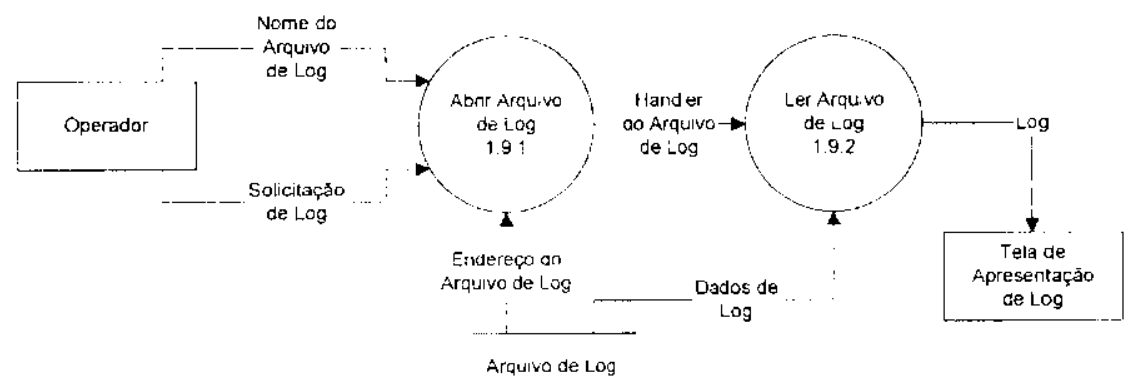

Figura 4.16: DFD 1.9 - Mostrar arquivo de $\log$. 


\subsubsection{DFD 1.10 - Capturar Imagem}

O DFD apresentado na figura 4.17 mostra como o MB captura as imagens a partir do vídeo recebido do MA. Após uma solicitaçāo do usuário, os pixels da tela de apresentação de vídeo são lidos e transformados em uma arquivo do tipo .bmp ou .jpg

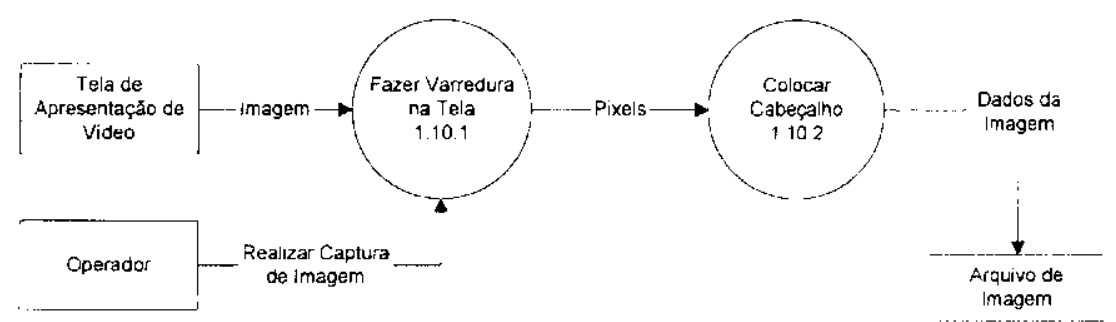

Figura 4.17: DFD 1.10 - Capturar imagem.

\subsubsection{DFD 1.11 - Visualizar Imagem}

O DFD apresentado na figura 4.18 mostra como o MB apresenta os arquivos de imagem. Este processo envolve somente a abertura do arquivo de imagem e sua apresentação na tela após uma solicitaçāo do usuário.

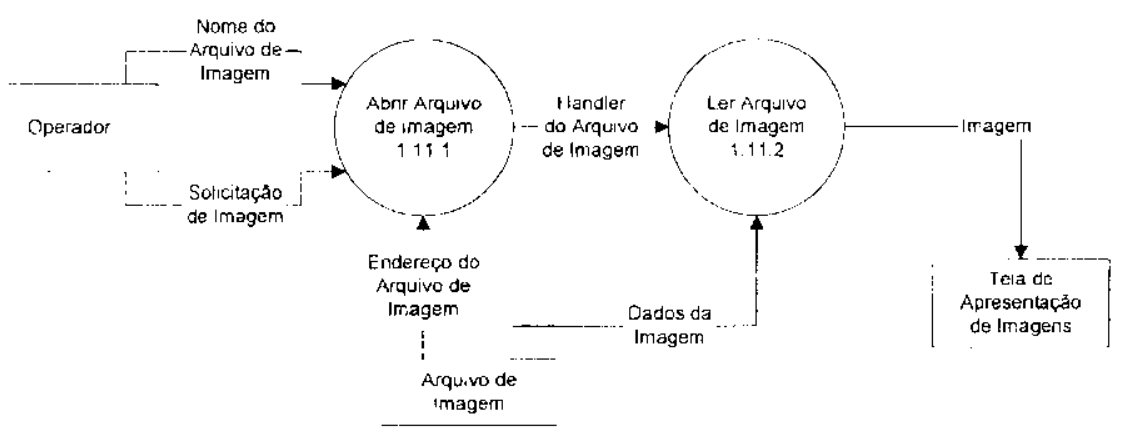

Figura 4.18: DFD 1.11 - Visualizar imagem. 


\subsubsection{DFD 1.12 - Mostrar Estatística}

O DFD apresentado na figura 4.19 mostra como são calculadas e apresentadas as estatísticas de um determinado arquivo de log. O processo de apresentação de estatística consiste em percorrer cada registro de um arquivo de $l o g$, calcular o valor mínimo, médio e máximo dos principais campos desse registro e apresentá-los na tela.

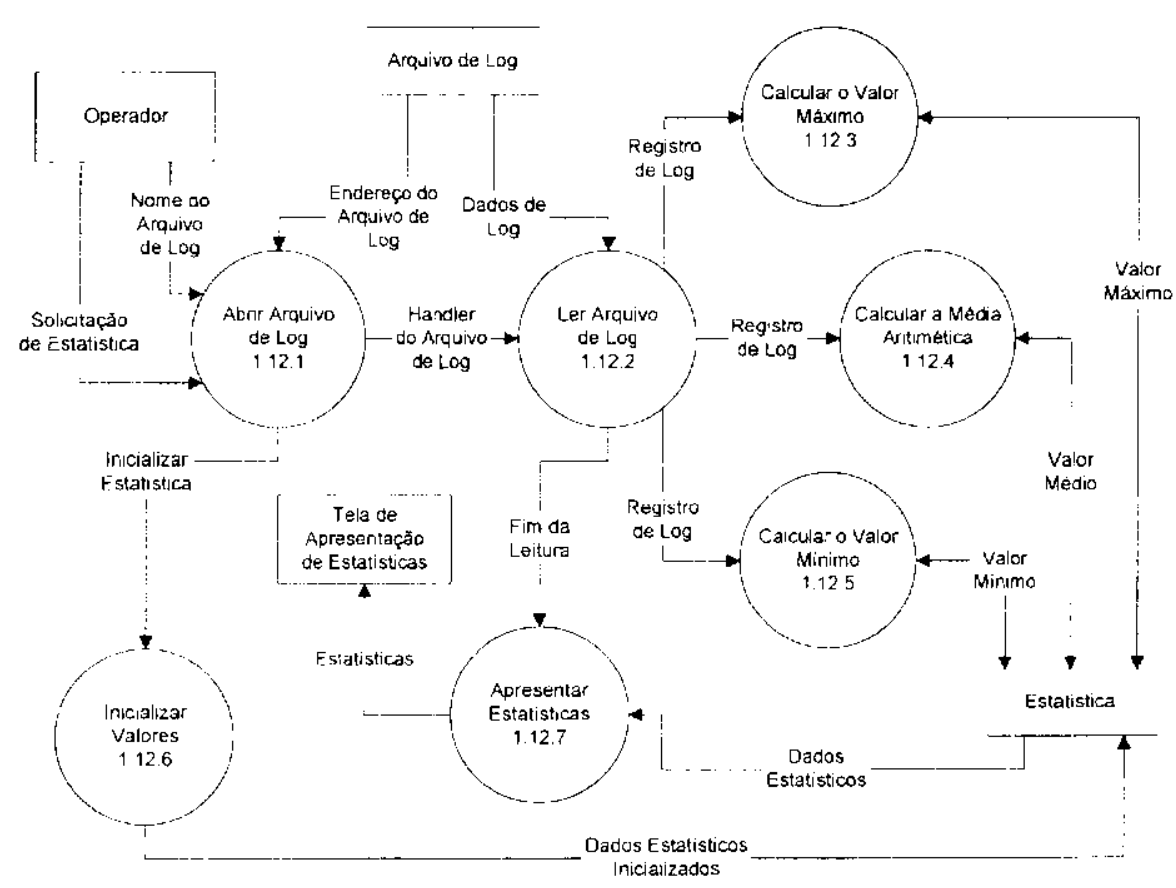

Figura 4.19: DFD 1.12 - Mostrar estatística.

\subsection{Sumário}

Este capítulo apresentou a modelagem do STT utilizando uma notação de análise estruturada. Ao longo deste capítulo, os requisitos do capítulo anterior foram traduzidos em diagramas de fluxo de dados. Para efeito dessa análise, o STT foi dividido em dois módulos, MA e MB. Os elementos dos DFDs apresentados neste capítulo foram descritos em um dicionário de dados, apresentado no apêndice B.

No próximo capítulo são apresentados os detalhes de implementação da nova versăo do STT. 


궁

\section{Projeto e Implementação}

Como já citado anteriormente, o STT foi divido cm dois módulos: MA e MB. Devido às restriçōes de hardware e facilidade de implementação, foram adotados sistemas operacionais distintos em cada módulo. O MA é executado em PC-104, utilizando um kernel reduzido do sistema operacional Linux. O MB é executado em um microcomputador padrão IBM-PC, utilizando o sistema operacional Windows.

O MA foi implementado na linguagem de programação $\mathrm{C}$, utilizando o compilador gec e o MB foi implementado em Delphi 5.0 (Borland, 2000). Levando-se em consideração MA e MB, foram escritas aproximadamente 6000 linhas de código divididas em 20 bibliotecas. A escolha do Delphi para o desenvolvimento do MB é justificada pela facilidade de desenvolvimento de aplicações gráficas e pela grande disponibilidade de bibliotecas VCL (Visual Component Library), também chamadas de classes de componentes visuais (Cantu, 1997), disponíveis na Internet. Outra justificativa da utilização do Delphi é manter a compatibilidade com os outros sistemas desenvolvidos para o projeto $A R A R A$ para futura integração, visto que os mesmos foram desenvolvidos em Delphi.

No desenvolvimento do MB foram utilizados componentes OCX, sendo, alguns desses componentes, desenvolvidos por Ribeiro (2000). Os componentes OCX, também conhecidos por controles ActiveX, são implementados utilizando a tecnologia de OLE 2.0 (Object Linking and Embedding). Estes controles são dependentes da MFC (Microsoft Foundation Classes) e podem ser 
desenvolvidos em Microsoft Visual C, Borland Delphi, Borland C e em Microsoft Visual Basic (Chappell, 1996). Os mostradores do MB foram implementados utilizando componentes OCX, distribuídos pela Global Majic (Majic, 2001). Utilizando esses componentes, é possível construir vários tipos de mostradores.

Além dos componentes VCL do Delphi, foram utilizados componentes adicionais para a transmissão de dados pela porta serial, componentes para a obtenção de dados do joystick e componentes para a captura e apresentação de vídeo.

Este capítulo apresenta os detalhes de implementação do STT. Nesse contexto, são apresentados na seção 5.1, o projeto de hardware do STT detalhando seus componentes, na seção 5.2, os programas de transmissão de vídeo pesquisados, na seção 5.3, o protocolo de comunicação utilizado para a transmissão de dados entre MA e MB, na seção 5.4, os detalhes de implementação do STT, na seção 5.5, a interface gráfica do STT, e finalmente, na seção 5.6, são apresentados os testes realizados com o STT.

\subsection{Projeto de Hardware}

A figura 5.1, apresenta um diagrama de blocos descrevendo os componentes de hardware utilizados na fase II do projeto ARARA. A seguir, será apresentada uma breve descrição desses componentes.

\subsubsection{Componentes de Hardware da Aeronave}

- Antena Omidirecional: Conectada ao modem de RF, é responsável por enviar e receber os sinais $\mathrm{para} / \mathrm{da}$ estação de solo;

- Câmera de Vídeo 1: É instalada no bico da aeronave, com seu foco direcionado para frente. Sua função é auxiliar o piloto na realização de vôos manuais. Pode ser ligada a um codificador de vídeo ou a uma entrada USB (Universal Serial Bus) do computador de bordo;

- Câmera de Vídeo 2: É instalada na parte inferior da aeronave, com seu foco direcionado para baixo. Sua função é auxiliar o piloto no posicionamento da aeronave para a obtenção de fotografias. Pode ser ligada a um codificador de vídeo ou a uma entrada USB do computador de bordo;

- Câmera Fotográfica: Câmera fotográfica química ou digital, de baixo peso, instalada no parte inferior da fuselagem da acronave, com seu foco direcionado para baixo; 

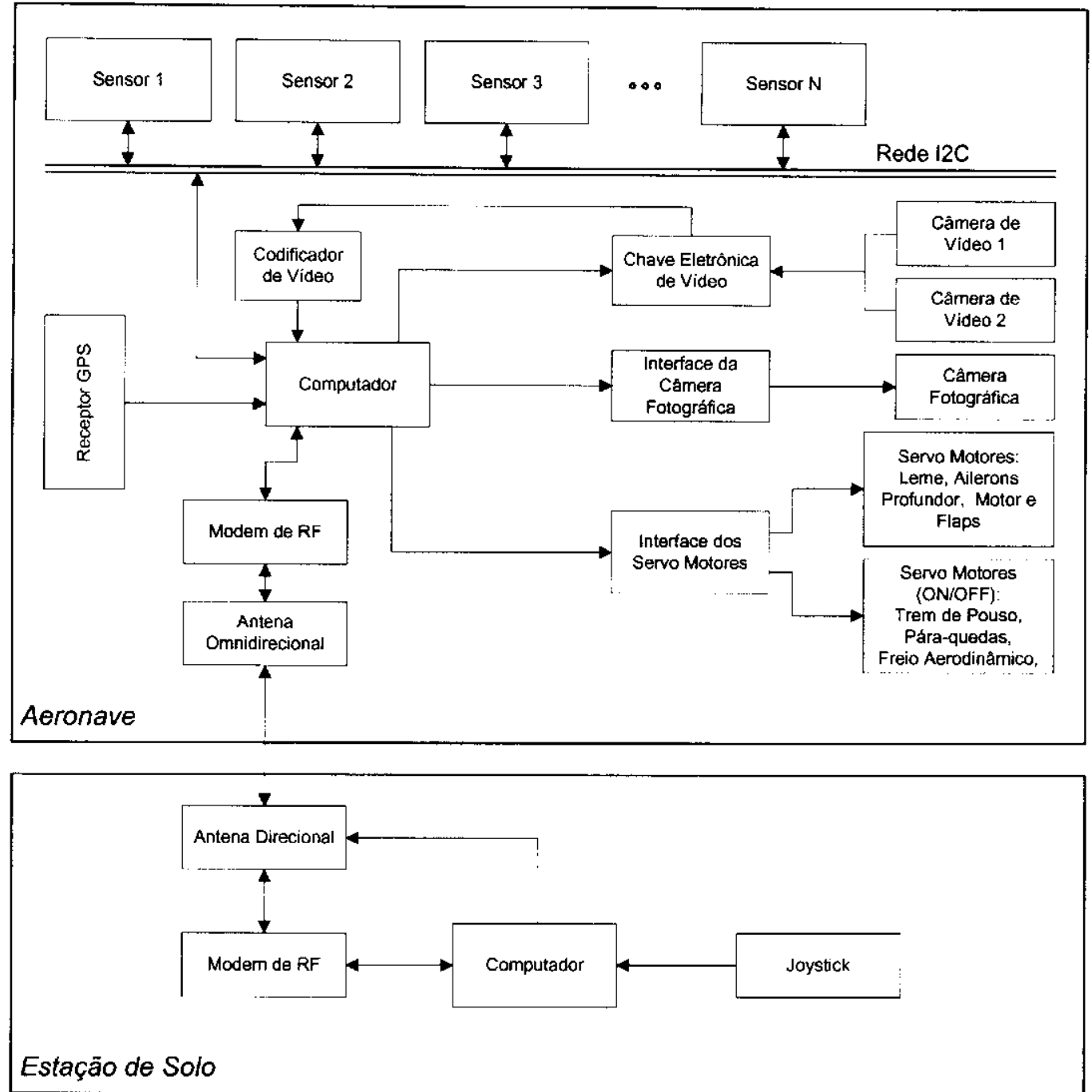

Figura 5.1: Componentes de hardware do STT.

- Chave Eletrônica de Vídeo: É composta por duas entradas e uma saída de vídeo e é conectada ao computador de bordo. Esse computador envia os dados que indicam qual das duas entradas será comutada para a saída de vídeo;

- Codificador de Vídeo: Digitaliza o vídeo composto recebido da chave eletrônica de vídeo e o envia ao computador de bordo. Esse componente de hardware pode ser excluído se a câmera for conectada diretamente ao computador por uma interface USB;

- Computador: Foi selecionado um PC-104, devido às restrições de peso e consumo de energia. O modelo selecionado possui 4 MBytes de memória, 2 MBytes de memória de estado sólido, 4 portas seriais e 1 porta paralela; 
- Interface da Câmera Fotográfica: Essa interface permite disparar a câmera fotográfica a partir de comandos recebidos do computador de bordo;

- Interface dos Servomotores: Ligada ao computador de bordo, essa interface recebe os dados que, depois de transformados em pulsos elétricos, irão movimentar os servomotores da aeronave;

- Receptor GPS: Está conectado a uma porta serial do computador de bordo. O GPS possui uma entrada para GPS diferencial;

- Rede $\mathbf{I}^{2} \mathbf{C}$ : A rede padrão $\mathrm{I}^{2} \mathrm{C}$ (Inter-IC) permite que o computador receba os dados dos sensores. Sua implementação é simples e a vantagem de sua utilização é a existência de muitos dispositivos compatíveis com esse padrão. Essa rede é conectada ao computador de bordo e pode transmitir dados a $100 \mathrm{kbits} / \mathrm{s}$;

- Modem de RF: Modem de rádio frequiência que realiza toda a transmissão dos dados entre a aeronave e a estação de solo;

- Sensor 1..N: Sensores utilizados na medição de vários parâmetros. Esses sensores foram especificados na seção 3.1 .1 ;

- Servomotores: São responsáveis pela movimentação das superfícies de controle da aeronave;

- Servomotores (ON/OFF): Responsáveis por acionar dispositivos de dois estados (ligado ou desligado), como, por exemplo, o pára-quedas dáaeronave.

\subsubsection{Componentes de Hardware da Estação de Solo}

- Antena Direcional: Durante o vôo, a antena da estação de solo sempre deve estar apontada para a aeronave. Para automatizar esse processo, o computador de solo envia os dados de localização da aeronave para o suporte que sustenta a antena. Esse suporte é dotado de um microprocessador, dois servomotorores e uma bússola. O microprocessador utiliza a bússola para transformar os dados de localização em pulsos elétricos os quais são aplicados aos servomotores que, por sua vez, rotacionam o suporte para a direção desejada;

- Computador: Computador padrăo IBM-PC utilizado para a visualização dos dados transmitidos pela acronave (telemetria e vídeo). Também é utilizado para enviar comandos e parâmetros de configuraçăo para a acronave; 
- Joystick: Utilizado como dispositivo de entrada da estação de solo. Movimentos no joystick são transformados em comandos e transmitidos para a aeronave. Esses comandos têm a função de movimentar as superfícies de controle da aeronave (ailerons e profundor). Um pedal poderá ser utilizado para a movimentação do leme de direçāo da aeronave;

- Modem de RF: Modem de rádio freqüência que realiza toda a transmissão dos dados entre a aeronave e a estação de solo.

\subsection{Programas para Transmissão de Vídeo}

A proposta inicial deste trabalho foi desenvolver um sistema embarcado para transmissão digital de vídeo e dados, em tempo real, para o projeto ARARA. Como o desenvolvimento de um software para captura, compressāo e transmissão de vídeo demandaria mais tempo do que um trabalho de mestrado dispõe, foi decidido pesquisar programas de domínio público, com código aberto, que possuíssem essas funções para, posteriormente, integrá-los ao STT. Durante essa pesquisa foram encontrados vários programas; entretanto eles não atendiam a todos os requisitos do projeto proposto.

$\mathrm{Na}$ fase final do desenvolvimento desse trabalho, foram encontrados dois programas contendo a maioria dos requisitos. Contudo, o tempo restante para a integração dos mesmos ao STT não era suficiente, já que a pesquisa tinha se estendido muito além do cronograma planejado. Diante deste problema, foi decidido modificar o escopo do trabalho para estender as funcionalidades do STT. Neste sentido, a integração do sistema de transmissão de vídeo digital tornou-se uma proposta para um trabalho futuro.

Esta seção apresenta um resumo dos dois programas encontrados (FFMPEG e MPEG4IP) que poderiam ser utilizados para uma posterior integração com o STT. Todos os programas encontrados foram desenvolvidos para o sistema opcracional Linux e utilizam as APIs do módulo v41 (video4linux) para capturar imagens da câmera de vídeo.

\subsubsection{FFMPEG}

O FFMPEG (Lantau, 2001) é uma solução para distribuição de áudio e vídeo, ao vivo, em redes TCP/IP. Ele possibilita codificar e transmitir, simultaneamente, diferentes formatos de áudio e vídeo. A arquitetura do FFMPEG é dividida em duas partes: FFMPEG e FFServer. O FFMPEG é responsável pela captura de áudio e vídeo, pela compressão dos mesmos e pela criação do fluxo 
de transporte. O FFServer é um servidor HTTP que redireciona o fluxo de transporte gerado pelo FFMPEG conforme as requisições recebidas.

As tabela 5.1 e 5.2, apresentam, respectivamente, os formatos de arquivo c os CODECs de áudio e vídeo que podem ser utilizados com o FFMPEG:

Tabela 5.1: Formatos de arquivo utilizados pelo FFMPEG.

\begin{tabular}{|l|c|c|}
\hline \multicolumn{1}{|c|}{ Formatos de Arquivo } & Codificação & Decodificação \\
\hline MPEG audio & $\times$ & $\times$ \\
\hline MPEG PS (áudio e vídeo multiplexado) & $\times$ & $\times$ \\
\hline ASF & $\times$ & $\times$ \\
\hline AVI & $\times$ & $\times$ \\
\hline WAV & $\times$ & $\times$ \\
\hline Macromedia Flash & $\times$ & Somente Áudio \\
\hline Real Audio e Video & $\times$ & $\times$ \\
\hline imagens PGM, YUV, PPM, JPEG & $\times$ & $\times$ \\
\hline Raw AC3 & $\times$ & $\times$ \\
\hline Raw MJPEG & $\times$ & $\times$ \\
\hline Raw MPEG vídeo & $\times$ & $\times$ \\
\hline
\end{tabular}

Tabela 5.2: CODECs utilizados pelo FFMPEG.

\begin{tabular}{|l|c|c|}
\hline \multicolumn{1}{|c|}{ CODECs } & Codificação & Decodificação \\
\hline MPEG-1 video & $\times$ & $\times$ \\
\hline MPEG-2 video & & $\times$ \\
\hline MPEG audio layer 2 & $\times$ & $\times$ \\
\hline MPEG audio layer 3 & & $\times$ \\
\hline MPEG-4 (aka Open DIVX) & $\times$ & $\times$ \\
\hline AC3 & $\times$ & $\times$ \\
\hline MS-MPEG4 V3 (aka DIVX) & $\times$ & $\times$ \\
\hline H263+ (aka Real Video 1.0) & $\times$ & $\times$ \\
\hline MJPEG & $\times$ & $\times$ \\
\hline
\end{tabular}

Embora o FFMPEG pareça uma solução completa para transmissão de vídeo ao vivo em redes TCP/IP, devido à variedade de codificadores que ele possui, ele ainda não se encontra em uma versão estável. A preocupação dos desenvolvedores em disponibilizar vários codificadores para o FFMPEG, manteve o processo de transmissão de áudio e vídeo em scgundo plano, deixando o FFServer incompleto e contendo alguns bugs. A versão disponível do FFserver utiliza o protocolo HTTP para transmissão de áudio e vídeo. Como o HTTP não é apropriado para a transmissão desse tipo de mídia, o atraso de transmissão é relativamente alto para sistemas de tempo real. 


\subsubsection{MPEG4IP}

O MPEG4IP (Mackie et al., 2001) é um sistema de codificação, transmissão e apresentação de áudio e vídeo MPEG-4. Seu desenvolvimento é baseado na integração de vários programas de código aberto, já existentes, e seu principal objetivo é disponibilizar bibliotecas de software, não proprietárias, para desenvolvedores que desejam trabalhar com áudio e vídeo MPEG-4.

O desenvolvimento do MPEG4IP teve com base a plataforma Linux; entretanto ele já está sendo escrito para Windows, Solaris, FreeBSD, BSD/OS e MacOSX. O MPEG4IP disponibiliza um codificador de áudio MPEG-4 AAC, um codificador MP3, dois codificadores de vídeo MPEG4, um software para criar arquivos MP4, um servidor de streaming baseado nas especificações da IETF (Internet Engineering Task Force) e um player MPEG-4.

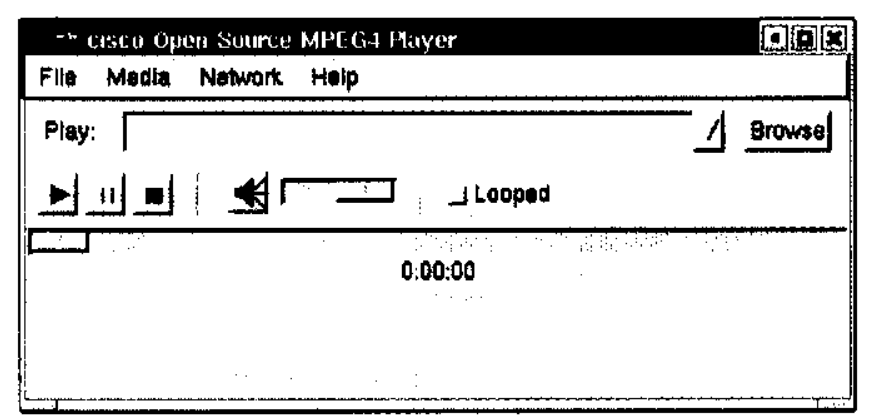

Figura 5.2: Interface gráfica do gmp4player.

Os dois principais programas disponibilizados pelo MPEG4IP são o gmp4player e o mp4live. Esses programas são construídos a partir das bibliotecas disponibilizadas pelo MPEG4IP. O gmp4player (figura 5.2) é um player dotado de uma interface gráfica simples que permite apresentar arquivos AVI, CMP, DIVX, AAC, MP3, MP4 e WAV. O mp4live (figura 5.3) permite a transmissão de fluxos de áudio e/ou vídeo capturados de um dispositivo v4l para uma rede TCP/IP, em modo unicast ou multcast. O protocolo de comunicação utilizado pelo mp4live é o RTP (Realtime Transport Protocol) sobre UDP (User Datagram Protocol). A transmissão é controlada pelo RTSP (Real Time Streaming Protocol).

Embora o MPEG4IP seja um sofiware de domínio público de código aberto, é possível perceber que ele apresenta estabilidade e qualidade de nível comercial. Vale ressaltar que seus três desenvolvedores são especialistas em transmissão de vídeo da Cisco Systems Inc. e, apesar da Cisco não oferecer qualquer garantia pelo MPEG4IP, é possível perceber o envolvimento da mesma no projeto MPEG4IP devido ao nome Cisco na barra de título do mp4live e do gmp4player. Infelizmente, mesmo com toda a qualidade apresentada pelo MPEG4IP, a transmissão de vídeo ainda apresenta um atraso considerável para transmissões em tempo real. 


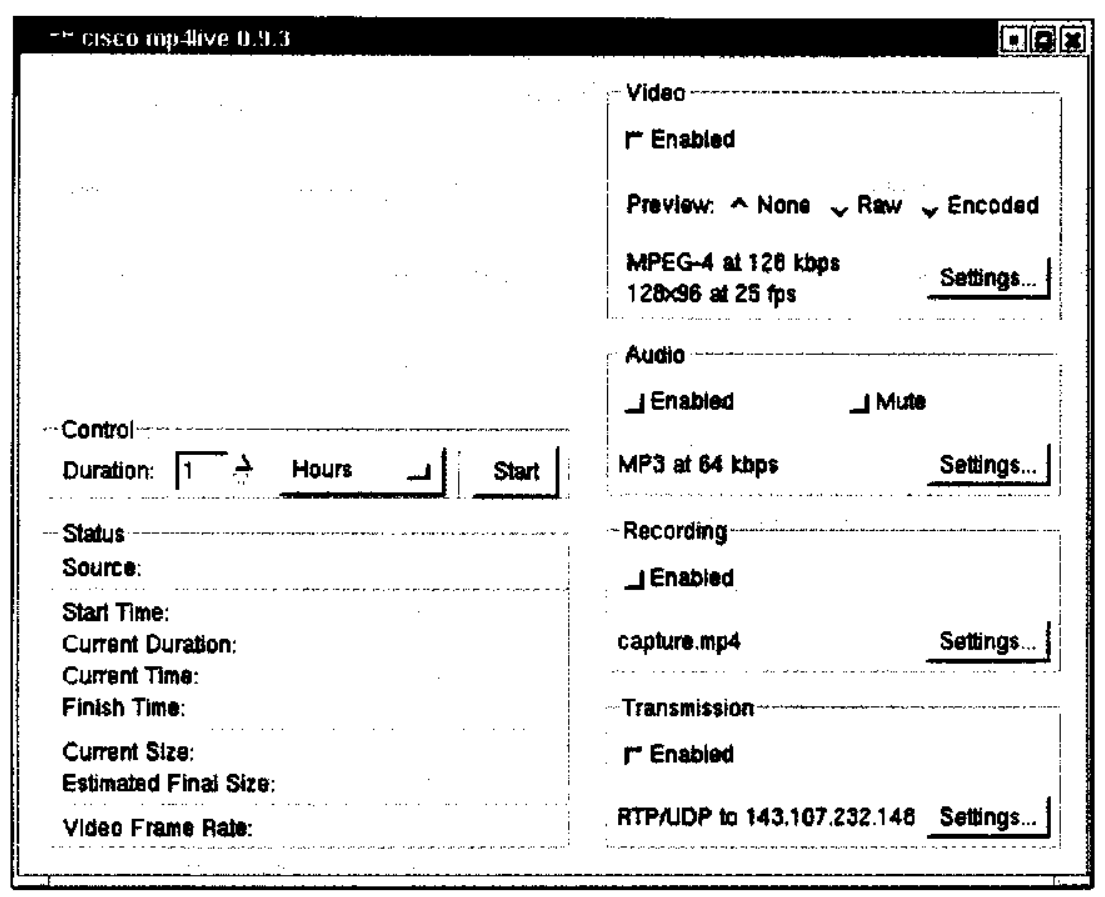

Figura 5.3: Interface gráfica do mp4live.

\subsubsection{Testes de Transmissão de Vídeo}

Nos testes realizados com os programas de transmissão de vídeo, foram utilizados dois computadores; um simulando a aeronave e outro simulando a estação de solo. Os computadores utilizavam o protocolo TCP/IP e estavam interligados por uma rede Ethernet de $10 \mathrm{Mbps}$. Para simular o computador da aeronave, foi utilizado um Pentium II $266 \mathrm{MHz}$, com 32 MBytes de mémoria RAM e disco rígido de 1,5 GBytes. Para a estação de solo, foi utilizado um Pentium II $233 \mathrm{MHz}$, com 64 MBytes de memória RAM e disco rígido de 3 GBytes.

O primeiro software testado foi o FFMPEG. Além de apresentar um desempenho muito baixo para aplicações de tempo real, aproximadamente sete segundos de atraso, o FFMPEG não se mostrou um software estável. Foram raras as vezes em que o FFMPEG permeneceu mais que 10 segundos transmitindo vídeo sem occorrer algum erro. Outro problema apresentado foi a obrigação imposta pelo FFMPEG que todo o conteúdo transmitido deve ser gravado. Isso faz com que o computador da aeronave necessite de grande espaço de armazenamento.

O MPEG4IP, o segundo software testado, se saiu melhor que o FFMPEG nos testes realizados, tanto em desempenho quanto em estabilidade. Durante os testes, o MPEG4IP não "travou" nehuma vez e não apresentou nenhum erro repentino. Contudo, mesmo que o desempenho de transmissão do MPEG4IP seja superior ao do FFMPEG, ele ainda nāo foi adequado para transmissões em tempo real, pois apresentou um atraso de transmissão de aproximadamente três segundos. 


\subsection{O Protocolo de Comunicação}

A comunicação entre a aeronave e a estação de solo é caracterizada por ser uma comunicação ponto-a-ponto. Devido à camada de enlace de dados oferecer esse tipo de serviço (conexão pontoa-ponto), o protocolo de comunicação utilizado pelo STT foi projetado para atuar na referida camada. Esse protocolo é responsável por coordenar a comunicação realizada entre o UAV e estação de solo do projeto ARARA. Vale ressaltar que esse protocolo já existia na primeira versão do STT, mas devido às falhas do protocolo anterior e às novas necessidades do projeto $A R A R A$, foi necessário desenvolver um novo protocolo.

Os dados transmitidos pelo canal de comunicação entre a estação de solo e o UAV são divididos em dois grupos de dados: dados de telecomando e dados de telemetria. O grupo de dados de telecomando possui dois tipos de pacote (pacotes de superfície de comando e pacotes de parâmetros de configuração); o grupo de dados de telemetria possui apenas um tipo de pacote.

Ainda que os grupos de dados precisem ser tratados de maneiras diferenciadas, existem algumas semelhanças que devem ser consideradas. É importante destacar que todos os tipos de pacotes utilizados pelo STT possuem um cabeçalho de 24 bits. Os primeiros 8 bits do cabeçalho são utili.. zados para o DLE (Data Link Escape); os próximos 8 bits para o STX (Start of Text) e os últimos 8 bits do cabeçalho, para indicar o tipo do pacote. Para indicar o final de um pacote é inserido um caracter DLE, seguido do caracter ETX ( ind of Text).

Todos os tipos de pacotes, exceto os pacotes de parâmetros de configuração (grupo de dados telecomando), são transmitidos utilizando um serviço sem confirmação e sem conexão. Os pacotes de parâmetros de configuração são transmitidos utilizando um serviço com confirmação e sem conexão.

Outra característica, presente em todos os tipos de pacotes, é a utilização da técnica de character stuffing para a transmissão de dados e a utilizaçāo de um algoritmo CRC-16 (Cyclic Redundance Code de 16 bits), para detecção de erros. Como o protocolo do STT não prevê nenhum tipo de retransmissão, o CRC-16 somente é utilizado para descartar os pacotes que possuem erro. Tanenbaum (1996) descreve a técnica character stuffing e o algoritmo CRC-16.

A seguir serão apresentadas as características dos grupos de dados e o formato dos pacotes dos respectivos grupos de dados.

\subsubsection{Dados de Telecomando}

Os dados de telecomando são provenientes da estação de solo c são responsáveis pelo controle remoto da aeronave, ou seja, intervenções do operador por meio de um dispositivo conectado ao 
microcomputador da estação de solo (joystick, mouse, teclado, etc...), irão gerar dados que atuarão no controle da aeronave.

Os dados de telecomando podem atuar, diretamente, nos dispositivos de controle da aeronave como profundor, leme de direção, ailerons, flaps e aceleraçāo do motor, ou em outros tipos de dispositivos como, por exemplo, câmeras fotográficas (acionamento), câmeras de vídeo (seleçāo de câmera e configuração de parâmetros de resolução) e pára-quedas (acionamento).

Com o intuito de melhorar o desempenho do protocolo foram criados dois tipos de pacotes de telecomando: pacotes de superfície de comando e pacotes de configuração de parâmetros.

\section{Pacotes de Superfície de Comando}

Os pacotes de superfície de comando são enviados do MB para o MA, em intervalos de $30 \mathrm{~ms}$. Composto por 10 canais de 16 bits, onde cada canal atua $\mathrm{cm}$ um servomecanismo da aeronave, $\mathrm{e}$ 16 canais de 1 bit que atuam em dispositivos do tipo ON/OFF, como, por exemplo, o seletor de câmera de vídeo. Pode-se afirmar que essa subcategoria é a mais importante do grupo de dados de telecomando porque seus dados atuam diretamente nas superfícies de controle da aeronave.

A tabela 5.3, descreve o formato dos pacotes de superfície de comando e a tabela 5.4, descreve os canais ON/OFF (campo 11, da tabela 5.3).

Tabela 5.3: Formato dos pacotes de superfície de comando.

\begin{tabular}{|c|c|c|c|}
\hline & Dado & Tamanho & \multirow{2}{*}{$\frac{\text { Valor }}{16}$} \\
\hline & DLE & 8 bits & \\
\hline & STX & 8 bits & $2^{-\cdots-1}$ \\
\hline & Tipo do Pacote & 8 bits & 126 \\
\hline 1 & Potência do Motor & 16 bits (com sinal) & \\
\hline 2 & Aileron Direito & 16 bits (com sinal) & \\
\hline 3 & Aileron Esquerdo & 16 bits (com sinal) & \\
\hline 4 & Leme de Direção & 16 bits (com sinal) & \\
\hline 5 & Profundor & 16 bits (com sinal) & \\
\hline 6 & Flaps & 16 bits (com sinal) & \\
\hline $7 . .10$ & Reservado & 16 bits (com sinal) & \\
\hline \multirow[t]{5}{*}{11} & Canais ON/OFF & 16 bits & \\
\hline & $\mathrm{CRC}$ & 16 bits (com sinal) & \\
\hline & DLE & 8 bits & 16 \\
\hline & ETX & 8 bits & 3 \\
\hline & Total (sem caracteres de controle): & 176 bits (22 Bytes) & \\
\hline
\end{tabular}


Tabela 5.4: Descrição dos canais ON/OFF

\begin{tabular}{|l|l|c|}
\hline 1 & Trem de Pouso & I bit \\
\hline 2 & Pára-quedas & 1 bit \\
\hline 3 & Freio Aerodinâmico & 1 bit \\
\hline 4 & Seletor de Câmera & 1 bit \\
\hline 5 & Acionador da Câmera Digital & 1 bit \\
\hline 6.16 & Reservado & 1 bit \\
\hline
\end{tabular}

\section{Pacotes de Parâmetros de Configuração}

São enviados do MB para o MA mediante uma solicitação do usuário. Composto por 8 canais de tamanhos variados onde cada canal pode atuar em um dispositivo de hardware ou no software da aeronave (MA). Esse é o único tipo de pacote transmitido utilizando um serviço com confirmação e sem conexão, ao contrário de todos os outros que são transmitidos em um serviço sem confirmação e sem conexão.

Tabela 5.5: Formato dos pacotes de parâmetros de configuração.

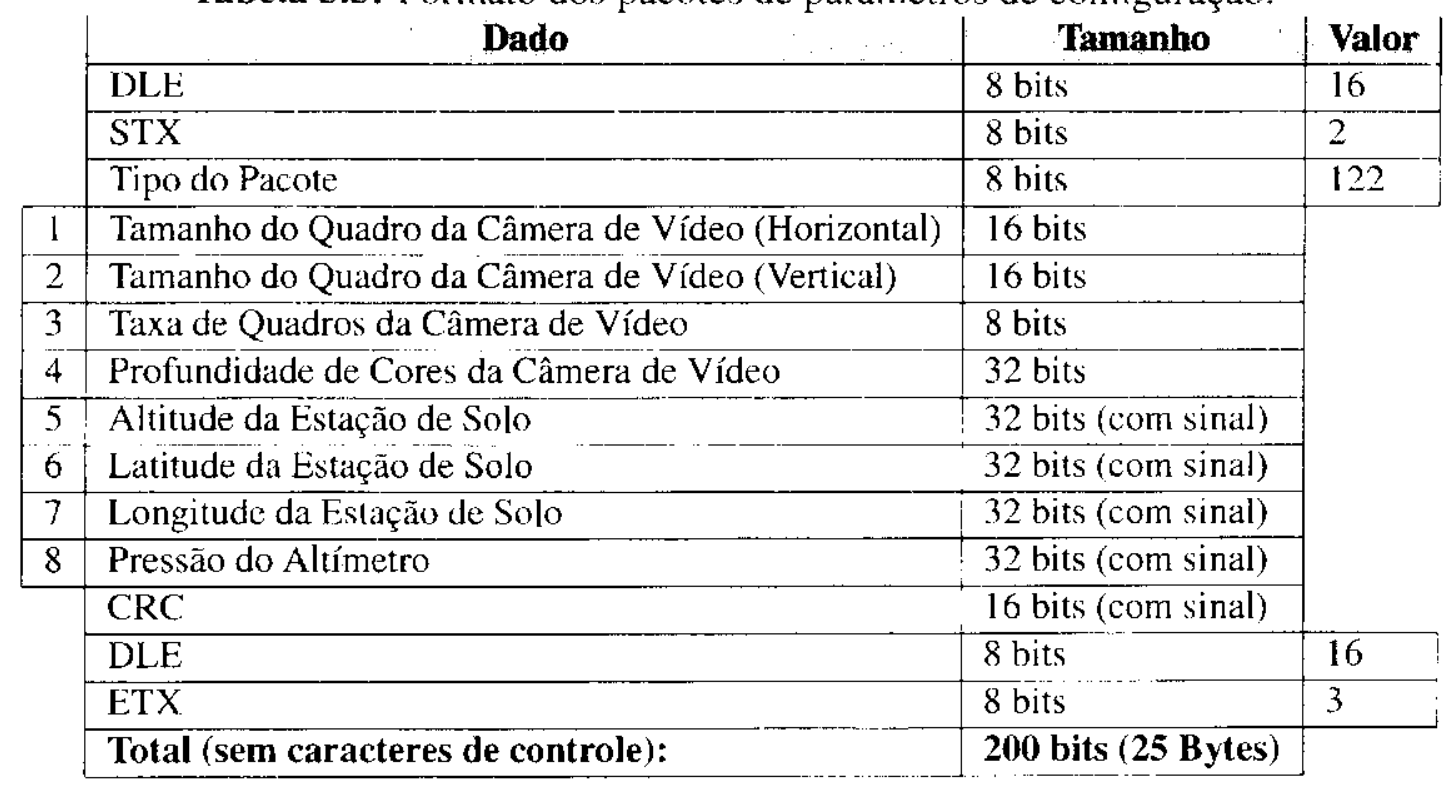

\subsubsection{Dados de Telemetria}

Quando o usuário da estação de solo decide pilotar manualmente a aeronave, ele necessita de instrumentos que indiquem o estado da aeronave (telemetria) como, por exemplo, a direção e a altitude da aeronave. Os dados de telemetria são gerados pelos sensores da aeronave e são utilizados principalmente na realização de vôos manuais. 
Os pacotes de dados de telemetria são transmitidos do MA para o MB em intervalos de $500 \mathrm{~ms}$. Para realizar essa transmissão, o MA lê os dados dos sensores da aeronave e os empacota segundo o formato dos pacotes de telemetria apresentados na tabela 5.6. Vale lembrar que os sensores são dispositivos que captam os indicadores de estado da aeronave como, por exemplo, altitude, razão de subida/descida e temperatura do motor.

Tabela 5.6: Formato dos pacotes de telemetria.

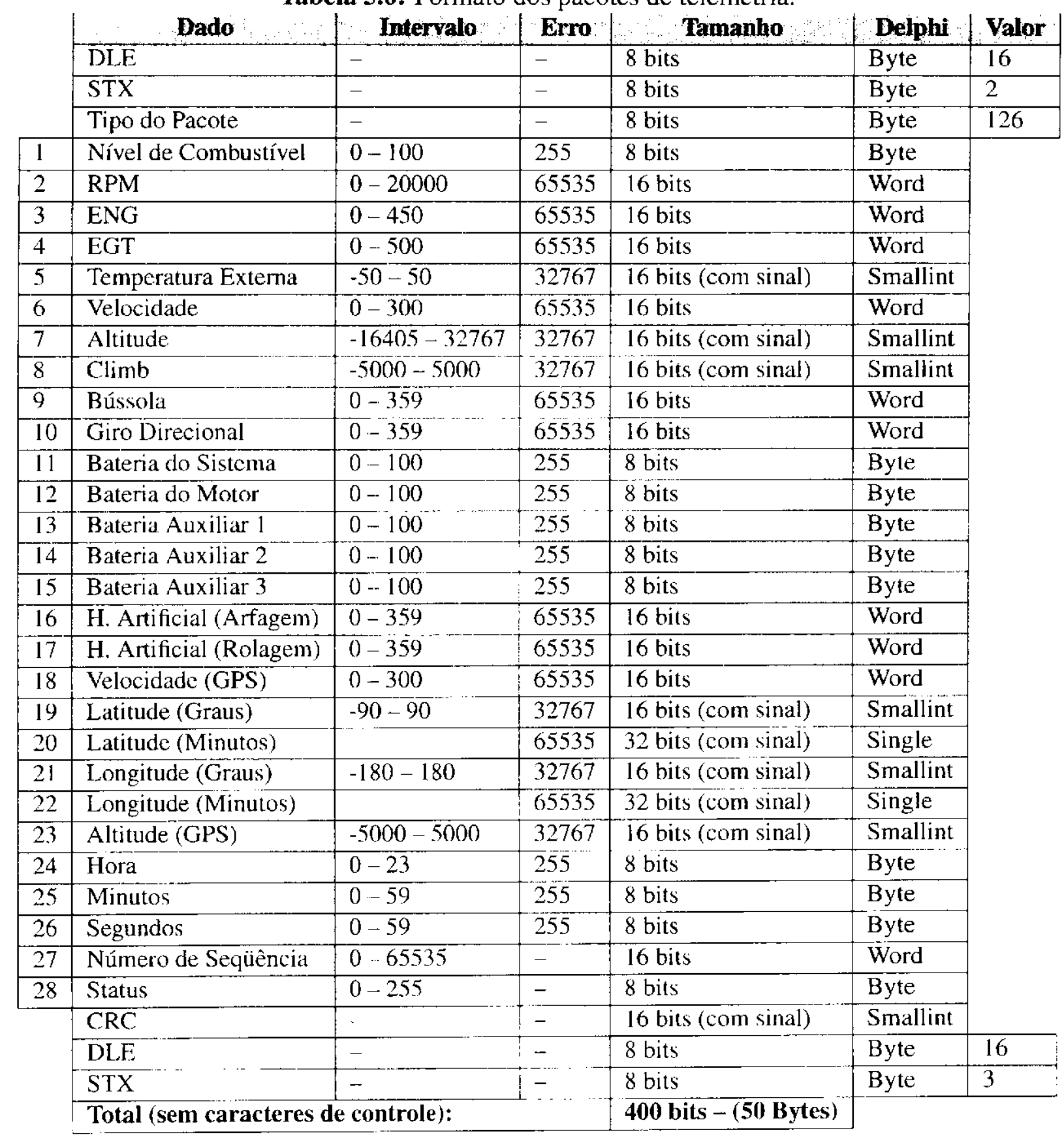




\subsection{Detalhes de Implementação}

A arquitetura do STT é apresentada na figura 5.4, onde é possível identificar a presença das principais entidades relacionadas ao STT: usuário, hardware (servomotores e atuadores da aeronave) e sensores (GPS e diversos sensores presentes na aeronave). O usuário interage com o sistema enviando comandos e recebendo a telemetria através da GUI (Graphical User Interface); o hardware do sistema recebe os comandos enviados pelo $\mathrm{MB}$ e os sensores fornecem dados para compor a telemetria enviada ao MB.

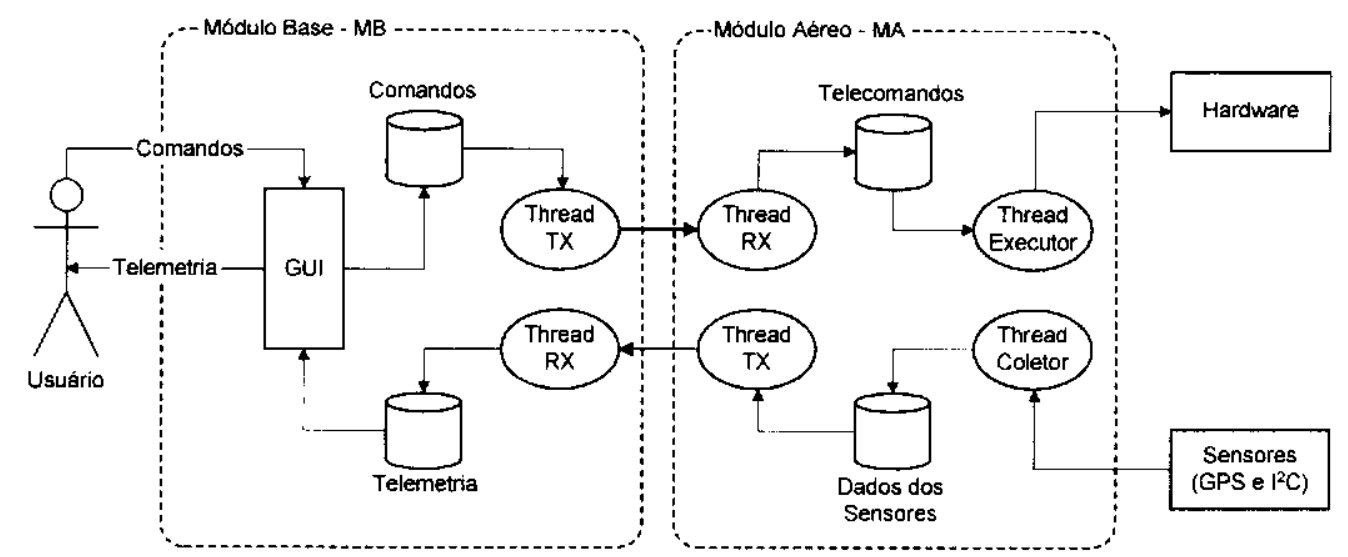

Figura 5.4: Arquitetura de software do STT.

É possível observar que a utilização de threads foi importante para a arquitetura do STT. No processo de transmissão dos dados, os threads são utilizados para permitir o envio e o recebimento dos dados de maneira simultânea. Neste contexto, o thread TX do MB comunica-se com o thread RX do MA e vice-versa.

No MA, threads também são utilizados para coletar os dados dos sensores (thread Coletor) e para a execução dos comandos recebidos do MB. No MA, os threads trabalham em um processo conhecido como produtor $\times$ consumidor. Neste sentido, o thread $\mathrm{RX}$ (produtor), recebe os dados de telecomando do MB e os armazena em variáveis que serāo posteriormente utilizadas pelo thread Executor (consumidor). O mesmo processo é utilizado com os threads Coletor (Produtor) e TX (Consumidor).

As subseções seguintes apresentam os detalhes de implementação do MA e do MB.

\subsubsection{Módulo Aéreo}

O módulo aéreo foi desenvolvido utilizando técnicas convencionais de programação estruturada. Ele é composto, basicamente, das seguintes funções: 
- Função main( ) - A função main( ) controla a chamada de todas as funções do MA;

- Funções Get( ) - Para cada sensor presente na aeronave existe uma função Get( ). Essas funções são responsáveis pela obtenção dos dados dos sensores conectados na rede $\mathrm{I}^{2} \mathrm{C}$ e pela transformação desses dados em dados de telemetria;

- Funções GPS - São utilizadas para obter os dados do GPS conectado em uma porta serial e para transformar as sentenças NMEA recebidas do GPS, em dados de telemetria;

- Funções de Transmissão - São responsáveis pelo envio e recebimento de dados para/da porta serial;

- Funções Set( ) - Transformam os dados de telecomando em comandos para a aeronave. Os comandos podem atuar no software e no hardware da aeronave.

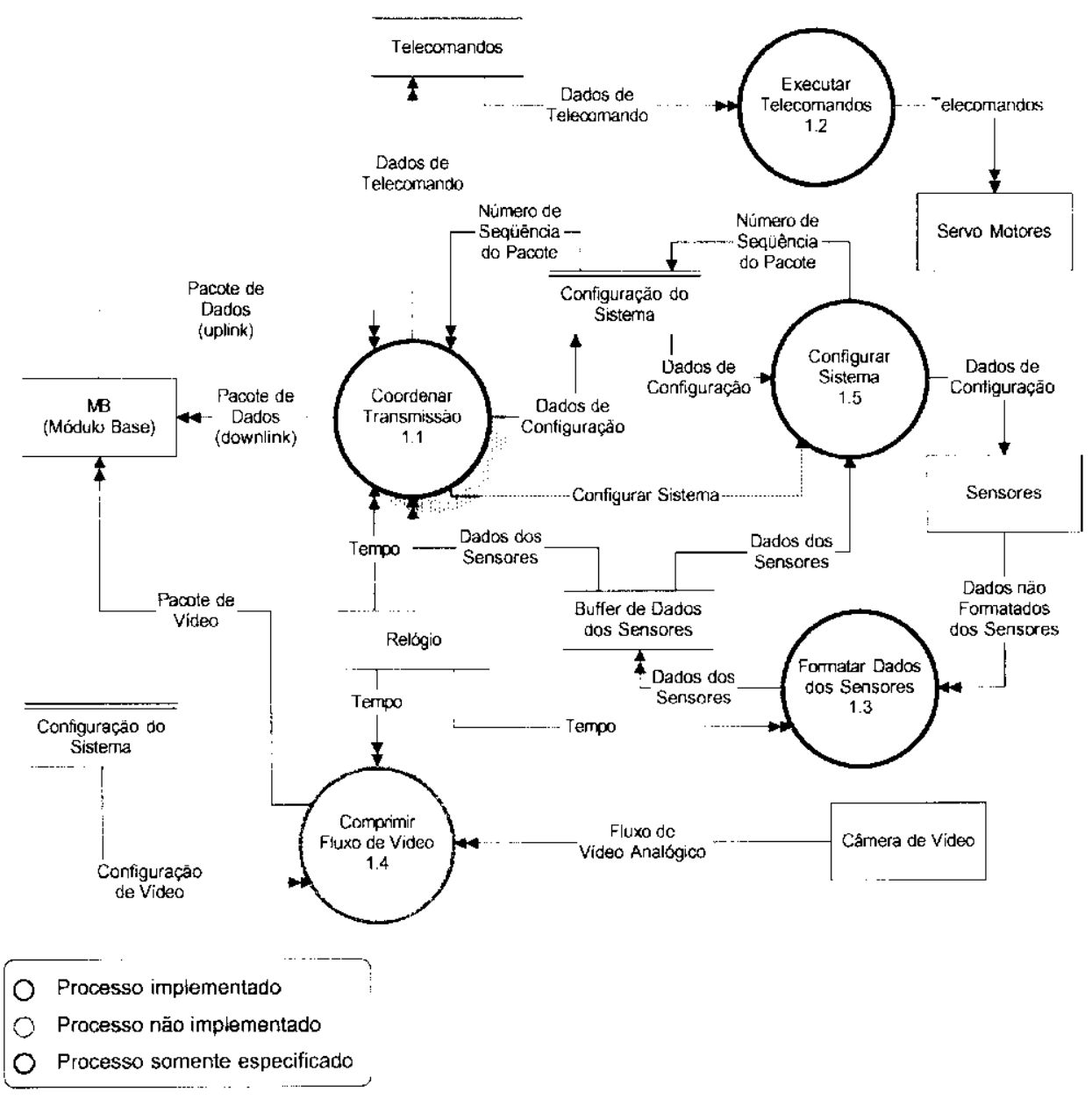

Figura 5.5: Estado da implementação do MA. 
A figura 5.5, apresenta o DFD, nível 1, do MA ressaltando o estado da implementação do mesmo. Os processos coloridos de verde denotam os processos completamente implementados; os processos em azul representam os processos especificados e não implementados e os processos em vermelho denotam os processos não implementados. Nessa figura é possível observar que o processo de compressảo de vídeo foi o único não implementado devido às razões apresentadas na seção 5.2 .

\subsubsection{Módulo Base}

$\mathrm{Na}$ implementação do MB, foi utilizado o paradigma de orientação a objetos. Neste sentido, foram criadas classes de dois tipos: classes de interface (herdadas da classe TForm do Delphi), que implementam a interface com o usuário, e classes funcionais, que implementam as funções específicas do sistema. A figura 5.6, apresenta um diagrama de classes simplificado do MB.

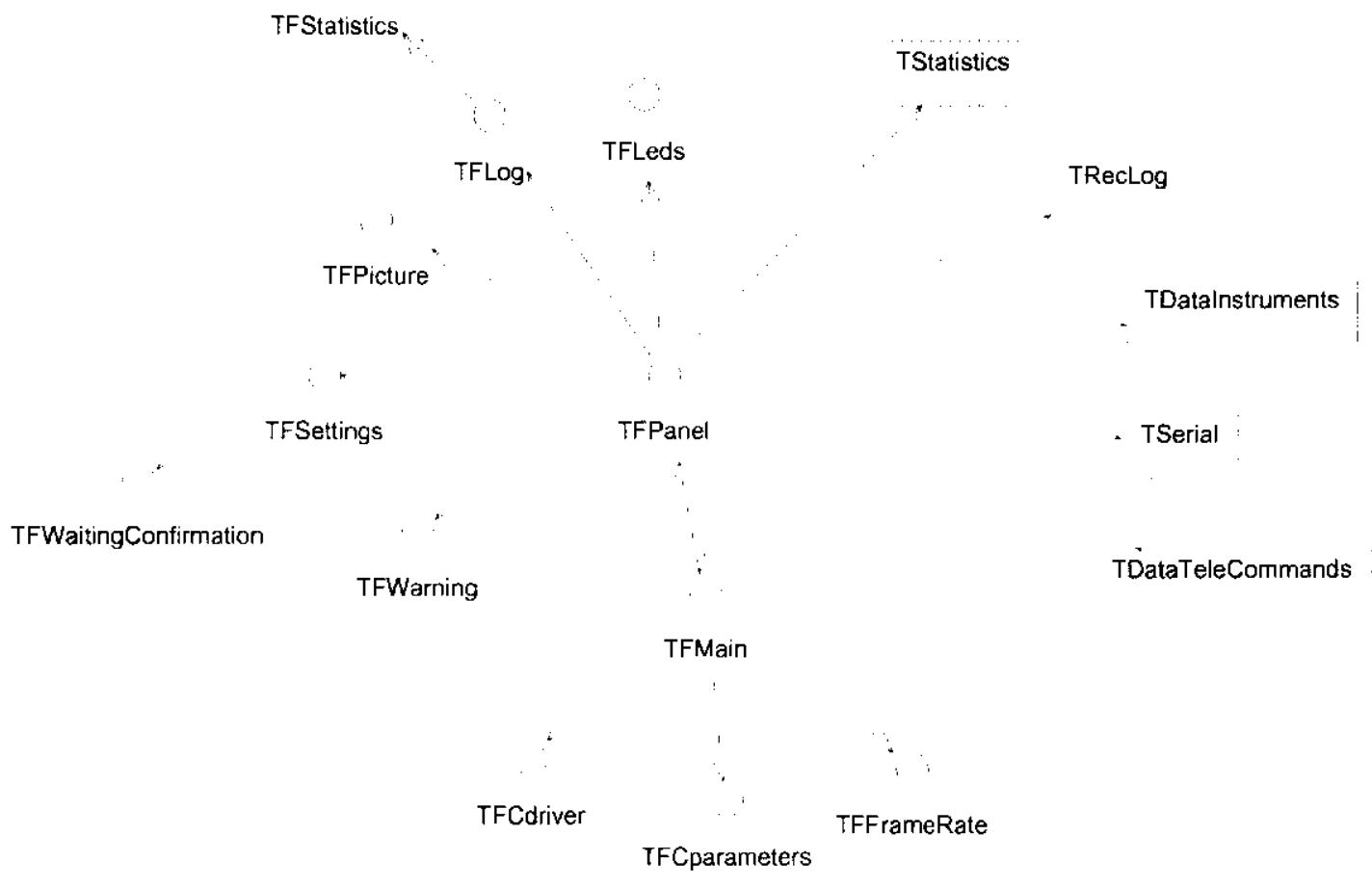

Figura 5.6: Diagrama de classes simplificado do MB.

Dentre as classes de interface (representadas por um círculo), as classes TFMain e TFPanel podem ser consideradas as principais classes devido ao grande número de associações que elas possuem em relação às outras classes de interface do MB. Também é possível observar na figura 5.6 
que a classe TFPanel é a única classe associada às classes funcionais. Isso mostra que a classe TFPanel é a principal classe do MB.

A seguir será apresentada uma breve descrição de cada classe do MB:

- TFMain - Responsável pela apresentação do vídeo e pela configuração de alguns parâmetros referentes à apresentação de vídco, como o tipo (NTSC, PAL, PAL-M) e tamanho do quadro de vídeo;

- TFPanel - Implementa a principal interface gráfica do MB. Essa classe possui objetos de quase todas as outras classes do MB. Suas principais funções são receber os comandos do operador, apresentar a telemetria e apresentar os alertas do sistema;

- TFFrameRate - Apresenta a interface utilizada para configurar a taxa de quadros do vídeo apresentado pela classe TFMain;

- TFCParameters - Implementa a interface utilizada para a configuração dos parâmetros de captura de vídeo como taxa quadros, tempo de captura e nome do arquivo onde o vídeo será gravado;

- TFCDriver - Responsável pela implementação da interface utilizada na seleção do driver de captura de vídeo;

- TFWarning - Utilizada para realizar a configuração dos parâmetros de alerta como distância máxima de aeronave, temperatura máxima do motor e mínima quantidade de combustível;

- TFSettings - Implementa a interface utilizada na configuração dos parâmetros da estação de solo e do UAV. Dentre esses parâmetros estão as coordenadas da estação de solo, a configuração das câmeras do UAV e a pressão atmosférica local utilizada para calibrar o altímetro do UAV;

- TFWaitingConfirmation - Responsável por verificar e informar ao usuário se os parâmetros de configuração do UAV foram recebidos corretamente pelo mesmo;

- TFPicture - Tem a função de apresentar ao usuário imagens do tipo BMP e JPG;

- TFLog - Implementa a interface utilizada para apresentar os arquivos de log gravados durante as sessões de vôo do UAV;

- TFStatistics - Responsável por apresentar os dados estatísticos de um determinado arquivo de $\log$ : 
- TFLeds - Implementa um painel de leds os quais são utilizados para identificar falhas nos sensores do UAV;

- TStatistics - Realiza os cálculos estatísticos referentes a um arquivo de $\log$ e fornece o resultado desses cálculos para a classe TFStatistics;

- TRecLog - Manipula os arquivos de log e fornece os dados retirados desses arquivos para a classe TFLog;

- TDataInstruments - É responsável pela a manipulação dos dados de telemetria e por fornecer esses dados para a classe TFPanel;

- TDataTelecommands - Implementa a manipulação dos dados de tclccomando. Também é responsável por fornecer os dados de telecomando para a classe TFPanel;

- TSerial - Cria os pacotes de telecomando a partir dos comandos do usuário e retira os dados de telemetria dos pacotes de telemetria. Também é responsável por enviar e receber os pacotes de dados $\mathrm{para} / \mathrm{da}$ porta serial. 
A figura 5.7 apresenta o DFD, nível 1, do MB, ressaltando o estado da implementação do mesmo. Os processos coloridos de verde denotam os processos completamente implementados e os processos em vermelho denotam os processos não implementados. Nessa figura é possível observar que o processo de descompressão de vídeo foi o único processo não implementado. Como o processo de compressão de vídeo do MA não foi implementado, não houve a necessidade de implementar o processo que faz a descompressão no MB.

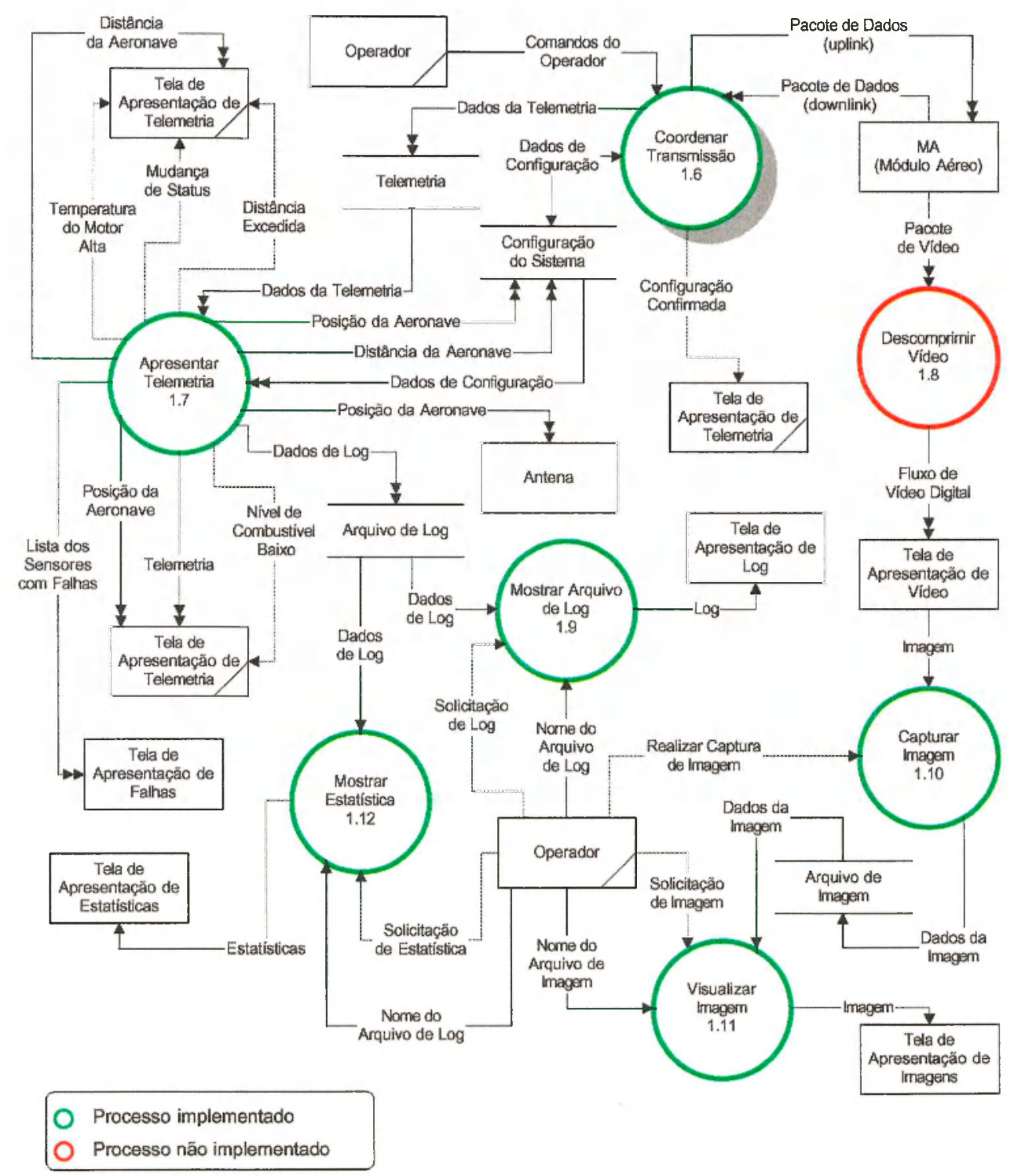

Figura 5.7: Estado da implementação do MB. 


\subsection{Interface Gráfica do STT}

Esta seção apresenta a interface gráfica do STT. Como o MA não possui interface gráfica, somente será apresentada a interface gráfica do MB. Essa interface é responsável por toda a interação com o usuário no STT.

A figura 5.8, mostra o fluxo de navegação das telas do MB ressaltando as diferenças em relação a primeira versão do STT. Nessa figura, cada retângulo representa uma tela do MB. Os retângulos verdes representam as telas já existentes na versão anterior do STT que foram redesenvolvidas na nova versão; os retângulos azuis representam as telas modificadas e os retângulos vermelhos representam as telas criadas na nova versão.

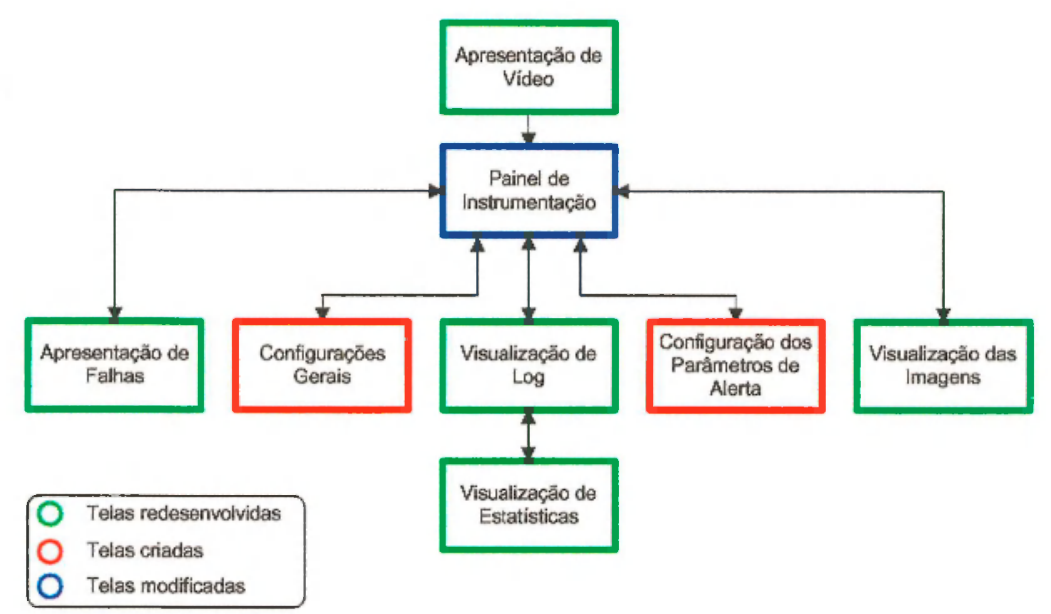

Figura 5.8: Fluxo de navegação das telas do MB.

Nas próximas subseções, serão descritas todas as telas contidas nesse fluxo de navegação. 


\subsubsection{Tela Principal}

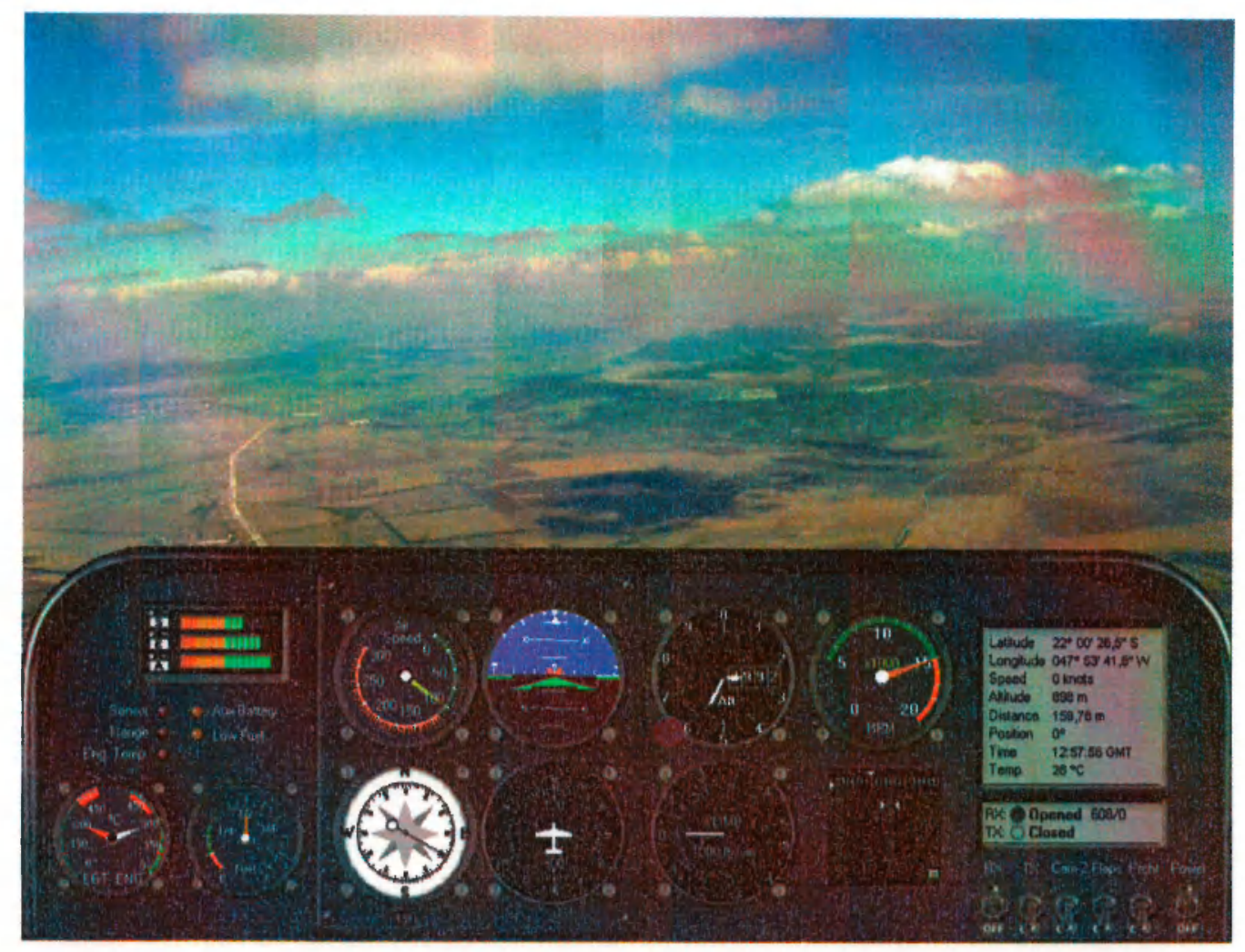

Figura 5.9: Tela de principal do MB.

A tela principal do MB é composta por duas telas: a tela de apresentação de vídeo e o painel de instrumentação. Para que o MB se pareça com um simulador de vôo, a tela de apresentação de vídeo é sobreposta pelo painel de instrumentação. Todas as outras telas do MB, exceto a tela de visualização de estatísticas, são chamadas utilizando um menu do tipo pop-up. Esse menu é acionado a partir de um clique com o botão direito do mouse sobre o painel de instrumentação.

O usuário, provavelmente, considerará o painel de instrumentação e a tela de apresentação de vídeo como uma única tela, pois elas sempre aparecem juntas. A figura 5.9 mostra a tela de apresentação de vídeo, sobreposta pelo painel de instrumentação. 


\subsubsection{Painel de Instrumentação}

A figura 5.10, apresenta o painel de instrumentação do MB, elaborado segundo os requisitos funcionais da seção 3.2.1.

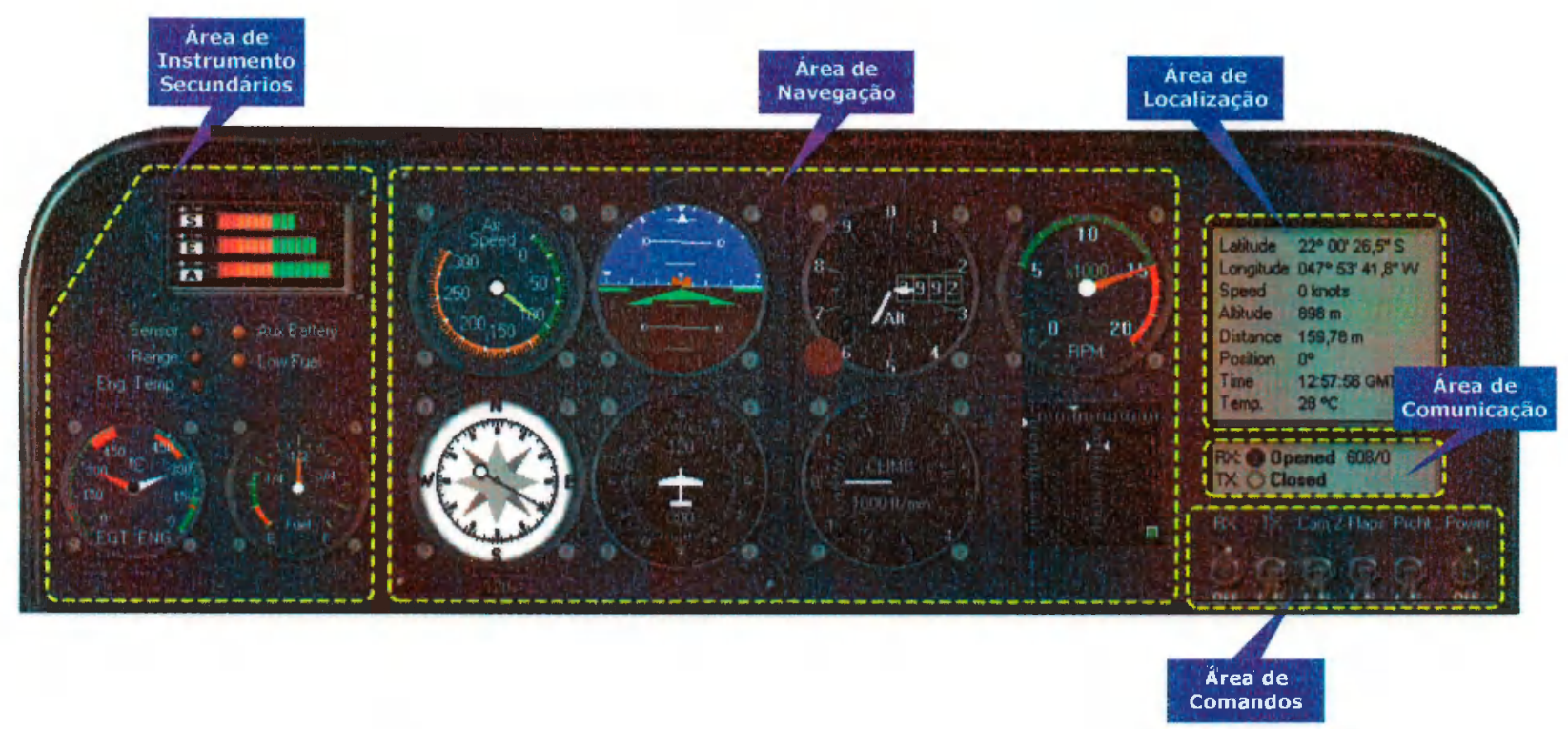

Figura 5.10: Painel de instrumentação do MB.

Para facilitar a leitura dos instrumentos, o painel de instrumentação foi dividido em cinco áreas lógicas:

- Área de Navegação: É estrategicamente localizada na parte central do painel de instrumentação, para facilitar a leitura dos instrumentos mais utilizados na realização de um vôo. Esses instrumentos são: indicador de velocidade do ar, bússola, horizonte artificial, bússola giroscópica, altímetro, indicador de velocidade vertical, RPM e indicador de posição do joystick;

- Área de Localização: Onde são apresentados todos os dados utilizados para a localização da aeronave. Esses dados são compostos pelos dados GPS recebidos do MA. A partir dos dados GPS, a posição e a distância da aeronave em relação à estação de solo são calculadas e apresentadas nessa área do painel de instrumentação. Por motivos de estética e de economia de espaço, a temperatura externa da aeronave também é apresentada nessa área do painel;

- Área de Comunicação: Local onde são apresentados os dados referentes ao canal de comunicação, como por exemplo, se os canais estão abertos/fechados (TX e RX), a quantidade de pacotes recebidos $(\mathrm{RX})$ e a quantidade de pacotes descartados $(\mathrm{RX})$; 
- Área de Comandos: É localizada na parte inferior direita do painel de instrumentação onde estão colocadas chaves do tipo ON/OFF que realizam as funções de abrir/fechar os canais de comunicação (TX e RX), alternar a câmera de vídeo da aeronave, acionar os flaps da aeronave, abrir o pára-quedas e finalizar o sistema;

- Área de Instrumentos Secundários (amarelo): Localizada à esquerda no painel de instrumentação, é composta pelos leds de alerta e pelos instrumentos de medição de quantidade (combustível, carga de baterias e temperatura).

\subsubsection{Painel de Apresentação de Falhas}

Durante um vôo, caso ocorra uma falha em algum sensor da aeronave, o led Sensor, localizado na área de instrumentos secundários do painel de instrumentação, começa a piscar. Para identificar qual sensor está com problema, basta "clicar" sobre esse led. Um painel (figura 5.11) apresentará um conjunto de leds onde cada led representa um sensor da aeronave. Quando algum desses leds estiver aceso, significa que o respectivo sensor da aeronave não está funcionando corretamente.

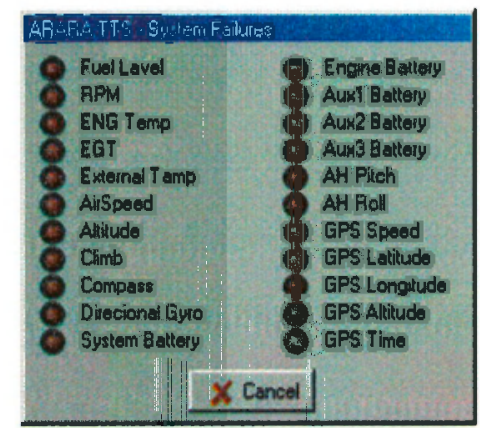

Figura 5.11: Painel de apresentação de falhas.

\subsubsection{Configurações Gerais}

A figura 5.12, apresenta a tela de configurações gerais do MB. Nela é possível configurar tanto parâmetros do MB como do MA. Se for realizada uma configuração nos parâmetros do MA o operador também pode enviar esses parâmetros pelo canal de comunicação ao próprio MA. Para tanto, a chave TX, localizada na área de comandos do painel de instrumentação, deve estar na posição $O N$. 


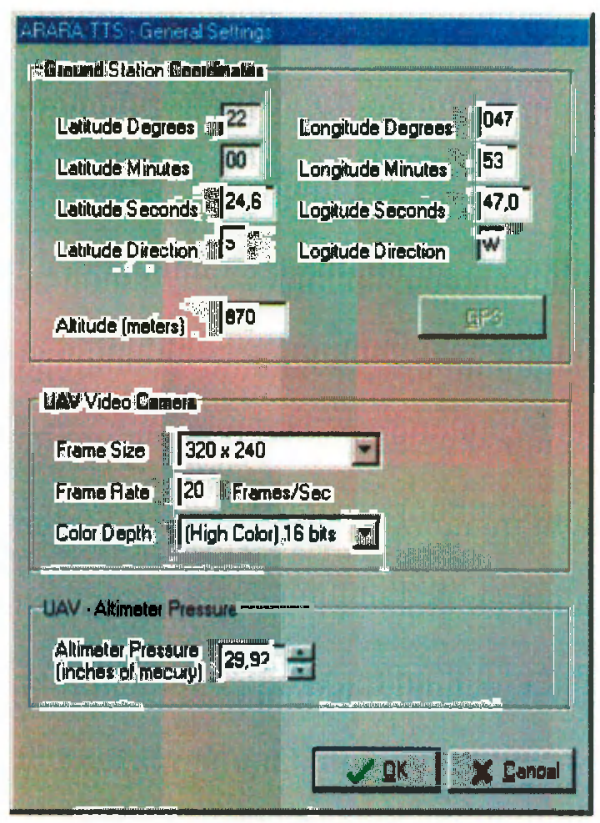

Figura 5.12: Tela de configurações gerais.

\subsubsection{Visualização de $\log$}

A figura 5.13, apresenta a tela utilizada para a visualização do arquivo de $\log$ da telemetria. Para visualizar um arquivo de $\log$, o operador deve pressionar o botão load e inserir o nome do arquivo desejado em uma caixa de diálogo de abertura de arquivo padrão.

\begin{tabular}{|c|c|c|c|c|c|}
\hline \multicolumn{6}{|c|}{ 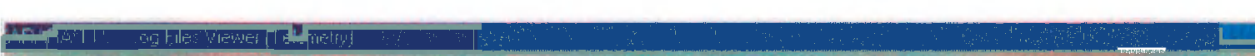 } \\
\hline$\angle$ Lood & \multicolumn{5}{|c|}{ 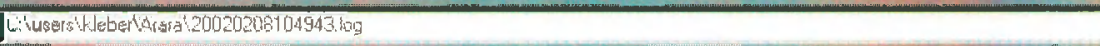 } \\
\hline & IOPS Longlude & TOPS Altude (m) & Jops The & \multicolumn{2}{|l|}{ Sequence Number } \\
\hline 127 & $047^{\circ} 55^{4}+2,83^{2}$ & $1292 \times 2=$ & $1252.44 .6 \mathrm{MT}$ & $248 \%$ a & \\
\hline 148 & $047^{\circ} 63^{4} 42,3^{\prime \prime} W$ & 702 & 12:52:45 5MTT & 248 & \\
\hline 140 & $047^{\circ} 53^{\circ} 42,3^{\prime \prime} \mathrm{W}$ & 702 & $1952.46 \mathrm{GMT}$ & 250 & \\
\hline 180 & $047^{\circ} 53^{\prime} 42,3^{n} \mathrm{~W}$ & 782 & 12:52:48 OMT & 261 & \\
\hline 181 & $047^{\circ} 83^{\prime} 42,3^{\prime \prime} W$ & 702 & 12:52:47 OMT & 262 & \\
\hline 162 & $047^{\circ} 63^{\circ} 42,3^{3 \prime} \mathrm{W}$ & 704 & 12:62:46 OMT & 253 & \\
\hline 163 & $047^{\circ} 53^{\prime} 42,3^{\prime \prime} W$ & 704 & $12: 52: 40$ OMT & 264 & \\
\hline 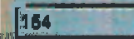 & $047^{\circ} 63^{\prime} 42,3^{3 \prime} \mathrm{W}$ & 706 & $12: 62: 40 \mathrm{OMT}$ & 266 & \\
\hline 150 & $047^{\circ} 53^{\prime} 42,3^{34}, W$ & 766 & 12:62:60 OMT & 268 & \\
\hline 1168: & $047^{\circ} 53^{\prime} 42,3^{n} \mathrm{~W}$ & 766 & 12:52:51 OMT & 267 & \\
\hline 1167 & $047^{*} 63^{\prime} 42,3^{\prime \prime} \mathrm{W}$ & 766 & 12:62:51 OMT & 258 & \\
\hline 168 & $047^{\circ} 63^{\prime} 42,3^{\prime \prime} \mathrm{W}$ & 760 & $12: 52: 52$ ONT & 250 & \\
\hline 180 & $047^{\circ} 83^{\prime} 42,3^{3} \mathrm{~W}$ & 780 & 12:62:63 OMT & 260 & \\
\hline 160 & $047^{\circ} 83^{1} 42,3^{m} \mathrm{~W}$ & 766 & 12:52:54 OMT & 261 & \\
\hline$\sqrt{101}$ & $047^{\circ} 83^{\prime} 42,3^{3} \mathrm{~W}$ & 701 & 12.52.54 OMT & 202 & \\
\hline 162 & $047^{\circ} 63^{\prime} 42,3^{\prime \prime} \mathrm{W}$ & 701 & $12.52 .56 \mathrm{OMT}$ & 263 & in \\
\hline [1] & 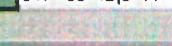 & & 830 & & Inin \\
\hline Number of Rer & $10 d x: 1556$ & & & $\sqrt{\text { Statistics }}$ & 2 close \\
\hline
\end{tabular}

Figura 5.13: Tela de visualização de $\log$. 


\subsubsection{Visualização de Estatísticas}

Após abrir um arquivo de log, utilizando a tela de visualização de log (figura 5.13), o operador pode escolher a opção de visualizar as estatísticas desse arquivo, pressionando o botão statistics. As estatísticas do arquivo de log mostram o valor máximo, o valor mínimo e a média aritmética de alguns dados do log. A figura 5.14, apresenta a tela de visualização de estatísticas.

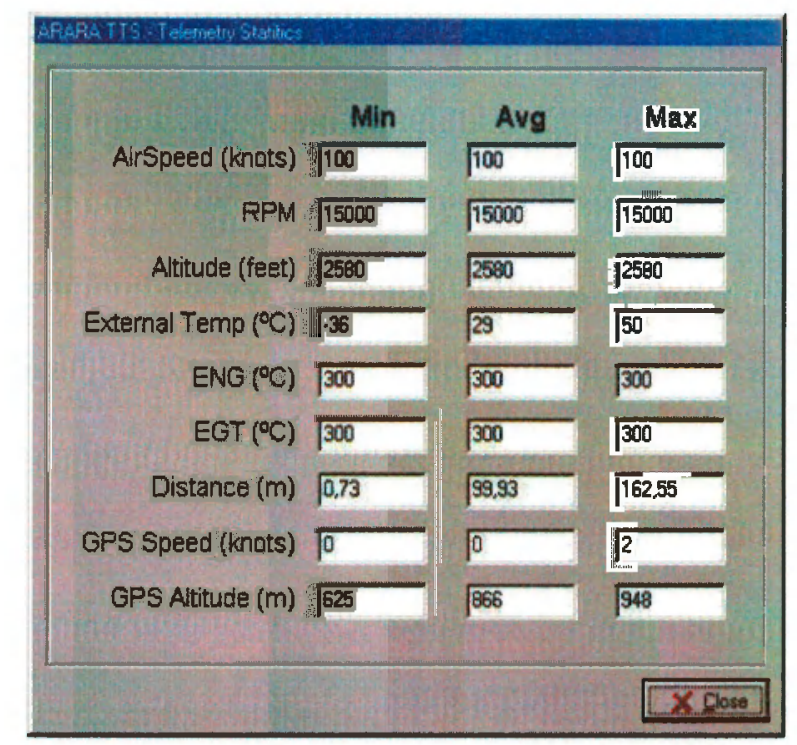

Figura 5.14: Tela de visualização de estatísticas.

\subsubsection{Configuração dos Parâmetros de Alerta}

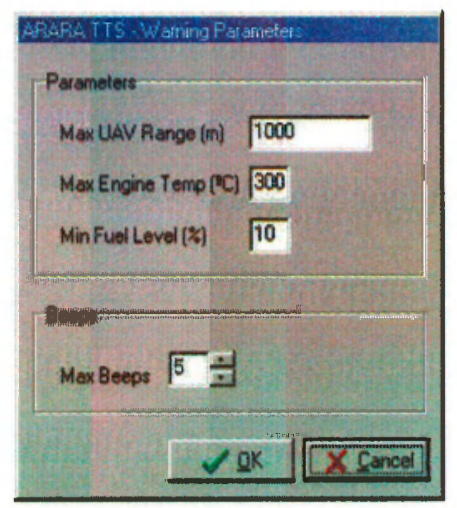

Figura 5.15: Tela de configuração dos parâmetros de alerta.

$\mathrm{Na}$ figura 5.15, é apresentada a tela de configuração dos parâmetros de alerta. Nessa tela o operador pode configurar alguns parâmetros que serão utilizados para a emissão de alertas. $\mathrm{O}$ 
operador pode, por exemplo, configurar a distância máxima permitida entre a aeronave e a estação de solo. Quando essa distância for excedida durante um vôo, o operador será alertado.

\subsubsection{Visualização de Imagens}

A figura 5.16, mostra a tela de visualização de imagens. Essa tela permite que o operador visualize imagens do tipo bmp ou jpg. Para abrir uma imagem, basta selecionar o nome do arquivo, na caixa de nomes, com um clique do mouse.

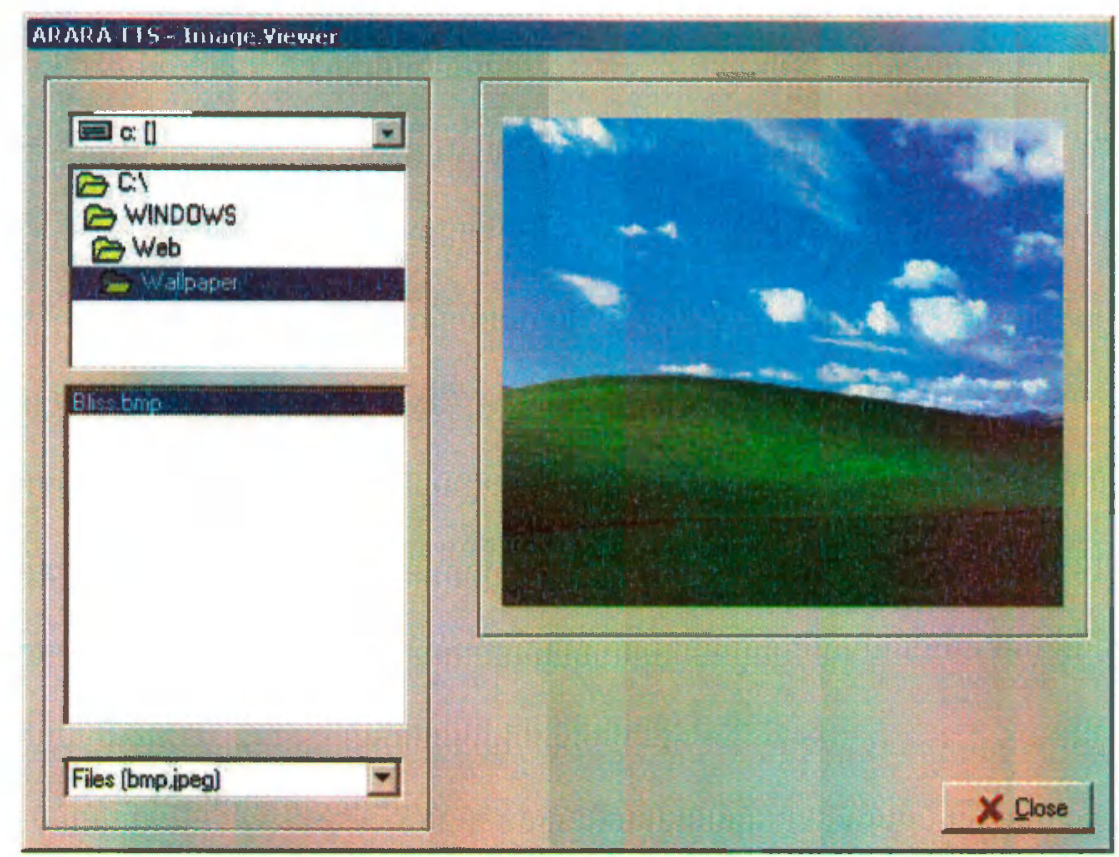

Figura 5.16: Tela de visualização de imagens.

\subsection{Testes e Validação do STT}

Devido à falta de recursos para aquisição de alguns componentes de hardware necessários para a implementação dos intrumentos de bordo da aeronave 'ARARA II, não foi possível realizar os testes do STT com a aeronave em vôo. Diante desta situação, optou-se por realizar uma simulação utilizando dois computadores interligados por um cabo serial, onde um computador executava o MA (representando a aeronave) e outro executava o MB.

Para simular o computador da aeronave, foi utilizado um Pentium $120 \mathrm{MHz}$, com $32 \mathrm{MBytes}$ de mémoria RAM e disco rígido de 1,5 GBytes. Para executar o software da estação de solo, foi utilizado um Pentium II $233 \mathrm{MHz}$, com 64 MBytes de memória RAM e disco rígido de 3 GBytes. 
Uma lista de atividades foi elaborada para realizar os testes do STT. Essas atividades são descritas a seguir:

- O STT - MA é iniciado - Nesse item, foi avaliado o comportamento do sistema durante a inicialização do mesmo. Foram avaliadas duas situações: com o MB inoperante e com o MB operante. Na primeira situação, o MA começou a transmitir a telemetria para a porta serial e ficou esperando os dados de telecomando, que não iriam chegar, devido ao MB estar inoperante. Na segunda situação, o MA começou a transmitir a telemetria para a porta serial e receber os dados de telecomando da porta serial. Em ambas as situações o MA não apresentou nenhum problema.

- O STT - MB é iniciado - O STT - MB foi iniciado sem apresentar nenhum problema. O painel de apresentação de vídeo foi inicializado juntamente com o painel de instrumentação.

- STT - MA e MB são desligados por falta de energia - Nesse item, foi avalido se o sistema tinha condições de ser reiniciado após uma queda de energia. Nesses testes os computadores do MA e do MB foram desligados abrutamente e reiniciados várias vezes. Nenhum arquivo foi corrompido e os sistemas voltaram a operar normalmente.

- O operador abre os canais de comunicação (TX e RX) do MB - Foram analisadas duas situações: com o MA operante e com o MA inoperante. Em ambas as situações, o MB abriu os canais de comunicação sem apresentar nenhum problema. Na segunda situação a telemetria não foi apresentada devido ao MA estar inoperante.

- O operador fecha os canais de comunicação durânte o vôo - Os canais de comunicação foram abertos e fechados várias vezes. O sistema efetou o reconhecimento dos pacotes sem apresentar nenhum erro.

- Funcionamento do STT em 24 horas initerruptas - O sistema se comportou normalmente durante 24 horas contínuas de funcionamento apresentando uma quantidade de perda de pacotes menor que $0,01 \%$.

- Simulação de falha de sensores no MB - Nesse item, foi avaliado o comportamento do MB diante de falhas dos sensores do MA. Um falha pode ocorrer, quando um sensor está informando valores fora do intervalo especificado no pacote de telemetria (Tabela 5.6) ou quando um sensor não está respondendo. Nesse sentido, foram testados os valores limite de cada sensor, para verificar se o MB, indicava corretamente, as falhas decorrentes de valores fora do intervalo especificado. Para simular os erros apresentados em função da inoperância 
de um sensor, os sensores do computador de bordo foram retidados. Em ambos os casos, as falhas foram apresentadas no MB.

- Configuração do MA a partir do MB - Quando o usuário decide configurar o MA, ele deve abrir a tela de configurações gerais do MB (figura 5.12), fazer as modificações desejadas e "clicar" no botão OK. Se o canal de comunicação TX estiver aberto, o usuário será questionado ser descja ou não enviar as configurações ao MA. Em caso afirmativo, ele deverá esperar a configuração ser enviada ao MA e aguardar uma menssagem de confirmação de configuração. Essa menssagem é gerada após o MB receber um confirmação do MA. Nos testes realizados, os sistemas se comportaram como previsto.

\subsection{Sumário}

Este capítulo apresentou os detalhes de implementação do STT. Neste sentido, foram apresentados o ambiente de implementação do STT, o projeto de hardware, os programas de transmissão de vídco pesquisados, o protocolo de comunicação utilizado para a transmissão de dados entre o MA e MB, a interface gráfica e os testes realizados com o STT.

No próximo capítulo são apresentadas as conclusões deste trabalho, suas contribuições e algu* mas sugestões para trabalhos futuros. 


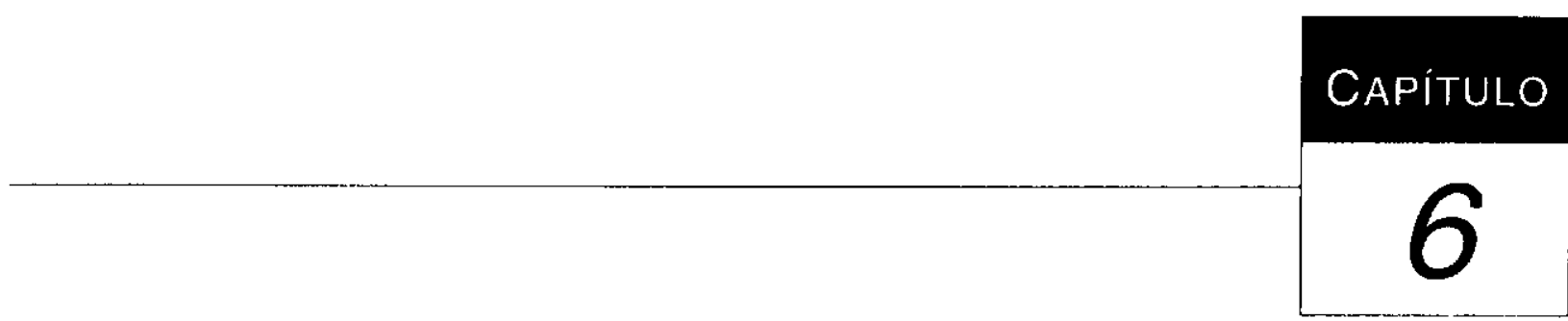

\section{Conclusões}

Neste trabalho foi desenvolvida uma extensão do STT para a transmissäo digital de dados. Para tanto, foi especificado e implementado um protocolo que coordenasse a transmissão entre o UAV e a estação de solo. O STT foi validado através de testes efetuados em um ambiente simulado.

Um dos objetivos iniciais deste trabalho, consistia na implementação do sistema de transmissão de vídeo digital para o projeto 'ARARA. Essa implementação seria baseada em bibliotecas e programas de domínio público. No início dessa pesquisa, acreditava-se que vários programas de domínio público estavam disponíveis; entretanto isso não ocorreu, provocando um esforço adicional de pesquisa e seu prolongamento muito além do planejado. Ao final da pesquisa, foram encontrados dois programas para transmissão de vídeo. Contudo, os mesmos não apresentam desempenho suficiente para transmissão de vídeo em tempo real, conforme os testes realizados.

Como a implementação de um sistema de captura, compressão e transmissão de vídeo digital demandaria mais tempo do que o disponível dentro de um trabalho de mestrado, essa etapa foi deixada para um trabalho futuro.

Durante o desenvolvimento da pesquisa, foi detectado que a primeira versāo do STT, desenvolvida por Ribeiro (2000), necessitaria de ajustes para suportar a transmissão de vídeo digital. Realizando uma análise mais detalhada na primeira versão do STT, percebcu-se que as modificaçōes necessárias não eram tão simples quanto pareciam. 
Baseado na pesquisa realizada, conclui-se que a transmissāo de vídeo digital realizada por software não é uma boa opção para o projeto ARARA, devido ao baixo desempenho dos programas disponíveis atualmente. Outras opções de transmissão de vídeo digital, como hardware e soft ware proprietário, não foram pesquisadas em detalhes, devendo fazer parte do trabalho futuro já mencionado.

A largura de banda do canal de transmissão ainda representa um obstáculo a ser superado. Os equipamentos de transmissão de dados disponíveis no mercado não satisfazem a todos os requisitos para utilização no projeto $A R A R A$. Equipamentos de baixo peso, baixo consumo de energia, tamanho pequeno e alcance adequado, normalmente apresentam uma largura de banda muito baixa para a transmissão de vídeo com uma resolução aceitável para a pilotagem dá aeronave.

Acredita-se que a melhor solução para manter o baixo custo do projeto ARARA ainda é a utilização do vídeo analógico que, apesar das suas desvantagens, apresenta boa relação custo/benefício.

Para resolver o problema da fase IV do projeto ARARA, onde as imagens digitais serão utili-zadas para a tomada de decisōes, sugere-se trabalhar com imagens estáticas ou imagens de vídeo com taxa de quadros muito baixa. Um trabalho neste sentido está sendo desenvolvido no âmbito do Laboratório de Computação de Alto Desempenho onde investiga-se a possibilidade de utilização da rede de telefonia celular para essa finalidade.

As seçōes 6.1 e 6.2, apresentam, respectivamente, as contribuiçōes mais relevantes deste trabalho e as sugestões para trabalhos futuros:

\subsection{Contribuições do Trabalho}

- Melhoria na interface do STT para permitir o vôo remotamente pilotado, sem visada direta da aeronave;

- Especificação e implementação do protocolo de comunicação utilizados na transmissão dos dados de telemetria e telecomandos entre a estação de solo e a aeronave;

- Implementação de uma interface para joystick, permitindo a pilotagem remota diretamente no computador sem a utilização de um equipamento de radio controle convencional;

- Avaliação de programas de domínio público para compactação e transmissão de vídeo e sua aplicabilidade para transmissão em tempo real;

- Documentação do sistema, utilizando notaçăo de análise estruturada, tornando mais fácil possíveis alterações de caracter evolutivo que se façam necessárias. 


\subsection{Sugestões para Trabalhos Futuros}

A seguir está relacionada uma série de trabalhos que podem dar continuidade ao trabalho até aqui desenvolvido:

- Desenvolver um Framework para telemetria e telecomandos que possa ser utilizado em vários tipos de veículos, sejam eles aéreos, marítimos ou terrestres;

- Implementar um hardware específico para a compressão de vídeo digital tendo como entrada uma câmera de vídeo padrão USB;

- Desenvolver uma interface de telecomando que proporcione as mesmas funções providas por equipamentos de rádio controle computadorizados, tais como ajustes de fim de curso dos servomecanismos, resposta a comandos exponencial ou com taxas variáveis, configurações de vôo programáveis pelo usuário (pouso, decolagem, vôo de cruzeiro), entre outras.

- Implementar uma interface gráfica tridimensional para a visualizaçāo dos arquivos de log. Nessa interface o operador poderia acompanhar a trajetória feita pela aeronave;

- Migrar o software da estação de solo para o sistema operacional Linux. Com o aparecimento do Borland Kylix, esta tarefa tornou-se menos complexa. Apesar do Kylix facilitar essa migração, ainda é necessário muito trabalho para o desenvolvimento de todos os componentes Delphi e OCX utilizados no software da estação de solo. 
ANATEL Quadro de atribuição de faixas de frequiência no brasil. Disponível em 18/08/2001 na URL: http://www . anatel.gov.br/index.asp?link=/Radiofrequencia/ qaff.paf, 2001.

AVAro, O.; Eleftheriadis, A.; Herpel, C.; Rajan, G.; Ward, L. MPEG-4 systems: overview. Signal Processing - Image Communication, v. 15, n. 4-5, p. 281-298, 2000.

BARBOSA, L. C. P. SINACOM - sistema de navegação e controle de missão do projeto ARARA Dissertação (mestrado), Instituto de Ciências Matemáticas e de Computação, Universidade de São Paulo, São Carlos - SP, Brasil, 2001.

Basso, A.; Cash, G. L.; Civanlar, M. R. Real-time MPEG-2 delivery based on RTP: implementation issues. Signal Processing - Image Communication, v. 15, n. 1-20, p. 165-178, 1999.

Battista, S.; CASAlino, F.; LANDE, C. MPEG-4: A multimedia standard for the third millennium, part 1. IEEE Multimedia, v. 6, n. 4, p. 74-83, 1999.

Battista, S.; Casalino, F.; LANDE, C. MPEG-4: A multimedia standard for the third millennium, part 2. IEEE Multimedia, v. 7, n. 1, p. 76-84, 2000.

BORLAND Borland Delphi 5.0. Disponível em 01/08/2000 na URL: http: / / www . borland. com/delphi, 2000.

BÖRöCZKY, L.; NGAI, A. Y. Comparison of MPEG-2 and M-JPEG video coding at low bit rates. SMPTE Journal, v. 108, n. 3, p. 161-164, 1999.

Cantu, M. Dominando o Delphi 2. São Paulo-SP, Brasil: Makron Books, 1997.

Cappelaro, E. A.; Mendonça, F. C.; TeiXeira, J. Câmeras digitais. Disponível em 14/01/2002 na URL: http://www.educar.sc.usp.br/licenciatura/trabalhos/camera.htm, 1997. 
CASElla, I. R. S. Analise de um método de aquisição em dois estágios para uma sistema DS/CDMA. Dissertação (mestrado), Escola Politécnica - Departamento de Engenharia Eletrônica, Universidade de São Paulo, São Paulo - SP, Brasil, 1998.

Chappelu, D. Undertanding ActiveX and OLE. Strategic Technology Series. Redmond - WA, USA: Microsoft Press, 1996.

CIsco Designing internetworks for multimedia. Disponível em 18/08/2001 na URL: http: //www.cisco.com/univercd/cc/td/doc/cisintwk/idg4/nd2013.pdf, 2001.

Cote, G.; Erol, B.; Gallant, M.; Kossentini, F. H.263+: Video coding at low bit rates. IEEE Transactions on Circuits and Systems for Video Technology, v. 8, n. 7, p. 849-866, 1998.

Ebrahimi, T.; KunT, M. Visual data compression for multimedia applications. Proceedings of the IEEE, v. 86, n. 6, p. 1109-1125, 1998.

FAROUDJA, Y. C. NTSC and beyond. IEEE Transactions on Consumer Electronics, v. 34, n. 1, p. $166-176,1988$.

FURHT, B. A survey of multimedia compression techniques and standards - part I: JPEG. RealTime Imaging, v. 1, n. 1, p. 49-67, 1995.

Goularte, R.; Moreira, E. S. Produção de vídeo digital: teoria e prática. Notas Didáticas do ICMC-USP 30, Instituto de Ciências Matemáticas e de Computação, Universidade de São Paulo, São Carlos - SP, Brasil, 1998.

JACK, K. Video demystified. 2 ed. Eagle Rock - VA, Canadá: LLH Technology Publishing, 1996.

LANTAU, G. FFMPEG - streaming multimedia system. Disponível em 23/01/2001 na URL: ht tp: //f fmpeg. sourceforge. net, 2001.

LU, Y.; Chen, T. Q.; WeIMAN, C. F. R.; NovaK, B. Video compression for remotely controlled vehicles. Real-Time Imaging, v. 5, n. 3, p. 155-165, 1999.

Luther, A. C. Using digital video. Boston-MA, USA, 1995.

Mackie, D.; May, B.; Franquet, A. M. MPEG4IP - open streaming video and audio. Disponível em 28/02/2001 na URL: http: //mpeg 4 ip. sourceforge . net, 2001.

MAJIC, G. Gauges for aircraft. Disponivel em 15/05/2001 na URL: http://www. globalmajic. com, 2001.

MARTinez, A. A. G. Seqüências de códigos para uso em comunicação por espalhamento espectral. Dissertação (mestrado), Escola Politécnica - Departamento de Engenharia Eletrônica, Universidade de São Paulo, São Paulo - SP, Brasil, 1997.

Mitchell, J. L.; Pennebaker, W. B.; FogG, C. E. MPEG video: compression standart. New York - NY, USA: Chapman \& Hall, digital Multimedia Standards Series, 1996. 
NERIS, L. O. Um piloto automático para as aeronaves do projeto ARARA . Dissertação (mestrado), Instituto de Ciências Matemáticas e de Computação, Universidade de São Paulo, São Carlos - SP, Brasil, 2001.

Pennebaker, W. B.; Mitchell, J. L. JPEG still image data compresion standard. New York - NY, USA: Van Nostrand Reinhold, 1993.

Pereira, F. MPEG-4: Why, what, how and when? Signal Processing-Image Communication, v. 15, n. $4-5$, p. $271-279,2000$.

PRESSMAN, R. S. Software engineering: a practitioner's approach. 4 ed. New York - NY: McGraw-Hill, 1997.

RABBANI, M.; JONES, P. W. Digital image compression techiniques. Spie Optical Engineering Press, bellingham - WA, USA, 1991.

RAPPAPORT, T. S. Wireless communications - principles and practice. Upper Saddle River NJ, USA: Prentice Hall, 1996.

RIBEIRO, R. E. STT - um sistema para telemetria e telecomando de aeronaves do projeto ARARA . Dissertação (mestrado), Instituto de Ciências Matemáticas e de Computação, Universidade de São Paulo, São Carlos - SP, Brasil, 2000.

SoUZA, N. P. Sistemas alternativos para obtenção de imagem aérea e sua aplicação na agricul. tura. Dissertação (mestrado), Instituto de Ciências Matemáticas e de Computação, Universidade de São Paulo, São Carlos - SP, Brasil, 1999.

TAnenbaum, A. S. Computer networks. 3 ed. Upper Saddle River-NJ, USA: Prentice Hall, 1996.

TEKTRONIX A guide to MPEG fundamentals and protocol analysis. Disponível em 18/08/2001 na URL: http://www.tek.com/Measurement/App_Notes/ mpegfund/25W114180.pdf, 2001.

TUDOR, P. MPEG-2 video compression. IEE Electronics \& Communication Engineering Journal, v. 7, n. 6, p. 257-264, 1995.

WARD, P. T.; MELloR, S. Structured development for real time. New York - NY: Yourdon Press, 1985.

YACOUB, M. D. Foundations of mobile radio engineering. Boca Raton - FL, USA: CRC Press, 1993.

ZORAN Megapixel CMOS image sensors. Disponível em 14/01/2002 na URL: http://www.zoran.com/products/camera/arquity.asp, 2001. 


APENDICE

Aeronave 'ARARA II

Este apêndice apresenta a descrição da aeronave 'ARARA II, utilizada neste projeto. Ela foi construída no Laboratório de Computação de Alto Desempenho (LCAD) do Instituto de Ciências Matemáticas e de Computação da USP - São Carlos e foi projetada de forma a minimizar custos e diminuir o tempo de construção.

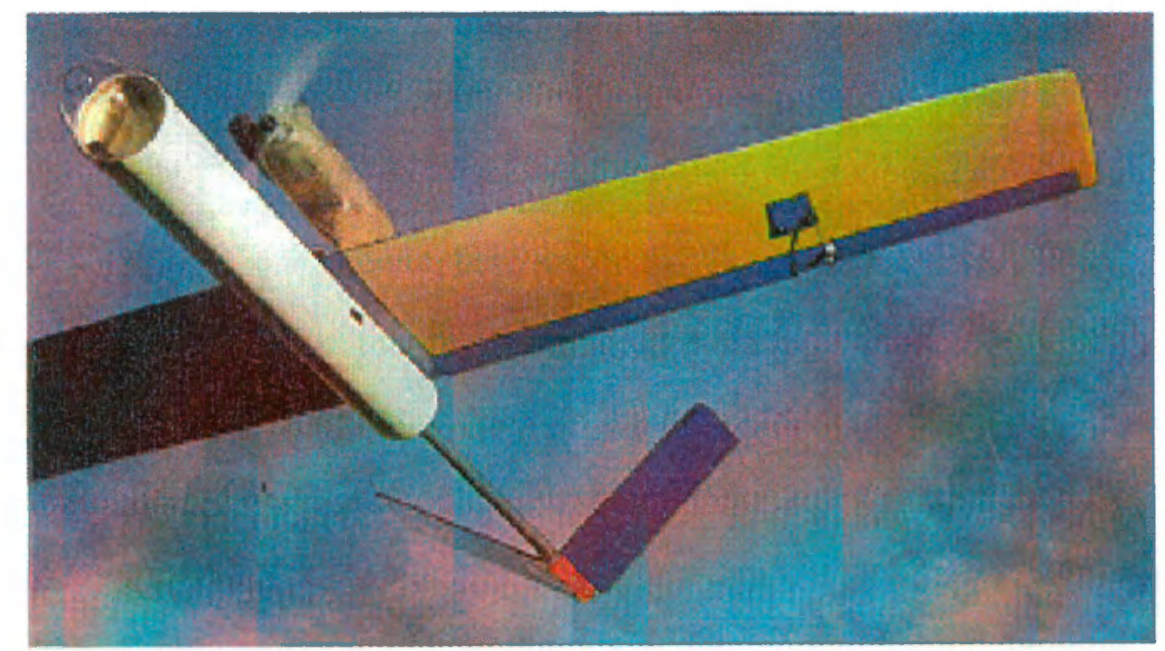

Figura A.1: Aeronave 'ARARA II.

Ilustrada na figura A.1, esta aeronave é composta em sua estrutura de materiais simples e de fácil manuseio, possui boa manobrabilidade, sustentação e alta resistência a quedas. Sua fuselagem 
é composta de um tubo de PVC comum de 1,3 milímetros de espessura, onde são abrigados os dispositivos eletrônicos. Um tubo de alumínio de 1 milímetro de espessura conecta a cauda à fuselagem da aeronave.

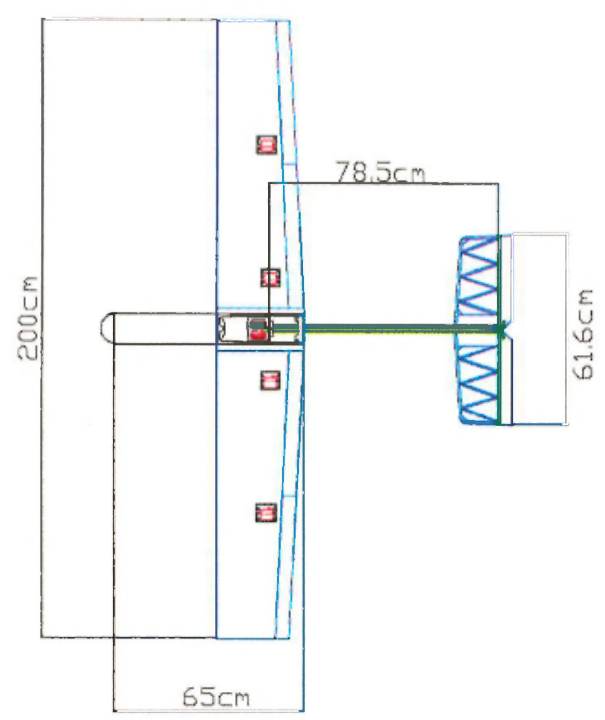

Figura A.2: Dimensões da aeronave 'ARARA II.

As asas são de isopor revestido por madeira e plástico adesivo. Devido à instalação de câmeras em sua parte frontal, o motor está posicionado sobre as asas. O seu peso total corresponde a 4 $\mathrm{Kg}$, podendo transportar até $1,5 \mathrm{~kg}$ de carga útil. A figura A.2 apresenta as dimensões exatas da aeronave 'ARARA II.

Empregada principalmente no monitoramento, inspeção e coleta de dados em áreas desprovidas de locais de pouso, a aeronave 'ARARA II não possui sistemas de aterrissagem (trem de pouso). A sua decolagem pode ser realizada com o auxílio de uma catapulta. O seu pouso é realizado através de um pára-quedas instalado na fuselagem. 


\begin{tabular}{l|l|l|} 
APENDICE \\
\hline
\end{tabular}

\section{Dicionário de Dados}

\section{B.1 MA (Módulo Aéreo)}

\section{B.1.1 Depósitos de Dados}

- Buffer de Quadros

Descrição: Armazena os quadros intra

Registro(s): Registros múltiplos

Representação: Quadro Intra

\section{- Buffer de Dados dos Sensores}

Descrição: Armazena os dados dos sensores da aeronave que foram coletados

Registro(s): Registro único

Representação: Dados dos Sensores 


\section{- Configuração do Sistema}

Descrição: Armazena os parâmetros necessários para a configuração do sistema Registro(s): Registro único

Representação: Dados de Configuração + Número de Seqüência do Pacote

\section{- Telecomandos}

Descrição: Armazena os dados de telecomando enviados pelo MB

Registro(s): Registro único

Representação: Dados de Telecomando

\section{- Telemetria}

Descrição: Armazena os dados de telemetria que serão enviados para o MB

Registro(s): Registro único

Representação: Dados da Telemetria

\section{- Relógio}

Descrição: Possui a hora atual do sistema

Registro(s): Registro único

Representação: Tempo

\section{B.1.2 Fluxos de Dados}

\section{- Calcular CRC}

Descrição: Solicita o cálculo do CRC

Processo(s): $\quad$ 1.1.1 - Receber Pacote de Dados (Saída)

1.1.2 - Calcular CRC do Pacote (Entrada)

Representação: *Fluxo de Controle* 
- Configuração de Vídeo

Descrição: Utilizada para configurar a compressão de vídeo da aeronave

Processo(s): $\quad$ 1.4.3 - Comprimir Interframe (Entrada)

1.4.4 - Comprimir Intraframe (Entrada)

Representação: Tamanho do Quadro + Taxa de Quadros + Profundidade de Cores

\section{- Configurar Sistema}

Descrição: Dispara o processo que configura os sensores da aeronave

Processo(s): $\quad$ 1.1.1 - Receber Pacote de Dados (Saída)

1.5.2 - Configurar Sensores (Entrada)

Representação: *Fluxo de Controle*

\section{- CRC}

Descrição: $\quad$ CRC de 16 bits para verificação da integridade do pacote de dados

Processo(s): $\quad$ 1.1.2 - Calcular CRC do Pacote (Saída)

1.1.4 - Enviar Pacote de Dados (Entrada)

Representação: Inteiro Curto

\section{- Dados da Telemetria}

Descrição: Dados de telemetria da aeronave que serão transmitidos para o MB

Processo(s): $\quad$ 1.1.3 - Armazenar Dados da Telemetria (Saída)

1.1.4 - Enviar Pacote de Dados(Entrada)

Representação: Dados dos Sensores + Número de Sequiência do Pacote + Status dos Sensores *definido no $\mathrm{MB}^{*}$

\section{- Dados de Configuração}

Descrição: Utilizados para a configuração da aeronave

Processo(s): $\quad$ 1.1.1 - Receber Pacote de Dados (Saída)

$$
\text { 1.5.2 - Configurar Sensores (Entrada/Saída) }
$$

Representação: Configuração de Vídeo + Configuraçāo da Estação de Solo 


\section{- Dados de Telecomando}

Descrição: Depois de transformado em pulsos elétricos, sāo utilizados para movimentar os servomotores da aeronave e ativar/desativar dispositivos do tipo ON/OFF

Processo(s): $\quad$ 1.1.1 - Receber Pacote de Dados (Saída)

1.2.1 - Movimentar Servomotores (Entrada)

Representação: Canais Percentuais + Canais ON/OFF

\section{- Dados dos Sensores}

Descrição: Dados obtidos dos sensores da aeronave

Processo(s): 1.1 .3 - Armazenar Dados da Telemetria (Entrada)

1.3.2 - Estruturar Dados dos Sensores (Saída)

\subsection{2 - Configurar Sensores (Entrada)}

Representação: Nível de Combustível *definido no $\mathrm{MB}^{*}+$ Dados do Motor + Temperatura Externa + Velocidade + Altitude (em pés) + Variação de Atitude + Bússola + Bússola Giroscópica + Bateria do Sistema + Bateria do Motor + Baterias Auxiliares * 3 baterias* + Horizonte Artificial + Dados do GPS

\section{- Dados não Formatados dos Sensores}

Descriçāo: Dados obtidos dos sensores da aeronave. Esse dados não possuem nenhuma formatação

Processo(s): $\quad$ 1.3.1 - Ler Dados dos Sensores (Entrada)

Representação: *cada sensor tem um formato de dados específico determinado pelo fabricante/desenvolvedor*

\section{- Fluxo de Vídeo Analógico}

Descrição: $\quad$ Fluxo de vídeo analógico da câmera de vídeo da aeronave

Processo(s): $\quad$ 1.4.1 - Digitalizar Vídeo (Entrada)

Representação: *Vídeo Composto*

\section{- Fluxo Elementar de Vídeo}

Descrição: Fluxo de vídeo sem informações de tempo

Processo(s): $\quad 1.4 .5$ - Ordenar Quadros (Saída)

$$
\text { 1.4.6 - Adicionar Informações de Tempo (Entrada) }
$$


Representação: *Depende do algoritmo de compressão adotado*

\section{- Fluxo de Vídeo Digital Comprimido}

Descrição: Fluxo de vídeo com informações de tempo

Processo(s): $\quad$ 1.4.6 - Adicionar Informações de Tempo (Saída)

\subsection{7 - Enviar Pacote de Vídeo (Entrada)}

Representação: *Depende do algoritmo de compressão adotado*

\section{- Número de Seqüência do Pacote}

Descrição: $\quad$ É incrementado todas as vezes que um Pacote de Dados (uplink) contendo Dados de Configuração chegar (na aeronave). Como esse número sempre é transmitido para a estação de solo (MB), é possível saber se os Dados de Configuração foram recebidos pela aeronave

Processo(s): $\quad$ 1.1.3-Armazenar Dados da Telemetria (Entrada)

\subsection{1 - Incrementar Número de Seqüência (Entrada/Saída)}

Representaçāo: Palavra

\section{- Pacote de Dados (downlink)}

Descrição: Pacote de dados enviado do MA para o MB

Processo(s): $\quad$ 1.1.4 - Enviar Pacote de Dados (Sá́da)

Representação: DLE + STX + Dados da Telemetria + DLE + ETX + CRC

\section{- Pacote de Dados (uplink)}

Descrição: $\quad$ Pacote de dados enviado do MB para o MA

Processo(s): $\quad 1.1 .1$ - Receber Pacote de Dados (Entrada)

Representação: DLE + STX + [ Dados de Telecomando I Dados de Configuração ] + DLE + $\mathrm{ETX}+\mathrm{CRC}$

\section{- Pacote de Vídeo}

Descrição: $\quad$ Pacote de vídeo digital comprimido enviado do MA para o MB

Processo(s): $\quad$ 1.4.7 - Enviar Pacote de Vídeo (Saída)

Representação: *Depende do algoritmo de compressão adotado* 
- Pixels

Descrição: $\quad$ Sequiência de pixels

Processo(s): $\quad$ 1.4.1 - Digitalizar Vídeo (Saída)

1.4.2 - Decidir Compressão (Entrada)

Representação: $\{\text { Pixel }\}^{n}$

\section{- Quadro}

Descrição: Quadro de vídeo digital não comprimido

Processo(s): $\quad 1.4 .2$ - Decidir Compressão (Saída)

1.4.3 - Comprimir Interframe (Entrada)

1.4.4 - Comprimir Intraframe (Entrada)

Representação: $\{\text { Pixel }\}^{\text {TamanhodoQuadro }}$

\section{- Quadro Inter}

Descriçāo: Quadro de vídeo sem redundância temporal

Processo(s): $\quad$ 1.4.3 - Comprimir Interframe (Saída)

1.4.4 - Comprimir Intraframe (Entrada)

Representação: *Depende do algoritmo de compressão adotado*

\section{- Quadro Intra}

Descrição: Quadro de vídeo sem redundância espacial

Processo(s): $\quad$ 1.4.4 - Comprimir Intraframe (Saída)

$$
\text { 1.4.5 - Ordenar Quadros (Entrada) }
$$

Representação: *Depende do algoritmo de compressão adotado*

\section{- Sequiência de Bytes}

Descrição: Seqüencia de bytes

Processo(s): $\quad$ 1.1.1 - Receber Pacote de Dados (Saída)

1.1.2 - Calcular CRC do Pacote (Entrada)

1.3.1 - Ler Dados dos Sensores (Saída)

Representação: $\{[0|1| \ldots \mid 255]\}^{n}$ 


\section{- Sistema Configurado}

Descrição: Indica que os sensores já foram configurados

Processo(s): $\quad$ 1.5.1 - Incrementar Número de Sequiência (Entrada)

$$
\text { 1.5.2 - Configurar Sensores (Saída) }
$$

Representação: *Fluxo de Controle*

\section{- Status do CRC}

Descrição: Indica se o CRC calculado é válido ou não

Processo(s): $\quad$ 1.1.1 - Receber Pacote de Dados (Entrada)

$$
\text { 1.1.2 - Calcular CRC do Pacote (Saída) }
$$

Representação: *Fluxo de Controle*

\section{- Telecomandos}

Descrição: Sinais de pulso variável (em milisegundos) que movimentam os servomotores Processo(s): $\quad$ 1.2.1 - Movimentar ServoMotores (Saída)

Representação: [ $1 \mid 1.11 \ldots$ | 2 ]

\section{- Tempo}

Descrição: Tempo atual

Processo(s): $\quad$ 1.1.4 - Enviar Pacote de Dados (Entrada)

1.3.1 - Ler Dados dos Sensores (Entrada)

1.4.6 - Adicionar Informações de Tempo (Entrada)

Representação: Hora + Minuto + Segundo + Milésimos de Segundo

\section{- Tipo do Quadro}

Descrição: $\quad$ Tipo do quadro a ser comprimido

Processo(s): $\quad 1.4 .2$ - Decidir Compressão (Saída)

1.4.3 - Comprimir Interframe (Entrada)

Representação: [ P | B ] 


\section{B.2 MB (Módulo Base)}

\section{B.2.1 Depósitos de Dados}

- Arquivo de Log

Descrição: $\quad$ Armazena os dados de $\log$

Registro(s): Registros múltiplos

Representação: Dados de Log + Endereço do Arquivo de Log

\section{- Arquivo de Imagem}

Descrição: Arquivo de imagem .bmp ou .jpg

Registro(s): Registros múltiplos

Representação: Dados da Imagem

\section{- Buffer de Vídeo}

Descrição: Armazena o fluxo de vídeo digital comprimido

Registro(s): Registros múltiplos

Representação: Fluxo de Vídeo Digital Comprimido

\section{- Configuração do Sistema}

Descrição: Armazena os dados necessários para a configuração do MB

Registro(s): Registro único

Representação: Dados de Configuração

\section{- Estatística}

Descrição: $\quad$ Armazena alguns dados estatísticos de um arquivo de log

Registro(s): Registro único

Representação: Dados Estatísticos

\section{- Relógio}

Descrição: Possui a hora atual do sistema

Registro(s): Registro único

Representação: Tempo 


\section{- Telecomandos}

Descrição: $\quad$ Armazena os dados de telecomando que são enviados para o MA

Registro(s): Registro único

Representação: Dados de Telecomando

\section{- Telemetria}

Descrição: Armazena os dados de telemetria que são recebidos do MA

Registro(s): Registro único

Representação: Dados da Telemetria

\section{B.2.2 Fluxos de Dados}

\section{- Aguardar Confirmação}

Descrição: Quando os dados de configuração são enviados para o MA, esse fluxo de controle ativa o processo que verifica se o número de sequiência do pacote de telemetria foi incrementado.

Processo(s): $\quad$ 1.6.2 - Identificar Comandos (Saída) 1.6.4 - Verificar Número de Seqüência (Entrada)

Representação: *Fluxo de Controle*

\section{- Calcular CRC}

Descrição: $\quad$ Solicita o cálculo do CRC

Processo(s): $\quad$ 1.6.2 - Enviar Pacote de Dados (Saída)

1.6.3 - Calcular CRC do Pacote (Entrada)

1.6.5 - Receber Pacote de Dados (Saída)

Representação: *Fluxo de Controle*

\section{- Calcular Posição}

Descrição: Ativa o processo que faz os cálculos para encontrar a posição da aeronave

Processo(s): $\quad$ 1.7.2 - Atualizar Instrumentos (Saída)

- 1.7.7 - Calcular a Posição da Aeronave (Entrada)

Representação: *Fluxo de Controle* 


\section{- Cancelar Confirmação}

Descrição: Cancela a verificação do número de sequiência

Processo(s): $\quad$ 1.6.1 - Identificar Comandos (Saída)

- 1.6.4 - Verificar Número de Seqüência (Entrada)

Representação: *Fluxo de Controle*

\section{- Comandos do Operador}

Descrição: Ações do operador que modificam os dados do MA ou do MB

Processo(s): $\quad$ 1.6.1 - Identificar Comandos (Entrada)

Representação: * Todas ações do operador que modificam os dados de telecomando ou os dados de configuração*

\section{- Configuração Confirmada}

Descrição: Indica os dados de configuração foram recebidos pelo MA

Processo(s): $\quad 1.6 .4$ - Verificar Número de Seqüiência (Saída)

Representação: *Fluxo de Controle*

\section{- Configurar Sistema}

Descrição: Faz com que o processo que envia os pacotes de dados envie um pacote de Dados de Configuração ao invés de um pacote Dados de Telemetria

Processo(s): 1.6.1 - Identificar Comandos (Saída)

1.6.2 - Enviar Pacote de Dados (Entrada)

Representação: *Fluxo de Controle*

\section{- Coordenadas da Aeronave}

Descrição: Coordenadas da aeronave

Processo(s): $\quad$ 1.7.2 - Atualizar Instrumentos (Saída)

1.7.3 - Verificar Distância da Aeronave (Entrada)

1.7.7 - Calcular a Posição da Aeronave (Entrada)

Representação: Latitude + Longitude + Altitude (metros) 


\section{- Coordenadas da Estação de Solo}

Descrição: Coordenadas geográficas da estação de solo

Processo(s): $\quad$ 1.7.3 - Verificar Distância da Aeronave (Entrada)

1.7.7 - Calcular Posição da Aeronave (Entrada)

1.7.8 - Gravar Registro de Log (Entrada)

Representação: Latitude + Longitude + Altitude (metros)

\section{$\bullet$ CRC}

Descrição: $\quad$ CRC de 16 bits para verificação da integridade do pacote de dados

Processo(s): $\quad$ 1.6.2 - Enviar Pacote de Dados (Entrada)

1.6.3 - Calcular CRC do Pacote (Saída)

Representação: CRC *definido no MA*

\section{- Dados de Configuração}

Descrição: $\quad$ Parâmetros necessários para a configuração do MB

Processo(s): $\quad$ 1.6.1 - Identificar Comandos (Saída)

\subsection{2 - Enviar Pacote de Dados (Entrada)}

Representação: Posição da Aeronave + Coordenadas da Estação de Solo + Altitude (metros) + Pressão Atmosférica + Nível Mínimo de Combustível + Distância da Aeronave + Distância Máxima Permitida + Temperatura Máxima Permitida + Configuração de Vídeo *definido no MA*

\section{- Dados da Imagem}

Descrição: Dados necessários (além dos pixels) para formar uma imagem do tipo .bmp ou .jpg

Processo(s): $\quad$ 1.10.2 - Colocar Cabeçalho (Saída)

1.11.2 - Ler Arquivo de Imagem (Entrada)

Representação: *Imagem do tipo .bmp ou .jpg* 


\section{- Dados da Telemetria}

Descrição: Dados de telemetria da aeronave enviados pelo MA

Processo(s): $\quad$ 1.6.5 - Receber Pacote de Dados (Saída)

1.7.2 - Atualizar Instrumentos (Entrada)

1.7.4 - Verificar Falhas nos Sensores (Entrada)

1.7.8 - Gravar Registro de Log (Entrada)

Representação: Dados da Telemetria *definido no MA*

\section{- Dados de Log}

Descrição: $\quad$ Dados que devem ser armazenados em um arquivo de $l o g$

Processo(s): $\quad$ 1.7.8 - Gravar Registro de Log (Saída)

1.9.2 Ler Arquivo de Log (Entrada)

1.12.2 Ler Arquivo de Log (Entrada)

Representação: Dados da Telemetria + Coordenadas da Estação de Solo + Distância da Aeronave + Posição da Aeronave

\section{- Dados de Telecomando}

Descrição: Depois de transformado em pulsos elétricos, são utilizados para movimentar os servomotores da aeronave e ativar/desativar dispositivos do tipo ON/OFF

Processo(s): 1.6.1 - Identificar Comandos (Saída)

\subsection{2 - Enviar Pacote de Dados (Entrada)}

Representação: Dados de Telecomando *definido no MA*

\section{- Dados Estatísticos}

Descriçāo: $\quad$ Dados estatísticos obtidos de um arquivo de $\log$

Processo(s): $\quad$ 1.12.7 - Apresentar Estatísticas (Entrada)

Representação: Valor Mínimo + Valor Médio + Valor Máximo

\section{- Dados Estatísticos Inicializados}

Descrição: Dados estatísticos inicializados

Processo(s): $\quad$ 1.12.6 - Apresentar Estatísticas (Saída)

Representação: Dados Estatísticos 


\section{- Distância da Aeronave}

Descrição: Distância da Aeronave em Relação a Estação de Solo

Processo(s): $\quad$ 1.7.3 - Verificar Distância da Aeronave (Saída)

1.7.8 - Gravar Registro de Log (Entrada)

Representação: Real

\section{- Distância Excedida}

Descrição: Indica que a distância máxima permitida entre a aeronave e a estação de solo foi excedida

Processo(s): $\quad$ 1.7.3 - Verificar Distância da Aeronave (Saída)

Representação: *Fluxo de Controle*

\section{- Distância Máxima Permitida}

Descrição: Maior distância permitida entre a aeronave e a estação de solo

Processo(s): $\quad$ 1.7.3 - Verificar Distância da Aeronave (Entrada)

Representação: Distância da Aeronave

\section{- Endereço do Arquivo de Imagem}

Descrição: $\quad$ Endereço do arquivo de imagem no disco rígido

Processo(s): $\quad$ 1.11.1 - Abrir Arquivo de Imagem (Entrada)

Representação: *Depende do sistema operacional*

\section{- Endereço do Arquivo de Log}

Descrição: $\quad$ Endereço do arquivo de $\log$ no disco rígido

Processo(s): 1.9 .1 - Abrir Arquivo de Log (Entrada)

1.12.1 - Abrir Arquivo de Log (Entrada)

Representação: *Depende do sistema operacional*

\section{- Estatísticas}

Descrição: Interface gráfica para mostrar os dados estatísticos

Processo(s): $\quad$ 1.12.7 - Apresentar Estatísticas (Saída)

Representação: *Interface gráfica para mostrar os dados estatísticos* 


\section{- Fluxo de Vídeo Digital}

Descrição: $\quad$ Fluxo de vídeo digital pronto para apresentação

Processo(s): $\quad$ 1.8.4 - Compressão Interframe Inversa (Saída)

Representação: $\left\{\text { Quadro *definido no } \mathrm{MA}^{*}\right\}^{n}$

\section{- Fluxo de Vídeo Digital Comprimido}

Descrição: $\quad$ Fluxo de vídeo com informações de tempo

Processo(s): $\quad$ 1.8.1 - Receber Pacote de Vídeo (Saída)

1.8.2 - Identificar Quadros (Entrada)

Representação: Fluxo de Vídeo Digital Comprimido *definido no MA*

\section{- Gravar Log}

Descrição: $\quad$ Ativa o processo que grava um registro de log

Processo(s): $\quad$ 1.7.2 - Atualizar Instrumentos (Saída)

1.7.8 - Gravar Registro de Log (Entrada)

Representação: *Fluxo de Controle*

\section{- Handler do Arquivo de Imagem}

Descrição: $\quad$ É utilizado para manipular o arquivo de imagem

Processo(s): $\quad$ 1.11.1 - Abrir Arquivo de Imagem (Saída)

1.11.2 - Ler Arquivo de Imagem (Entrada)

Representação: Endereço do Arquivo de Imagem

\section{- Handler do Arquivo de Log}

Descrição: $\quad$ É utilizado para manipular o arquivo de $\log$

Processo(s): $\quad$ 1.9.1-Abrir Arquivo de Log (Saída)

1.9.2 - Ler Arquivo de Log (Entrada)

1.12.1 - Abrir Arquivo de Log (Saída)

1.12.2 - Ler Arquivo de Log (Entrada)

Representação: Endereço do Arquivo de Log 


\section{- Imagem}

Descrição: Imagem pronta para apresentação no monitor de vídeo

Processo(s): $\quad$ 1.10.1 - Fazer Varredura na Tela (Entrada)

1.11.2 - Ler Arquivo de Imagem (Saída)

Representação: Quadro *definido no MA*

\section{- Inicializar Estatística}

Descrição: $\quad$ Ativa o processo que inicializa os dados estatísticos

Processo(s): $\quad$ 1.12.1 - Abrir Arquivo de Log (Saída)

$$
\text { 1.12.6 - Inicializar Valores (Entradia) }
$$

Representação: *Fluxo de Controle*

\section{- Lista dos Sensores com Falhas}

Descrição: Lista de sensores da aeronave que apresentam falhas

Processo(s): $\quad$ 1.7.4 - Verificar Falhas nos Sensores (Saída)

Representação: $\{\text { Bit }\}^{\text {QuantidadedeSensores }}$

\section{$\bullet \log$}

Descrição: Interface gráfica para mostrar os dados de $\log$

Processo(s): $\quad$ 1.9.2 - Ler Arquivo de Log (Saída)

Representação: *Interface gráfica para mostrar os dados de $\log *$

\section{- Mudança de Status}

Descrição: Indica que houve alguma mudança de estado nos sensores da aeronave.

Processo(s): $\quad$ 1.7.6 - Verificar Status (Saída)

Representação: *Fluxo de Controle*

\section{- Nível de Combustível}

Descrição: Percentual de combustível restante no tanque da acronave

Processo(s): $\quad$ 1.7.1 - Verificar Nível de Combustível (Entrada)

1.7.2 - Atualizar Instrumentos (Saída)

Representação: Percentual 
- Nível de Combustível Baixo

Descrição: Indica que o nível de combustível da aeronave está abaixo do nível mínimo

Processo(s): $\quad$ 1.7.1 - Verificar Nível de Combustível (Saída)

Representação: *Fluxo de Controle*

\section{- Nível Mínimo de Combustível}

Descrição: Nível mínimo de combustível que deve estar contido no tanque da aeronave (em porcentagem)

Processo(s): $\quad$ 1.7.1 - Verificar Nível de Combustível (Entrada)

Representação: Nível de Combustível

\section{- Nome do Arquivo de Imagem}

Descrição: Nome do arquivo de Imagem que deverá ser utilizado

Processo(s): $\quad$ 1.11.1 - Abrir Arquivo de Imagem (Entrada)

Representação: Nome de Arquivo

\section{- Nome do Arquivo de Log}

Descrição: $\quad$ Nome do arquivo de log que deverá ser utilizado

Processo(s): $\quad$ 1.9.1 - Abrir Arquivo de Log (Entrada)

1.12.1 - Abrir Arquivo de Log (Entrada)

Representação: Nome de Arquivo

\section{- Número de Seqüêencia do Pacote}

Descrição: $\quad$ É incrementado todas as vezes que um Pacote de Dados (uplink) contendo Dados de Configuração chegar (na aeronave). Como esse número sempre é transmitido para a estação de solo (MB), é possível saber se os Dados de Configuração foram recebidos pela aeronave

Processo(s): $\quad$ 1.6.4 - Verificar Número de Sequiência (Entrada)

Representação: Palavra 


\section{- Pacote de Dados (downlink)}

Descrição: Pacote de dados enviado do MA para o MB

Processo(s): $\quad$ 1.6.5 - Receber Pacote de Dados (Entrada)

Representação: Pacote de Dados (downlink) *definido no MA*)

\section{- Pacote de Dados (uplink)}

Descrição: Pacote de dados enviado do MB para o MA

Processo(s): $\quad$ 1.6.2 - Enviar Pacote de Dados (Saída)

Representação: Pacote de Dados (uplink) *definido no MA*

\section{- Pacote de Vídeo}

Descrição: $\quad$ Pacote de vídeo digital comprimido enviado do MA para o MB

Processo(s): $\quad$ 1.8.1 - Receber Pacote de Vídeo (Entrada)

Representação: Pacote de Vídeo *definido no MA*

\section{- Pixels}

Descriçāo: $\quad$ Sequiência de pixels

Processo(s): $\quad$ 1.10.1 - Fazer Varredura na Tela (Saída)

1.10.2 - Colocar Cabeçalho (Entrada)

Representação: Pixels *definido no MA*

\section{- Posição da Aeronave}

Descrição: Indica a posição da aeronave em relação a estação de solo (em graus)

Processo(s): $\quad$ 1.7.7 - Calcular Posição da Aeronave (Saída)

\subsection{8 - Gravar Registro de Log (Entrada)}

Representação: Bússola

\section{- Quadro Inter}

Descrição: Quadro de vídeo sem redundância temporal

Processo(s): $\quad$ 1.8.3 - Compressāo Intraframe Inversa (Saída) 1.8.4 - Compressão Interframe Inversa (Entrada)

Representação: Quadro Inter *definido no MA* 


\section{- Quadro Intra}

Descrição: Quadro de vídeo sem redundância espacial

Processo(s): $\quad$ 1.8.2 - Identificar Quadros (Saída)

1.8.3 - Compressão Intraframe Inversa (Entrada)

Representação: Quadro Intra *definido no MA*

\section{- Realizar Captura de Imagem}

Descrição: Inicia o processo de captura de uma imagem da tela de apresentação de vídeo

Processo(s): $\quad 1.10 .1$ - Fazer Varredura na Tela (Entrada)

Representação: *Fluxo de Controle*

\section{- Registro de Log}

Descrição: Registro que contém alguns dados de $\log$

Processo(s): $\quad$ 1.12.2 - Ler Arquivo de Log (Saída)

\subsection{3 - Calcular o Valor Máximo (Entrada) \\ 1.12.4 - Calcular a Média Aritmética (Entrada) \\ 1.12.5 - Calcular o Valor Mínimo (Entrada)}

Representação: Dados do Motor + Temperatura Externa + Velocidade + Atitude (em Pés) + Velocidade ${ }^{*}$ GPS $*$ Altitude (em metros) ${ }^{*}$ GPS $*$ Distância da Aeronave

\section{- Seqüência de Bytes}

Descrição: Seqüencia de bytes

Processo(s): $\quad$ 1.6.2 - Enviar Pacote de Dados (Saída)

1.6.3 - Calcular CRC do Pacote (Entrada)

1.6.5 Receber Pacote de Dados (Saída)

Representação: Sequiência de Bytes *definido no MA*

\section{- Solicitação de Estatística}

Descrição: $\quad$ Solicita a visualização das estatísticas de um arquivo de $\log$

Processo(s): $\quad$ 1.12.1 - Abrir Arquivo de Log (Entrada)

Representação: *Fluxo de Controle* 


\section{- Solicitação de Imagem}

Descrição: Solicita a visualização de um arquivo de imagem

Processo(s): $\quad$ 1.11.1 - Abrir Arquivo de Imagem (Entrada)

Representação: *Fluxo de Controle*

\section{- Solicitação de Log}

Descrição: Solicita a visualização de um arquivo de log

Processo(s): $\quad$ 1.9.1 - Abrir Arquivo de Log (Entrada)

Representação: *Fluxo de Controle*

\section{- Status do CRC}

Descrição: Indica se o CRC calculado é válido ou não

Processo(s): $\quad$ 1.6.3 - Calcular CRC do Pacote (Saída)

$$
\text { 1.6.5 - Receber Pacote de Dados (Entrada) }
$$

Representação: *Fluxo de Controle*

\section{- Status dos Sensores}

Descrição: Status dos sensores da aeronave

Processo(s): $\quad$ 1.7.2 - Atualizar Instrumentos (Saída)

$$
\text { 1.7.6 - Verificar Status (Entrada) }
$$

Representação: Status da Bateria Auxiliar $1+$ Status dos Sensores (Reservados)

\section{- Telemetria}

Descrição: Interface gráfica para mostrar os dados de telemetria

Processo(s): $\quad$ 1.7.2 - Atualizar Instrumentos (Saída)

Representação: *Interface gráfica para mostrar os dados de telemetria*

\section{- Temperatura do Motor}

Descrição: Temperatura do cabeçote do motor da aeronave (em graus Celsius)

Processo(s): $\quad$ 1.7.2 - Atualizar Instrumentos (Saída)

$$
\text { 1.7.5 - Verificar Temperatura do Motor (Entrada) }
$$

Representação: [0|1|..|450] 


\section{- Temperatura do Motor Alta}

Descrição: Indica que a temperatura do motor está acima da temperatura máxima permitida

Processo(s): $\quad$ 1.7.5 - Verificar Temperatura do Motor (Saída)

Representação: *Fluxo de Controle*

\section{- Temperatura Máxima Permitida}

Descrição: Temperatura máxima permitida ao motor

Processo(s): $\quad$ 1.7.5 - Verificar Temperatura do Motor (Entrada)

Representação: Temperatura do Motor

\section{- Tempo}

Descrição: Tempo atual

Processo(s): $\quad$ 1.6.2 - Enviar Pacote de Dados (Entrada)

1.7.8 - Gravar Registro de Log (Entrada)

Representação: Tempo *definido no MA*

\section{- Valor Máximo}

Descrição: Maior valor obtido a partir de alguns dados de log

Processo(s): $\quad$ 1.12.3 - Calcular o Valor Máximo (Entrada/Saída)

Representação: Registro de Log

\section{- Valor Médio}

Descrição: Valor médio obtido a partir de alguns dados de $\log$

Processo(s): $\quad$ 1.12.4 - Calcular a Média Aritmética (Entrada/Saída)

Representação: Registro de Log

\section{- Valor Mínimo}

Descrição: Menor valor obtido a partir de alguns dados de $\log$

Processo(s): $\quad$ 1.12.5 - Calcular o Valor Mínimo (Entrada/Saída)

Representação: Registro de Log 
- Temperatura do Motor Alta

Descrição: Indica que a temperatura do motor está acima da temperatura máxima permitida Processo(s): $\quad$ 1.7.5 - Verificar Temperatura do Motor (Saída)

Representação: *Fluxo de Controle*

\section{- Temperatura Máxima Permitida}

Descrição: Temperatura máxima permitida ao motor

Processo(s): $\quad$ 1.7.5 - Verificar Temperatura do Motor (Entrada)

Representação: Temperatura do Motor

\section{- Tempo}

Descrição: Tempo atual

Processo(s): $\quad$ 1.6.2 - Enviar Pacote de Dados (Entrada)

1.7.8 - Gravar Registro de Log (Entrada)

Representação: Tempo *definido no MA*

\section{- Valor Máximo}

Descrição: $\quad$ Maior valor obtido a partir de alguns dados de $\log$

Processo(s): $\quad$ 1.12.3 - Calcular o Valor Máximo (Entrada/Saída)

Representação: Registro de Log

\section{- Valor Médio}

Descrição: $\quad$ Valor médio obtido a partir de alguns dados de $\log$

Processo(s): $\quad$ 1.12.4 - Calcular a Média Aritmética (Entrada/Saída)

Representação: Registro de Log

\section{- Valor Mínimo}

Descrição: $\quad$ Menor valor obtido a partir de alguns dados de $\log$

Processo(s): $\quad$ 1.12.5 - Calcular o Valor Mínimo (Entrada/Saída)

Representação: Registro de Log 


\section{- Verificar Combustível}

Descrição: Ativa o processo que verifica o nível de combustível da aeronave

Processo(s): $\quad$ 1.7.1 - Verificar Nível de Combustível (Entrada)

1.7.2 - Atualizar Instrumentos (Saída)

Representação: *Fluxo de Controle*

\section{- Verificar Distância}

Descrição: Ativa o processo de calculo da distância entre a aeronave e a estação de solo

Processo(s): $\quad$ 1.7.2 - Atualizar Instrumentos (Saída)

1.7.3 - Verificar Distância da Aeronave (Entrada)

Representação: *Fluxo de Controle*

\section{- Verificar Falhas}

Descrição: Ativa o processo que verifica se existem falhas nos sensores da aeronave

Processo(s): $\quad$ 1.7.4 - Verificar Falhas nos Sensores (Entrada)

Representação: *Fluxo de Controle*

\section{- Verificar Status}

Descrição: Ativa o processo de realiza a verificação do estado de alguns sensores da aeronave

Processo(s): $\quad$ 1.7.2 - Atualizar Instrumentos (Saída)

1.7.6 - Verificar Status (Entrada)

Representação: *Fluxo de Controle*

\section{- Verificar Temperatura}

Descrição: $\quad$ Ativa o processo que verifica se a temperatura do motor está acima da temperatura permitida

Processo(s): $\quad$ 1.7.2 - Atualizar Instrumentos (Saída)

1.7.5 - Verificar Temperatura do Motor (Entrada)

Representação: *Fluxo de Controle* 


\section{B.3 Dados Auxiliares}

\section{- Aileron Direito}

Descrição: Movimenta o aileron direito da aeronave

Representação: Inteiro Curto

\section{- Aileron Esquerdo}

Descrição: Movimenta o aileron esquerdo da aeronave

Representação: Inteiro Curto

\section{- Altitude (em pés)}

Descrição: $\quad$ Altitude da aeronave em relação a pressão atmosférica da estação de solo Representação: [ - 16405।-16404 | ... | 16405 ]

\section{- Altitude (metros)}

Descrição: Altitude em relação ao nível do mar (em metros)

Representação: [ -5000 | -4999 | ... I 5000 ]

\section{- Ângulo de Pitch}

Descrição: Variação de atitude da aeronave em relação ao seu eixo transversal Representação: Bússola

\section{- Ângulo de Roll}

Descrição: Variação de atitude da aeronave em relação ao seu eixo longitudinal Representação: Bússola

\section{- Baterias Auxiliares}

Descrição: Indica o percentual de carga restante das baterias auxiliares

Representação: $\{\text { Percentual }\}^{3}$ 


\section{- Bateria do Motor}

Descrição: Indica o percentual de carga restante da bateria do motor

Representação: Percentual

\section{- Bateria do Sistema}

Descrição: Indica o percentual de carga restante da bateria do sistema

Representação: Percentual

\section{- Bit}

Descrição: Tipo de dados numérico (binário)

Representação: [ $\left.0 \begin{array}{llll} & 1 & 1\end{array}\right]$

\section{- Bússola}

Descrição: Indica a variação da aeronave em relação ao norte magnético (em graus)

Representação: [ $0|1|$... $\mid 359$ ]

\section{- Bússola Giroscópica}

Descrição: Indica a variação da aeronave em relação ao norte magnético (em graus) com o auxílio de um giroscópio

Representação: Bússola

- Byte

Descrição: Tipo de dados numérico

Representação: [ 0111 ... $\mid 255$ ]

\section{- Câmera Digital}

Descrição: Quando 1, a câmera fotográfica digital da aeronave é disparada Representação: Bit

\section{- Canais ON/OFF}

Descrição: Utilizados para ativar/desativar dispositivos do tipo ON/OFF na aeronave Representação: Trem de Pouso + Páraquedas + Spoilers + Chave da Câmera de Vídeo 2 + Câmera Digital + Canais ON/OFF Reservados * 10 canais reservados* 


\section{- Canais ON/OFF Reservados}

Descrição: Ativam/Desativam algum dispositivo do tipo ON/OFF na aeronave Representação: $\{\text { Bit }\}^{10}$

\section{- Canais Percentuais}

Descrição: Utilizados para movimentar os servomotores da aeronave

Representação: Potência do Motor + Aileron Direito + Aileron Esquerdo + Leme de Direção + Profundor + Flaps + Eixo X da Câmera + Eixo Y da Câmera + Canais Percentuais Reservados $* 2$ canais reservados*

\section{- Canais Percentuais Reservados}

Descrição: Movimentam algum servomotor da aeronave

Representação: $\{\text { Inteiro Curto }\}^{2}$

\section{- Caractere}

Descrição: Tipo de dados do tipo caractere

Representação: [ 0 | 11 I. I 255 ] *ASCII*

\section{- Chave da Câmera de Vídeo 2}

Descrição: $\quad$ Ativa/Desativa a câmera de vídeo 2.

Representação: Bit

\section{- Configuração da Estação de Solo}

Descrição: Parâmetros da estação de solo que devem ser transmitidas para a aeronave Representação: Altitude (metros) + Latitude + Longitude + Pressāo Atmosférica

\section{- Dados do GPS}

Descrição: Dados recebidos do GPS

Representação: Velocidade + Latitude + Longitude + Altitude (em metros) + Horário 


\section{- Dados do Motor}

Descrição: Dados dos sensores instalados no motor da aeronave

Representação: RPM + Temperatura do Motor *definido no MB* + Temperatura dos Gases

\section{- DLE}

Descrição: Constante numérica que é sempre utilizada antes de um caracter delimitador de pacote (STX e ETX)

Representação: 16

\section{- Eixo X da Câmera}

Descrição: Movimenta horizontalmente o suporte das câmeras

Representação: Inteiro Curto

\section{- Eixo Y da Câmera}

Descrição: Movimenta verticalmente o suporte das câmeras

Representação: Inteiro Curto

\section{- ETX}

Descrição: Constante numérica que indica o fim de um pacote de dados

Representação: 3

\section{- Flaps}

Descrição: Abaixa/Levanta os flaps da aeronave

Representação: Inteiro Curto

\section{- Horário}

Descrição: Hora (hh:mm:ss)

Representação: Horas + Minutos + Segundos

\section{- Horas}

Descrição: Horas

Representação: [ $0|1| \ldots \mid 23$ ] 


\section{- Horizonte Artificial}

Descrição: Indica a variação de atitude da aeronave em relação aos ângulos de "roll” e "pitch"

Representação: Roll + Pitch

\section{- Inteiro Curto}

Descrição: Tipo de dados numérico

Representação: [ -32768 | -32767। ... | 32767 ]

\section{- Latitude}

Descrição: $\quad$ Latitude de um ponto geográfico (em graus, minutos e segundos)

Representação: [ -90 | -89 । ... | 90 ] *graus* + Minutos + Segundos + Milésimos de Segundo (duas casas)

\section{- Leme de direção}

Descrição: Movimenta o leme de direção da aeronave

Representação: Inteiro Curto

\section{- Longitude}

Descrição: Longitude de um ponto geográfico (em graus, minutos e segundos)

Representação: [ -180|-179| ... I 180] *graus* + Minutos + Segundos + Milésimos de Segundo (duas casas)

\section{- Milésimos de Segundo}

Descrição: $\quad$ Milésimos de Segundo

Representação: [ 0 | 1 | ... | 999 ]

\section{- Milésimos de Segundo (duas casas)}

Descrição: Milésimos de Segundo

Representação: [ $0|1| \ldots \mid 99$ ] *utilizado somente duas casas decimais* 
- Minutos

Descrição: Minutos

Representação: [ $0|1| \ldots \mid 59$ ]

- Nome de Arquivo

Descrição: Nome de um arquivo

Representação: \{Caractere $\}^{[0|1| \ldots \mid 255]}$

\section{- Palavra}

Descrição: Tipo de dados numérico

Representação: [ $0 \mid 11 \ldots$ 65535 ]

\section{- Páraquedas}

Descrição: Quando em 1, o páraquedas da aeronave é ativado Representação: Bit

\section{- Percentual}

Descrição: Indica a variação em percentual

Representação: [ $0|1| \ldots \mid 100$ ]

- Pixel

Descrição: Menor unidade em um fluxo de vídeo

Representaçāo: Profundidade de Cores

\section{- Potência do Motor}

Descrição: Aumenta/Diminui a potência do motor da aeronave Representação: Inteiro Curto

\section{- Pressão Atmosférica}

Descrição: Utilizada para calibrar o altímetro da aeronave (em polegadas de mercúrio) Representação: [ $20.00|20.01| \ldots \mid 40.00$ ] 


\section{- Profundidade de Cores}

Descrição: Quantidade de cores possíveis em um mesmo quadro de vídeo

Representação: [ 1 | 15 | 255 | 65535 | 16777215 | 4294967295 ]

\section{- Profundor}

Descrição: Movimenta o profundor da aeronave

Representação: Inteiro Curto

\section{- Real}

Descrição: Tipo de dados número que utiliza ponto flutuante

Representação: [ $5.0 \times 10^{324} \ldots 1.7 \times 10^{308}$ ]

\section{- RPM}

Descrição: Rotaçōes por minuto do motor da aeronave

Representação: [ $0111 \ldots$ |20000]

\section{- Segundos}

Descrição: Segundos

Representação: [0|1 $1 \ldots$ | 59]

\section{- Spoilers}

Descrição: Ativam/Desativam os freios aerodinâmicos da aeronave

Representação: Bit

\section{- Status da Bateria Auxiliar 1}

Descrição: Quando 1, indica que a bateria auxiliar número 1 está sendo utilizada Representação: Bit

\section{- Status dos Sensores (Reservados)}

Descrição: Campos para uso futuro que indicam o estado dos sensores da aeronave Representação: $\{\text { Bit }\}^{7}$ 


\section{-STX}

Descrição: Constante numérica que indica o início de um pacote de dados Representação: 2

\section{- Tamanho Horizontal do Quadro}

Descrição: Tamanho horizontal dos quadros de vídeo (em pixels) Representação: [ $80|160| 320 \mid 640$ ]

\section{- Tamanho Vertical do Quadro}

Descrição: Tamanho vertical dos quadros de vídeo (em pixels)

Representação: [ $60|120| 240 \mid 480$ ]

\section{- Tamanho do Quadro}

Descrição: Tamanho de um quadro de vídeo

Representação: Tamanho Horizontal do Quadro $\times$ Tamanho Vertical do Quadro

\section{- Taxa de Quadros}

Descrição: Quantidade de quadros que fluxo de vídeo terá por segundo Representação: [ 1 | 2 | .. | 30 ]

\section{- Temperatura dos Gases}

Descrição: Temperatura dos gases do escapamento da aeronave (em graus Celsius) Representação: [ $0|1| \ldots \mid 500$ ]

\section{- Temperatura Externa}

Descrição: Temperatura externa à aeronave (em graus Celsius)

Representação: [ -50|-49|... | 50 ]

\section{- Trem de Pouso}

Descrição: Ativam/Desativam os trens de pouso da aeronave Representação: Bit 
- Velocidade

Descrição: Velocidade aerodinâmica da aeronave (em knots)

Representação: [ $0|1| \ldots \mid 300$ ]

\section{- Variação de Atitude}

Descrição: Variação de atitude da aeronave (em pés)

Representação: Altitude (em pés) 